Spring 4-25-2020

\title{
Exploring Occupational Disruption in Newly Diagnosed Individuals with Cancer with Minor (Dependent) Children
}

\author{
Riley S. Harrold \\ University of St. Augustine for Health Sciences
}

DOI: https://doi.org/10.46409/sr.YUTL6300

Follow this and additional works at: https://soar.usa.edu/capstones

Part of the Alternative and Complementary Medicine Commons, Cancer Biology Commons, and the Occupational Therapy Commons

\section{Recommended Citation}

Harrold, R. S. (2020). Exploring Occupational Disruption in Newly Diagnosed Individuals with Cancer with Minor (Dependent) Children. [Doctoral project, University of St Augustine for Health Sciences]. SOAR @ USA: Student Capstone Projects Collection. https://doi.org/10.46409/sr.YUTL6300

This Capstone is brought to you for free and open access by the Student Research at SOAR @ USA. It has been accepted for inclusion in Student Capstone Projects by an authorized administrator of SOAR @ USA. For more information, please contact soar@usa.edu, erobinson@usa.edu. 
EXPLORING OCCUPATIONAL DISRUPTION IN NEWLY DIAGNOSED INDIVIDUALS WITH CANCER WITH MINOR (DEPENDENT) CHILDREN

by

Riley S. Harrold

A Capstone Presented in Partial Fulfillment

of the Requirement for the Degree of DOCTOR OF OCCUPATIONAL THERAPY

University of St. Augustine for Health Sciences 
EXPLORING OCCUPATIONAL DISRUPTION IN NEWLY DIAGNOSED INDIVIDUALS WITH CANCER WITH MINOR (DEPENDENT) CHILDREN

by

Riley S. Harrold

has been approved

APPROVED:

Susan MacDermott, OTD, OTR/L, Doctoral Coordinator

Becki Cohill, OTD, OTR/L, Doctoral Coordinator

Erin Schwier, EdD, OTD, OTR/L, Program Director

ACCEPTED AND SIGNED:

\begin{tabular}{|c|c|}
\hline 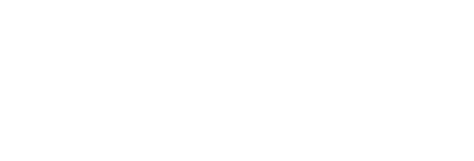 & 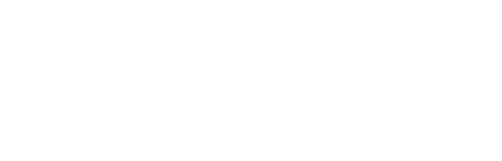 \\
\hline \multicolumn{2}{|c|}{ Susan MacDermott, OTD, OTR/L, Doctoral Coordinator } \\
\hline Becki Cohill OTD OT & 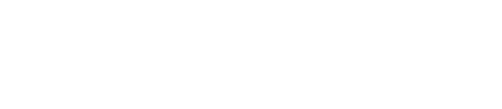 \\
\hline eschwier@usa.edu & 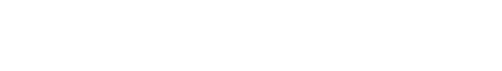 \\
\hline
\end{tabular}

Erin Schwier, EdD, OTD, OTR/L, Program Director 


\section{Table of Contents}

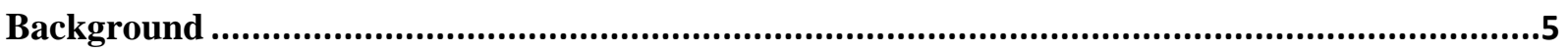

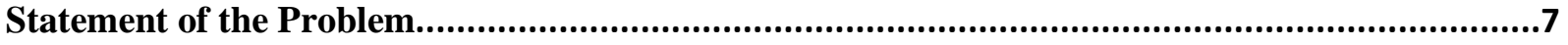

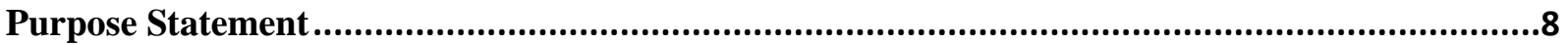

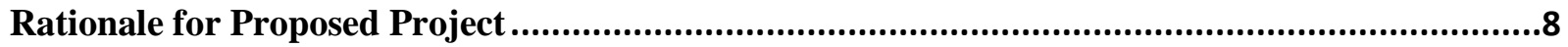

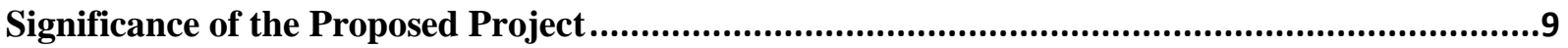

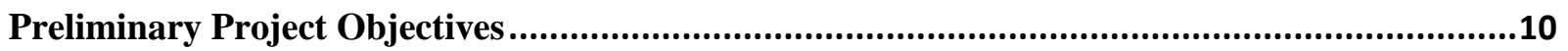

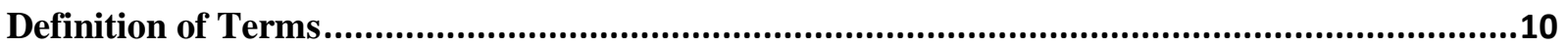

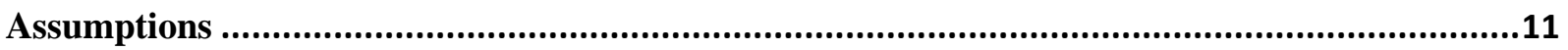

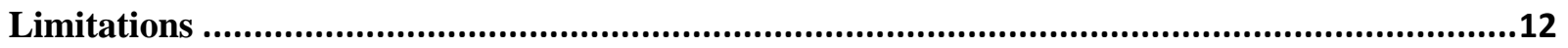

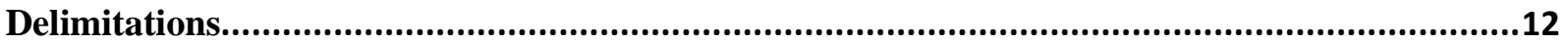

Occupational Therapy's Role in Cancer Care and Oncology .....................................................13

The Impact of Cancer on Individual and Family .....................................................................13

Addressing Psychosocial Issues Through Integrative Therapies ................................................14

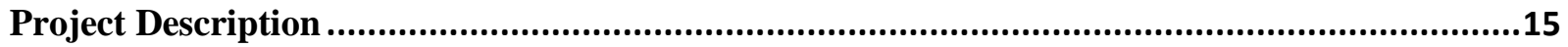

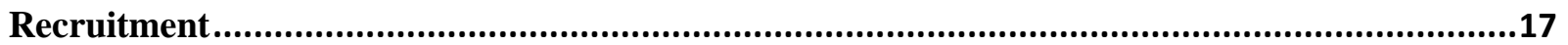

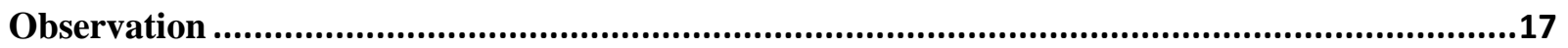

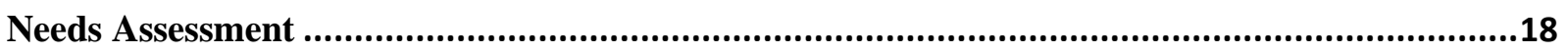

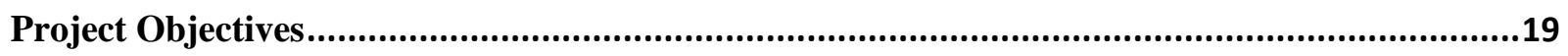

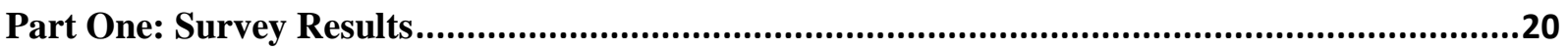

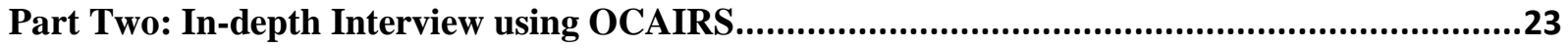

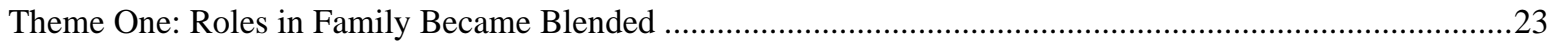

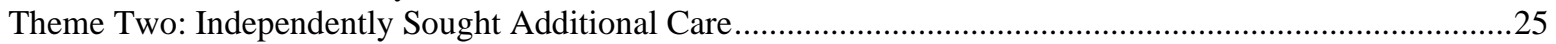

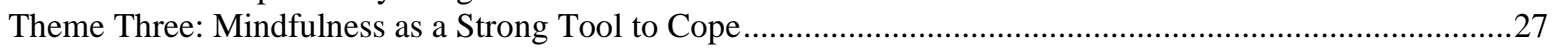

Part Three: In-depth Interviews with Instructors of Integrative Therapy Programs .................29

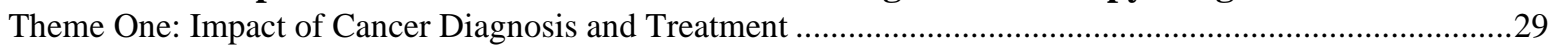

Theme Two: Need to Provide Education on Integrative Therapies ................................................................

Theme Three: Programs Typically Accessed After Treatment ........................................................................

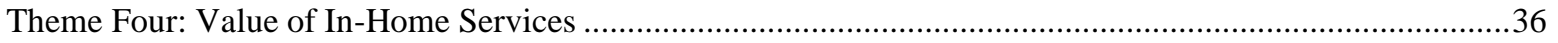

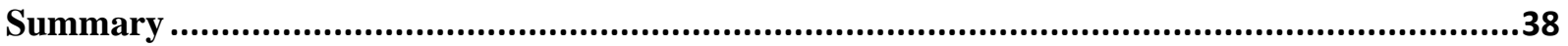

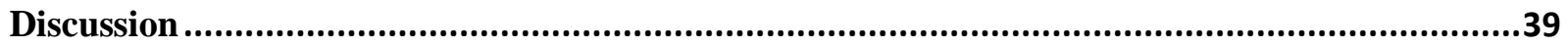

Collaboration with Interdisciplinary Team...........................................................................40

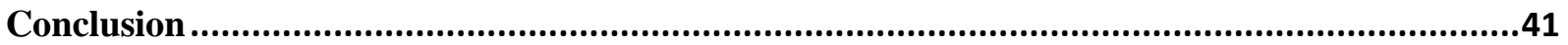

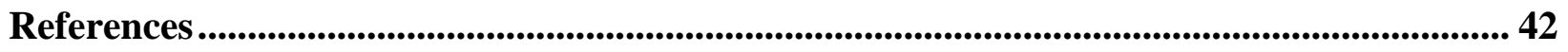

Appendix A: Participant Consent Form ............................................................................................. 46

Appendix B: Letter to Staff of Knight Cancer Institute .......................................................... 47 
Appendix C: Occupational Disruption Survey for Parents .......................................................... 48

Appendix D: OCAIRS Sample Interview Questions .............................................................. 49

Appendix E: Integrative Therapy Program Report ........................................................ 50

Appendix F: Occupational Therapy Program: "Healing at Home" ......................................... 72 


\section{EXPLORING OCCUPATIONAL DISRUPTION IN NEWLY DIAGNOSED INDIVIDUALS WITH CANCER WITH MINOR (DEPENDENT) CHILDREN}

\section{Background}

According to the American Cancer Society (2019), there were more than 1.7 million new cases of cancer in 2019 alone. Individuals are being diagnosed at a young age with $22.4 \%$ of cases occurring in individuals 22-55 years old and whom are childrearing age (Shah et al., 2017). There are an estimated 2.85 million children under the age of 18 who are living with a parent who has cancer (Shah et al., 2017). Newly diagnosed individuals face changes in daily life, the threat of possible death, fear of dying, and shared family roles, which can impact the entire family (Compas et al., 1994; Heiney et al., 1997; Helseth \& Ulfsæt, 2005). Grabiak (2007) found that children with parents who have cancer are at a higher risk for emotional and behavioral problems. Peh et al. (2016) reported when a parent is diagnosed with cancer, the initial shock of the diagnosis will likely bring about uncertainty regarding family and children, which may contribute to emotional distress.

The role of parenting is broad and may differ between cultures and societies. Within the home, parents or caregivers are responsible for childrearing, protection of their home and assets, financial obligations, and providing basic life necessities such as clothing, food, and shelter. Each household engages in routines to accomplish daily tasks to maintain the family's dynamic schedule. Routines within the family can fluctuate, but across cultures, families often share meals together, develop household routines, and address milestones in life (Crespo et al., 2013). Following a diagnosis of cancer, parents and their families could benefit from assistance in maintaining engagement of roles, rituals, and routines. 
The role of occupational therapy in oncology and cancer care is to assist clients in remediating, compensating, or adapting their abilities to achieve maximum independence in their meaningful daily occupations (American Occupational Therapy Association [AOTA], 2011). Occupational therapy practitioners work with individuals who have cancer and their caregivers at each stage of treatment: newly diagnosed, undergoing treatment, survivorship phase, palliative, or end-of-life care (AOTA, 2011; Hunter et al., 2017). Through a variety of approaches, occupational therapists assist clients in managing symptoms such as pain, fatigue, weakness, cognitive impairments, lymphedema, and psychosocial challenges secondary to treatment. Psychosocial issues addressed by occupational therapy include anxiety, depression, sleep disturbances, isolation and withdrawal, which surface as a result of the diagnosis and progression through treatment (Okamoto, 2011; Visser et al., 2004). Occupational therapists work with people to maintaining roles and routines within the family through engagement in cooccupations.

Traditional medical treatment for various cancers include a combination of some or all of the following modalities: chemotherapy, radiation, surgery, or immunotherapy (American Cancer Society, 2019). With the advancements in cancer treatment, the survival rate has improved, leaving many individuals with chronic physical and emotional impairments (Hunter et al., 2017). Cancer is now considered a chronic condition, and there is a shift to promote rehabilitation and maximizing occupational engagement. In addition to a medical plan of care, individuals can participate in alternative therapies such as yoga, mindfulness-based stress reduction (MBSR), acupuncture, writing groups, and massage (McCall et al., 2015; Raub, 2002; Smith et al., 2005; Seely et al., 2012). These integrative therapy programs, also known as complementary treatments, address the psychosocial concerns that arise from a diagnosis and are 
designed to improve the quality of life of an individual undergoing cancer treatment (Mackenzie et al., 2007; Raub, 2002; Smith et al., 2005; Seely et al., 2012). Hunter et al. (2017) determined that there is strong evidence that multidisciplinary rehabilitation programs that address psychosocial issues are helpful for individuals regardless of stage or type of cancer. Participation in some of these integrative therapy programs, such as writing groups, may provide social opportunities where individuals who have been impacted by cancer can interact with others with similar experiences. Other courses, like Mindfulness-Based Stress Reduction (MBSR), provide an environment to connect with others with less emphasis on direct communication. This modality can be beneficial for individuals who are overwhelmed with expectations. The primary goal of integrative therapy programs is to reduce negative symptoms of cancer treatment, improve emotional well-being, provide opportunities for social engagement, and to improve quality of life (Seely et al., 2012).

\section{Statement of the Problem}

Occupational therapists have been caring for individuals with cancer and their families since the early years of the profession. However, there is more recent demand to address cancer from a rehabilitation and chronic condition perspective (Coss, 2019). Psychosocial issues, secondary to cancer treatment, create barriers to participation in meaningful roles and routines (Kim et al., 2006). Individuals with minor (dependent) children face a challenge maintaining cooccupations within the family due to the never-ending responsibilities of a parenting role, among others. Research has shown that participating in programs such as yoga, massage, and mindfulness courses has positive effects on pain, stress, sleep quality, and fatigue in individuals and their caregivers (Smith et al., 2005). Occupational therapy is focused on improving an individual's ability to engage in activities that foster positive family roles and routines and a 
continued effort to establish, maintain, or restore participation in meaningful life activities

(AOTA, 2011).

\section{Purpose Statement}

The purpose of this project is to further explore the impact of a cancer diagnosis and subsequent treatment on the individual and their family. This project also aims to investigate the role of occupational therapy in integrative therapy services.

\section{Rationale for Proposed Project}

This capstone will follow the Model of Human Occupation (MOHO) to highlight the roles, routines, and habits surrounding the person and his or her environment (Taylor, 2017). Exploration into the dynamic relationship between the internal and external factors that influence motivation will help guide practice when working with individuals who have been newly diagnosed with cancer. MOHO focuses on "volition," which is the source of motivation that guides individuals to proceed with their lives (Taylor, 2017). According to Taylor (2017), volition can be described as a cycle of anticipating, choosing, experiencing, and interpreting one's life choices. The repetition of this cycle over time influences one's personal causation. A majority of parents undergoing cancer treatment are motivated to address their concerns that arise due to their high value of parenting. Many families have reported wanting to maintain a sense of "normal" with their children and family (Helseth \& Ulfsæt, 2005). It is important to explore one's personal causation, interests, and values during a life-altering stage, such as an initial diagnosis of cancer.

Identifying components of habituation within individuals and their family members' lives consists of emphasizing the habits and roles each family member possesses (Taylor, 2017). The mind-body connection is a main focus of this theory and can help guide practitioners when 
working with this population. Addressing these components of people and their environments can lead to improved occupational performance and overall quality of life (Taylor, 2017). The environment is an important area to address because it is the center in which we engage in our meaningful occupations and fulfill our life roles. These environments are shaped by our culture and vary between families (Taylor, 2017).

\section{Significance of the Proposed Project}

Current literature on cancer reveals the psychosocial impacts of the diagnosis and treatment on the individual, his or her partner, and their children (Okamoto, 2011; Visser et al., 2004). This project will further explore how the psychosocial aspects affect engagement in cooccupation for the individual diagnosed with cancer and his or her dependent children. The body of literature related to this project focuses on how individuals and families cope with the diagnosis and how roles within the family dynamics change. However, there are still questions regarding maintaining co-occupations between parents and children during this challenging time. Research has shown the positive effects of maintaining essential routines and rituals in times of distress. In the context of chronic conditions, the development of new routines and rituals demonstrate the families' ability to cope with the stress of the illness (Crespo et al., 2013). This project will identify what aspects of this experience still need to be addressed and how occupational therapy can support the family in engaging in co-occupations. In occupational therapy, it is believed that engagement in occupation is an essential component to our lives. According to the AOTA (n.d.), the pursuit of health and wellness is connected to engaging in meaningful occupations. 


\section{Preliminary Project Objectives}

1. Identify current resources available to parents with cancer and their families in the local community.

2. Identify the psychosocial and occupational impact of cancer and treatment on the parent diagnosed with cancer and family members.

3. Observe and participate in gentle yoga, writing groups, and mindfulness breath-by-breath courses offered through the Knight Cancer Institute to understand how occupational therapy can enhance current programming.

4. Determine the common concerns of the parent diagnosed with cancer in maintaining roles, rituals, and routines following the initial diagnosis.

5. Educate current staff on OT's role in cancer care and oncology with regards to integrative therapy.

\section{Definition of Terms}

- Newly diagnosed is defined as the beginning stage of a cancer diagnosis. For the purpose of this paper, newly diagnosed will be individuals with a diagnosis of cancer within six months.

- Minor (dependent) children are defined as individuals who are 18 years of age or younger who reside in their family home. For the purpose of this paper, minor (dependent) children will be referred to individuals who are primarily cared for by their parent or caregiver.

- Integrative therapy, also referred to as alternative or complementary therapy, is defined as interventions, such as spiritual therapies and relaxation techniques, that are aimed to address general well-being and health (Mackenzie et al. 2007; McCall et al. 2015). 
Integrative therapies are typically used in combination with traditional medical care (Mackenzie et al., 2007).

- Occupational disruption is defined as "interruption to participation in valued occupations" (Tolson et al., 2017, p. 394).

- Volition is defined as an individual's perception of what is valued, his or her ability to do what they want and need to do, and how effective he or she will be (Taylor, 2017).

- Habituation is defined as the development of habits and patterns of occupational engagement in an individual's life (Taylor, 2017).

\section{Assumptions}

- Parents and their families experience changes in roles, routines, and rituals following a diagnosis of cancer.

- Parents who are diagnosed with cancer have varying psychosocial issues, such as anxiety and depression, that arise while going through treatment.

- Traditional medical treatment alone does not address all the psychosocial issues secondary to a cancer diagnosis.

- Parents will be open to participating in integrative therapies in addition to their medical plan of care.

- Parents who are going through cancer treatment need additional support through a multidisciplinary perspective.

- Participation in integrative therapies will foster a positive, supportive experience for the individual.

- Occupational therapy has a role in supporting parents through cancer treatment through participation in integrative therapies. 


\section{Limitations}

- Access to participants

- Project timeline taking place fall 2019 through spring 2020, which could impact participation through winter months

- Project taking place in a medical outpatient setting rather than home environment

\section{Delimitations}

- This project will focus on individuals with a diagnosis of cancer and their family.

- Due to a wide variety of types and stages of cancer, this project will be open to participants with any diagnosis of cancer who have minor (dependent) children who reside in the home.

- This project will focus on the perspective of the parents and partners, not the children. 


\section{Chapter II: Literature Review}

\section{Occupational Therapy's Role in Cancer Care and Oncology}

Current literature on occupational therapy's role in cancer care expands across the lifetime, in a variety of settings, from point of diagnosis through treatment. Occupational therapy also assists individuals and their families through survivorship phase or palliative care. In traditional settings such as inpatient care, occupational therapists work with individuals on basic activities of daily living such as bathing, dressing, toileting, and using adaptive equipment (AOTA, 2011). In outpatient settings, occupational therapists collaborate with the client and family on environmental modifications to their home or to re-engage in social relationships (AOTA, 2011). In these settings, the focus of therapeutic intervention is aimed at addressing competence in instrumental activities of daily living and participation in meaningful roles and routines. Sleight and Dunker (2016) indicate that in stages of post-cancer treatment, occupational therapists can assist individuals with returning to work, creation and implementation of home exercise programs, and reconnection to leisure activities, among others.

\section{The Impact of Cancer on Individual and Family}

When an individual is diagnosed with cancer, the effect ripples to the family and close friends (Huizinga et al., 2011). Helseth \& Ulfsæt (2005) profess receiving a cancer diagnosis creates worries about the future and thoughts about dying. An individual going through cancer treatment may have difficulties fulfilling their parenting roles, and family structures begin to shift (Kim et al., 2006). Other family members and friends share the burden of responsibilities within the family dynamics (Grabiak et al., 2007; Helseth \& Ulfsæt, 2005; Kim et al., 2006).

The impact of cancer on children is discussed in a variety of literature across disciplines. Helseth \& Ulfsæt (2005) notes that many parents are concerned with how much information to 
share with the children and ultimately how to have those tough conversations. According to Okamoto and colleagues (2011), children who have a parent with cancer experience increasing emotional, behavioral, cognitive, and physical problems. Children and adolescents show an increase in behavioral issues when their parents demonstrate depressed moods secondary to a cancer diagnosis (Helseth \& Ulfsæt, 2005; Visser et al., 2004).

\section{Addressing Psychosocial Issues Through Integrative Therapies}

Integrative therapies are designed to address the additional psychosocial concerns that surface secondary to a diagnosis of cancer and the subsequent treatment (McCall et al., 2015; Raub, 2002; Smith et al. 2005). Fatigue is one of the most common and distressing effects of cancer and can impact participation in daily occupations (Bower et al., 2014). Bower and colleagues (2014) articulate that research shows that adequate levels of physical activity can reduce cancer-related fatigue. Mackenzie and colleagues (2007) identify that mindfulness-based stress reduction (MBSR) programs are designed for the patient to address symptoms of depression, improve quality of life, and decrease feelings of stress. This type of program aims explicitly to promote positive changes in patients' physical and emotional health status and provide participants with a sense of control over their disease process (Mackenzie et al., 2007). Participation in relaxation techniques, such a yoga, can improve sleep patterns (McCall et al., 2015; Raub, 2002). 


\section{Chapter III: Methods and Timeline}

\section{Project Description}

This capstone took place at the Knight Cancer Institute in Portland, Oregon. This organization is part of a larger hospital system, Oregon Health and Science University (OHSU). The population of interest includes individuals who are newly diagnosed with cancer and who have minor (dependent) children in the home. The primary goal of this project was to explore the impact of a cancer diagnosis on a parent and their family, particularly how a diagnosis and proceeding treatment alters family roles, routines, values, and habits.

Additionally, this project investigated the role of occupational therapy in integrative therapy services. There are currently a variety of disciplines on the traditional oncology treatment team, which includes occupational therapists. However, the opportunity to expand the role of occupational therapy in integrative medicine by supporting families through diagnosis and treatment in the home environment was further explored. The doctoral student worked closely with other disciplines to gain greater understanding of each scope of practice and to determine strategies to improve interdisciplinary collaboration.

To assess the needs of this population, information was gathered through observation and assessment from November 2019 - February 2020. The project was developed from March April 2020. See Table 1 for timeline details.

\section{Table 1}

Capstone Project Timeline

Dates

November 2019 - February 2020

Preliminary project
Objectives and Tasks

Orientation:

-Get acquainted with site

-Begin attending groups in the integrative

therapy program 
Needs Assessment:

-Develop and disseminate survey

-Recruitment of participants

-Participant observations through integrative therapy programs

-Assessment (modified OCAIRS interview)

-Interviews with staff

\section{Project Preparation:}

-Develop goals with staff

-Attend meetings with staff and faculty in integrative medicine department

-Contact new references/connections to expand understanding of programs offered and to build rapport with staff.

-Finish interviews and transcriptions

-Collaborate with team about project plan

-Assist with planning of May conference with a focus on increasing participant participation and advocating for occupational therapy's role in integrative medicine.

-Finalize details about project

March 2020 - April 2020

Interdisciplinary collaboration:

In-service on integrative therapy program at Knight Cancer Institute

-Present information about services to acute rehab department at OHSU

\section{Project Development:}

-Develop draft of Healing at Home

-Develop informational handouts for conference and future programs focused on the home environment.

\section{Dissemination:}

-Debrief with Susan Hedlund, site supervisor -Development of Healing at Home, a resource for parents going through cancer treatment. -Provide Integrative Therapy Program Report to Susan Hedlund and the integrative medicine department

-Poster

-Final Paper 


\section{Recruitment}

Integrative therapy programs such as gentle yoga, meditation mindfulness, and writing group met on a weekly schedule and participants were made aware of the proposed project. To gather a greater understanding of the impact of a cancer diagnosis and subsequent treatment, two participants were recruited through the mindfulness breath-by-breath class. Both participants were provided a consent form (See Appendix A) and a verbal description of the purpose of the interview.

Instructors of the various integrative therapy programs were recruited to participate in an in-depth interview. Each participant was provided a consent form (See Appendix A) prior to the interview taking place. The purpose of the interview was verbally described to each staff member. Staff interviews were conducted to gather information about their involvement in the programs and how the services can be enhanced. The in-depth interviews provided information about current participant recruitment techniques for the integrative therapy programs, how and to whom services are marketed, and strategies to incorporate integrative therapy foundations into the home for those who cannot attend groups regularly. Following the interview, staff and the doctoral student collaborated on goals for future projects.

\section{Observation}

Participant observation techniques were used to gather information about the culture and psychosocial concerns of the participants during integrative therapy programs. Observation notes were handwritten in a journal and included the doctoral student's perception of the impact of integrative therapies on this population. Weekly observation and active participation in the groups contributed to the overall understanding of the role of integrative medicine in cancer treatment. 


\section{Needs Assessment}

A brief survey was developed by the doctoral student to determine how psychosocial symptoms impact engagement in daily routines and the parenting role. This survey was developed both as hard copy and electronically and disseminated among staff at the Knight Cancer Institute and Compass Oncology with a letter attached (See Appendix B). Compass Oncology is a local cancer treatment center that works closely with the Knight Cancer Institute. This survey was given to ten participants who had both a diagnosis of cancer and dependent children (See Appendix C).

Two individuals were recruited from the mindfulness breath-by-breath class to participate in an in-depth interview. In-depth interviews were conducted using the Occupational Circumstances Assessment Interview and Rating Scale (OCAIRS) as a guide. The OCAIRS will was used as a modified version and incorporated the roles, habits, values, interests, and social environment sections of the OCAIRS Mental Health Interview (form 1) sections (See Appendix D). Interviews were recorded and later transcribed by the doctoral student to identify how cancer impacted the family and develop strategies to support the parent while they go through treatment. In-depth interviews with selected participants were analyzed and coded for common themes. This information was later used to develop resources for parents in the home environment. Interviews with instructors of the gentle yoga class, meditation mindfulness, women's writing group, inpatient oncology massage, and the director of patient and family resources for the Knight Cancer Institute, were conducted to identify strengths of current programing, gaps in recruitment, barriers to patient access to integrative programs, and goals for expanding programing to the home environment. Interviews were recorded and later transcribed by the doctoral student. A final proposal (See Appendix E) of staff interviews was developed and 
presented to Susan Hedlund, site supervisor, to share with her team. This report consists of a summary of the interview, identification of program strengths and possible enhancements.

\section{Project Objectives}

- Develop resources for the home environment to integrate services offered through the Knight Cancer Institute's integrative medicine program to support newly diagnosed parents and their families through treatment (See Appendix F).

- Investigate role of occupational therapy in integrative medicine to determine whether there is a need for occupational therapy services.

- Provide suggestions, education, and possible enhancements to therapeutic groups to increase access to integrative therapy programs through a final written report (See Appendix E).

- Student will communicate occupational therapy's role in oncology and cancer care to the integrative therapy team to increase interdisciplinary collaboration.

- Present in-service to the acute inpatient rehabilitation department at OHSU regarding outpatient integrative therapy programs to increase interdisciplinary collaboration and advocate for the role of OT in integrative medicine. 


\section{Chapter IV: Results \& Analysis}

The primary goal of this project was to explore the impact of cancer on newly diagnosed individuals who have minor (dependent) children. OHSU serves a large population of people and strives to continue to improve programming. The Knight Cancer Institute is an organization within OHSU. This project collected information from participants within the Knight Cancer Institute as well as the surrounding Portland community. Through a variety of methods, information was collected from November 2019 - February 2020 in the form of observations, surveys, interviews, and informal assessments. This information will be presented in three parts: survey results, in-depth interviews using OCAIRS, and in-depth interviews with instructors of integrative therapy programs.

\section{Part One: Survey Results}

A survey was developed and shared among social workers within the Knight Cancer Institute and Compass Oncology. The social workers then shared with individuals who had a diagnosis of cancer and also minor (dependent) children. The survey attracted 10 participants who reside in the Portland community, had a diagnosis of cancer, and have children under the age of 18. Of the ten participants, eight of them reported being in the pre-treatment stage or were currently receiving treatment. All but one of those eight participants reported having their daily routine impacted by pain or fatigue (see Figure 1, pg. 21). 


\section{Figure 1.}

Impact of Cancer on Daily Routine

My daily routine is impacted by pain or fatigue.

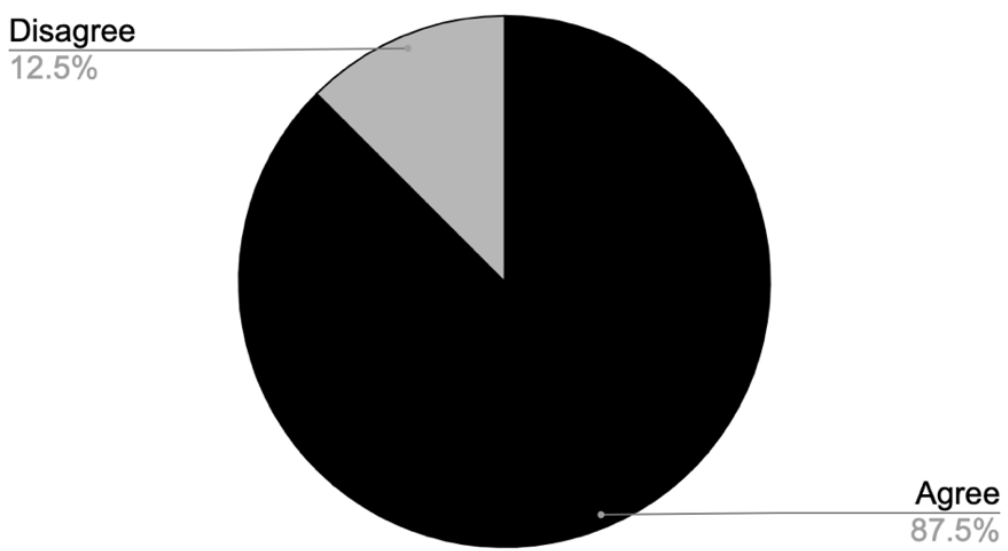

While $75 \%$ of individuals pre-treatment or in treatment report not having sufficient energy to complete the activities they need or want to do, half of those respondents identify difficulty with specific household tasks such as meal preparation, laundry, or cleaning. These individuals are all parents of minor (dependent) children and have responsibilities to care for others. This information suggests how levels of fatigue can impact an individual's ability to perform their everyday tasks. Secondary symptoms of a diagnosis and subsequent treatment often surface before treatment begins (see Figure 2, pg. 22). 


\section{Figure 2.}

\section{Difficulty Completing Household Tasks}

It is hard for me to complete household tasks such as meal prep, laundry, or cleaning.

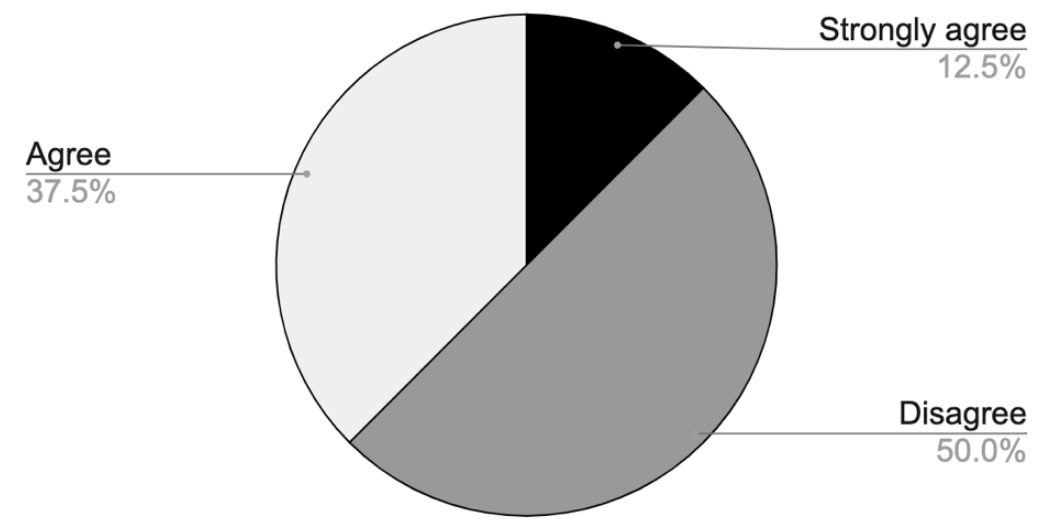

Sixty-three percent of individuals pre-treatment or in treatment report dissatisfaction with the quality and amount of sleep they experience. Physical limitations are coupled with psychosocial concerns such as anxiety and fear. Feelings of anxiety impact the ability to accomplish daily tasks in $60 \%$ of all respondents, with $80 \%$ experiencing feelings of fear surrounding their health.

\section{Figure 3.}

Impact of Anxiety

Anxiety impacts my ability to do the things I want and need to do.

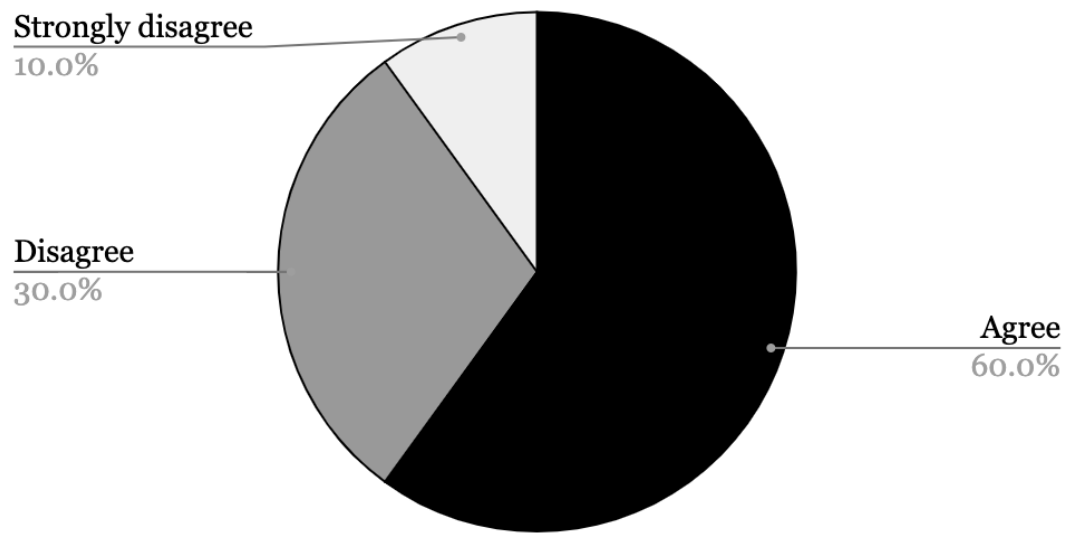




\section{Part Two: In-depth Interview using OCAIRS}

Using a modified version of the OCAIRS, two interviews were conducted to identify the impact of a diagnosis of cancer and subsequent treatment on individuals and their families. Indepth interviews were audio recorded and transcribed verbatim by the doctoral student. Each participant was asked a variety of questions regarding roles, habits, rituals, interests, and social environment following the Mental Health Interview (form 1) sections. The first participant was a female spouse of a man who was diagnosed with non-Hodgkin's lymphoma eight years ago. This couple had two daughters who were 11 and 13 at the time of the diagnosis. This participant will be referred to as "Participant A" to honor confidentiality. The second participant was a female cancer patient who was treated at another facility in Portland and who has been in remission since 2018. She was diagnosed in 2013 with thyroid cancer. For the following paragraphs, this participant will be referred to as "Participant B" to honor confidentiality. Common themes emerged from the in-depth interviews to better describe the impact of a diagnosis of cancer and subsequent treatment on the individual and their family.

\section{Theme One: Roles in Family Became Blended}

Having a parent go through cancer treatment effects the entire family. Whether the parent works full time, or stays home and manages the house, treatment will impact the participation in these roles. Roles within the family can change, extend to other family members, or be shared.

Each family has dynamic relationships which define the different roles and responsibilities within the home. While Participant A's spouse was going through treatment, it was important for him to continue to work part time, while his wife stayed home. Participant A shares: 
My background is in interior design, and I'm also a modeling contractor. I own my own business and I ended up shutting down for a year during that treatment process so that I could be home with the kids and help my husband. It was really important for him at that time to work full time to continue to be as normal as possible and to maintain that same lifestyle.

Making the decision to be at home to take care of her family was important to Participant A. Her role had shifted more to maintain the home, take care of the kids, and support her husband in treatment and in working. She continues:

He had to go through treatments, recovery period, and there was a lot of doctor visits, visits to other healthcare providers, but I shut down my business in order to provide the support that he needed and the kids needed at the time to be able to go through this process.

Some individuals decide it is too challenging to work during treatment.

Participant B was working part time when she was diagnosed in 2013. Her husband had recently switched careers when she was forced to quit working due to her physical and emotional symptoms of cancer treatment. Participant B shares:

He became a banker and a mortgage officer, so he had to do a complete change. That was really stressful for him. The questions are: "Is he going to make it? Is this going to be a viable career? Is he going to be able to support the family?" He was only a few years into his new career, and then I got diagnosed. And I'm sure that that was a big burden. Now he has this new stuff he is working on and now he's got a wife that he now has to take care of. 
Prior to Participant B's diagnosis and treatment, her role included most of the household maintenance. In the home, she describes how she would contribute to the routines the best she could. She and her husband would share the responsibilities within the home that helped stay connected to normal. She explained:

I did more of the cooking, but if he could get the food in the house, then I could at least... But he would do laundry and shopping, helping clean, definitely.

The impact of cancer extends beyond the borders of treatment. There are lasting physical and emotional changes, and families are faced with many challenges with maintaining meaningful routines.

\section{Theme Two: Independently Sought Additional Care}

The traditional methods of treatment in Western culture typically consist of a combination of chemotherapy, radiation, surgery, immunotherapy, or hormone therapy. While this medical plan is essential, many patients seek more holistic care to address some of the psychosocial symptoms that develop.

Unlike other cancer care centers, the Knight Cancer Institute offers a variety of integrative therapy programs. Patients outside this organization might not be fortunate enough to have access to this information. Participant B described a feeling of needing more support. She decided she needed to do her own research if she wasn't getting what she needed at her treatment center. She shares her experience seeking out mindfulness courses:

Because I wasn't in the Knight Cancer Institute at all, I wasn't even given this information. I remember Googling mindfulness and OHSU, thinking they have to have something. I had to do my own research and hunt it down and I am still trying to 
remember how I heard about the gentle yoga because I wasn't given any information. I'm sure it's because I did some digging to find it.

Valuing spiritual practice, Participant B knew she and her husband could benefit from

incorporating this aspect into their healing. She explains:

I have a religious or spiritual background, and I knew that that piece had to be part of the healing or it wasn't going to be a well-rounded approach to my health. Stress is a huge thing. As soon as you're diagnosed with cancer, the fear comes up. It was a lot for my husband, too, since he is a fear-based person. There had to be more than going to the doctor and relying on that.

Rather than a physician or medical professional encouraging alternative treatments, Participant B experienced the value in addressing the mind and body. She explains her experience with her husband and how they realized this type of approach to healing would suit them:

He even got on the floor and did some yoga, things that he never would have done. And he now practices mindfulness, he does a morning mediation, like a centering-prayer-type thing because he realizes how helpful it is. It was kind of his introduction into this whole world, and he jumped in with me.

Integrating meditation mindfulness practice into their daily routine was important for their recovery from cancer. Symptoms that developed during treatment such as anxiety were being addressed through alternative methods.

Following cancer treatment, many individuals and their families have lasting effects. With decreased stress about fear of death, there is space to evaluate where family support is needed. Participant A shares that eight years after her husband finished treatment, she still knew 
something needed to be done to address her stress. Once her husband was diagnosed a second time with a new type of cancer, fear and anxiety heightened. Participant A describes this time:

I definitely had moments where I just felt like I needed more time to decompress from whatever was going on at any given time period. I suppressed some of the deep emotions going on at the time, because I felt like I had to be on for everybody and be there for everybody. That created a whole lot of tension in my body and stress. It's one of the reasons why I did the Mindfulness-Based-Stress-Reduction course because I didn't realize this until many years later. I had all this tension in my body, and it took a while to figure out why it was there.

Both the patient and their spouse had lasting emotional and physical symptoms that weren't getting addressed in their daily routines.

\section{Theme Three: Mindfulness as a Strong Tool to Cope}

With the variety of integrative therapy approaches, meditation mindfulness is a practice used in many cultures. In the context of managing a chronic illness, mindfulness has been used to address fluctuating levels of stress, bring awareness to the present, and provide a space to reflect on what thoughts come up. Participant A illustrates how meditation has become an essential part of her daily healing:

I just do a formal practice, actually created a little space in one of our rooms with a cushion and meditative music. And it's just for formal practice. I do that about an hour each day and find time to have some quiet space. In addition to that, I'm just really trying to incorporate it into my daily life. 
Meditation practice brings awareness to the impermanence of the present. Cancer treatment alters how someone has planned their life. With mindfulness practice, Participant A shares her experience:

People hold on to the way it was before. I just shift that perspective a little bit and realize even if cancer wasn't here, it's still never going to be exactly the way it was before. I think that's one of the reasons the mindfulness has helped us, too, because - well, of course, nothing is.

Participant A describes how mindfulness practice has improved her ability to cope with the emotions that develop surrounding her husband's health and how she is empowered to continue her role as a mother. She explains:

I see myself being a mom, regardless of the situation. Cancer is something that came into our lives, and I feel like everyone has challenges. Everyone does. That's just part of life. This was one of our challenges during this time. It taught us to slow down a little bit and to realize what is important in the relationships that we have. We have wonderful lessons. Mindfulness practice provides a space to share gratitude for what life is handing us. When asked how mindfulness practice supports her healing, Participant B illustrates:

The word that comes up is "love." I don't mean in the surface way it's used a lot now. What's most important is for me is to get in touch with myself and then maybe help other people, steer them toward this understanding of this innate value in spirit that we all have. We are all connected to each other. If you drilled down to the source of that, I would say that's love. My practice is anything I'm looking at or wanting to learn is opening that up and building that up for me. 


\section{Part Three: In-depth Interviews with Instructors of Integrative Therapy Programs}

Through interviews with instructors of the gentle yoga class, meditation mindfulness, women's writing group, inpatient massage, and the program director, analysis of current programing was explored. In-depth interviews were recorded and later transcribed by the doctoral student. Interviews with each instructor revealed strengths within each therapeutic modality, barriers to recruitment and patient access, as well as goals for expanding programing to the parent population in the home environment (See Appendix E).

\section{Theme One: Impact of Cancer Diagnosis and Treatment}

The impact of a diagnosis of cancer and subsequent treatment is broad. The staff who work with these individuals and their families are aware of the rippling effect cancer has on what they do and how they do it. When a parent is diagnosed with cancer, there are aspects of the family that will change. Susan Hedlund, the director of patient and family services at the Knight Cancer Institute, shares her experience working with parents who have young children:

A cancer diagnosis always has a ripple effect across the whole family's system. It isn't just a disease of one person; it has an impact on anybody who cares about them, whether it is their partner or their parents or their siblings or friends. It can be so disruptive, with everything from not being able to continue to work, to not being able to do normal parenting. Young parents were so worried about the cancer disrupting normal developmental tasks for their children, yet they often lack the energy to do the kinds of things that they would normally be doing like playing sports with them or coaching their teams or volunteering in the classroom. There is often this real struggle between taking care of themselves as somebody with cancer and taking care of their families, in particular, the needs of their kids. 
Some roles are shared across family members, while habits and routines might change over time.

Kimberly Carson, the meditation mindfulness instructor, shares her perspective on the impact of cancer treatment.

In many different ways I have seen it bring families closer together, but I have also seen roles become less trusted. I have seen parents who don't trust themselves to be an optimal parent because their system is struggling so much. They lose confidence in that. There is also sometimes an enhanced tenderness and fear around outcome because of the concern for the children. It's different if you're in your 70s, and you've had a long, productive life. It still can be very scary, and people still want to be able to live longer rather than not, but it's a different lens if there are kids at home. The depth of that responsibility has a different pull.

Parents are in a unique situation as they take on the "patient" role. The needs of their family often come before their own, and the shift in normal becomes difficult to cope with. Cancer and subsequent treatment can cause physical and emotional symptoms such as anxiety, fatigue, pain, and social isolations. Carson shares:

When people are finished with radiation, finished with surgeries, there are so many ways in which tissue can be compromised going through treatment or through disease process itself. Being able to have appropriate range of motion exercise where you're keeping the system moving as functional as possible is really helpful.

People going through cancer treatment might not have the insight into the fact their body is changing. Elaine Cohn, the instructor of gentle yoga, explains how cancer can impact the body and how she works with people to adapt to their limitations. 
I talk to each person before they start and find out what is going on with them, their energy, their limitations, problems, soreness, etc. And I observe. And if I see they are having trouble, I can make adaptations. They always have the option. It's not right or wrong. I think that's really important, so they don't feel like a failure.

When someone is diagnosed with a chronic condition, that person can feel isolated, especially if treatment causes them to reside in the home. If secondary effects of treatment impact the ability to work or drive, it could cause the individual to become disconnected from their instrumental activities of daily living. Cohn explains:

I've learned with cancer survivors what's most valuable is to be around other cancer survivors and talk, to feel normal, to do normal things, to share.

\section{Theme Two: Need to Provide Education on Integrative Therapies}

As integrative medicine, also known as complementary or alternative therapy, becomes more popular in Western medicine, there is an increased need to educate the community on the benefits of these modalities. Integrative therapies in the cancer setting are designed to work with the patient's medical plan of care to augment support across all domains. While chemotherapy and radiation might address the physical dimensions of cancer, integrative therapy programs provide tools to address the psychosocial symptoms that develop over time. One tool is mediation mindfulness practice. Kimberly Carson further explains:

Part of what mindfulness training does, it's very explicit in its origin. It's working with the reality of impermanence, that everything that arises has its song and dance and then dissolves. In moment to moment, that's happening. It's happening with breath. It's happening with thought, sensation, emotion, 
conversation, always every single moment. As we become more comfortable with the reality of that, then the willingness to be here and embrace here, rather than ongoing worry about what could be, what will be. It's like that whole process is a completely different way to live. Just here.

Mindfulness training can be a strong tool for anyone to bring awareness and acceptance to our life challenges. In the context of a chronic condition, mindfulness can help reduce anxiety by allowing the mind space to process. Carson continues:

It's about recognizing that all of us get pulled into different patterns of thought and different patterns of emotional responding. Sometimes those patterns of thoughts and feelings can end up driving physiology and how little or how much at ease we feel in our systems. Mindfulness can really help bring clarity and some light to what those patterns might be and then allow some transformation of those so that people suffer less.

Meditation mindfulness practice is used to bring awareness to how our thoughts and feelings can impact our physical bodies. This practice provides an opportunity to reduce feelings of anxiety and bring awareness to our senses. There is a stigma around this type of therapy. In Eastern medicine, these practices have been used for hundreds of years. Until more recently, Western culture has begun to accept these practices in the treatment of cancer. It takes a while for change to take place in the medical field. Carson shares the difficulty:

This is a real challenge. And part of it, too, is the institutional training. It's a culture shift, which is never easy. If we truly had healthcare teams that recognized the value of this and would encourage patients whatever way they are able to step into the self-care work, and 
then it's getting told by the doctor, by the nurse, somebody else that's a stakeholder in their care, then I think it becomes something totally different than a piece of paper. In addition to the culture of the medical institution, there is an education component that is needed for the community. These services must be presented in a way that highlights the value and benefit to the patient and their family. Carson confirms:

It has to be in the culture of the family as well as the culture of the healthcare team. It has to been in both because the patient is just trying to survive. Literally. Yoga and positioning can be used to alleviate symptoms of pain, fatigue, and can help reduce anxiety. Contrary to traditional yoga, gentle yoga for cancer patients is designed to provide range of motion and light movement in a relaxing environment. Hatha and Kripalu are types of yoga that specifically cater to the individual and their current abilities. Elaine Cohn further explains: How it differs from other types of yoga is that it is really accepting of where you are at and learning to love and accept where you're at, who you are, what your body can do, and nurturing that instead of comparing yourself to others. It's tuning into your body, to the sensations, the feelings.

Cohn continues to describe how gentle yoga approaches the participants with a $70 \%$ effort guideline which will keep the person safe. Cohn explains:

It's a way people can still benefit but less likely to injure themselves. It's also where they can feel some positive feelings. When we go beyond $80,90,100 \%$, which we learn so much in our community, in our society, in America, to go full out. It's like... people start to hate what they are doing, they dread it. For some, it's about relearning not just to move in yoga but maybe even move in the world. Everything doesn't have to be $100 \%$. We may be hurting ourselves and missing out on some joy. It can still be effective. 
It can be difficult to help someone else gauge what $70 \%$ effort is to them. Part of what Cohn does is work with the participants to identify their safe range when engaging in these poses.

And $70 \%$ is a good thing because I don't know what is going on inside. They are the best gauge. I can look at their faces. If they are straining, I can say, 'Can you breathe and bring more ease to the pose?' Notice their breath. Encourage that deep belly breath to keep them more relaxed and aware what their breathing is like. 'Is your chest breathing fast?'

\section{Theme Three: Programs Typically Accessed After Treatment}

The integrative therapy programs at the Knight Cancer Institute are introduced when an individual is diagnosed. However, with the overload of initial information following a diagnosis, it is not often a priority. Many patients are in survival mode working with their oncology team to develop a treatment plan. Susan Hedlund, the director of patient and family services at the Knight Cancer Institute, explains how patients are more likely to access therapeutic programs after active treatment because they are emotionally ready to make lifestyle changes. Susan continues:

People are so ripe for these services at the end of treatment while they already have the emotional wherewithal and the physical energy more often. Secondly, they are highly motivated to make lifestyle changes.

When people are accessing integrative therapies post treatment, they are working to improve symptoms secondary to cancer treatment. Hedlund further explains how integrative medicine addresses the secondary impacts of cancer when the individual is finished with their medical plan of care: 
It's a time where people are often coming up for air and thinking, 'Whew! What have I been through and how do I stay safe?' So integrative therapies I think do several things, not only relieve particular side effects and symptoms of the disease like fatigue and neuropathies, anxiety and stress, but they also give people back a sense of control and mastery, which is something that cancer takes away from people.

From the point of diagnosis, there are psychosocial concerns that begin to arise. Emotions are heightened as things begin to change with their health. Kimberly Carson, the meditation instructor, explains how important it is to address these symptoms early in the process to prevent further suffering. She shares:

Another way these tools help, especially with pain, with anxiety, nausea, is teaching how to learn to work with those sensations. If the trajectory of the disease goes in the direction where the body is not able to fight it off and the medication and treatment is not able to fight off the disease, that's really important so that we are empowering folks early for however things unfold. Whatever rolls out.

Currently, the majority of people accessing the services offered through the Knight Cancer Institute are post treatment. However, individuals diagnosed with cancer, their partners, and their families all experience some degree of secondary psychosocial symptoms throughout the disease and treatment process. 


\section{Theme Four: Value of In-Home Services}

Cancer is considered a chronic condition and treatment extends beyond the hospital setting and into the home environment. When individuals are in the middle of treatment, they are often home for longer periods of time because of their fluctuating physical symptoms and changes in emotions. Some individuals are not able to drive or work during this time, which impacts them engaging in their normal roles and routines. Parents with dependent children have extended responsibilities in the home to care for their children. Susan Hedlund explains her perception of how parents are driven to fight cancer because of their children. She shares:

People are highly motivated to make lifestyle changes, whether it is to stop smoking or to eat healthier, to lose some weight or to get active. And that's a real pivotal point and much of that could and should occur in the home.

The Knight Cancer Institute currently offers these services on their main campus. If individuals are not able to participate in the groups in person, there is presently no alternative. Instead of disregarding these modalities, individuals can engage in these programs at home. Kimberly Carson describes the benefit of finding time in your daily routine to practice mindfulness. But it's really helpful to find a time of day that's somewhat reliable. With kids, that's tricky, so sometimes it means you have to get up before they do.

Sometimes people are worried that if they get up earlier, they are going to be more fatigued, and they are going to lose out on the benefit of sleep. But what most meditators will attest to is there is a deeper rejuvenation that comes from practice even than comes from sleep. It has its own nourishing capacity. It may be the last thing at night, after the kids go to bed. It may have to be during the day if somebody is working. Maybe it's 10 minutes in your office in which 
you close the door. Sometimes you have to get creative, but most importantly

it's to make the commitment and do it.

By providing opportunities for parents to engage in these programs at home allows for them to include their family. Carson further explains the benefit of incorporating the children into the conversation surrounding cancer. Depending on the children's developmental level, keeping communication open can help reduce anxiety in the home. Meditation mindfulness practice can be taught to children in the home is to introduce how we identify the different senses. Carson explains:

We did a little thing where we talked about the hungry ghost, that insatiable hunger, that desire for something different than what's here. So we would play with how do we bring the wisdom and the insight that comes from mindfulness training in ways that are more playful. But that's a whole different approach than adult learning.

By educating parents how to incorporate mindfulness practice at home, they can engage with their children to alleviate any fear and allow them a space to understand how they are feeling. She continues:

Being able to feel the body and helping children really come into the sensate realm and be able to see the difference from what they are experiencing versus what they are thinking about what they are experiencing. To be able to just see that and be reinforced for that recognition would be probably the most skillful way to bring this to kids, not having them sit still and need them to be able to focus on their breath for 20 minutes. 


\section{Chapter V: Summary, Conclusion, Discussion}

\section{Summary}

The primary objective of this project was to explore the impact of cancer on newly diagnosed individuals who have minor (dependent) children. The original intent was to interview newly diagnosed parents to gather information about how cancer and subsequent treatment alters family normalcy. However, due to a limited amount of newly diagnosed parents attending groups at the Knight Cancer Institute, the doctoral student approached this projective retrospectively. The initial question was still the focus, but the approach was altered. Instead of interviewing patients at the beginning of treatment, the interviews involved a former patient and a spouse of a current patient to determine the impact of cancer throughout treatment. Additionally, in-depth interviews with staff of the integrative therapy programs were conducted to further understand how cancer impacts a family with dependent children and how alternative therapeutic programming addresses the secondary symptoms of cancer and subsequent treatment.

A brief survey, which included ten patients in the Portland community, was conducted to gather initial information about the experiences of patients with cancer and how psychosocial symptoms are impacting their daily routines. A majority of the participants who reported being pre-treatment or in treatment were developing psychosocial symptoms such as pain and fatigue that impacted their ability to engage in meaningful tasks.

Through in-depth interviews using a modified version of the OCAIRS, three common themes emerged: Roles became blended within the family, additional care was independently sought out, and mindfulness practice was a strong coping tool. It was evident that following a diagnosis of a parent that roles within the household became altered. Participant A shared her experience leaving her business to stay home and support her husband through treatment and to 
take care of their adolescents, while Participant B, being the patient, was unable to work at this time due to increasing physical and psychosocial symptoms. Her role as employee, homemaker, and volunteer were put on hold during treatment, and her husband took on more within the household. Both participants shared their experience seeking out additional alterative modalities to address their secondary symptoms surrounding the diagnosis and treatment. Rather than receiving information regarding integrative therapy through their cancer treatment center, both participants wanted to incorporate modalities to support their mental health. Meditation mindfulness practice is highly valued in both participants and they shared how this practice has become an essential component of their healing and now, their daily routine.

The integrative therapy program instructors shared their experiences working with parents with cancer and their families through in-depth interviews. The staff have years of combined experience working in alternative medicine and value the benefits these practices offer their patients and their families. Through in-depth interviews, four common themes emerged: the impact of cancer diagnosis and treatment, the need to educate about integrative therapies, programs typically addressed after treatment, and the value of in-home services. These themes highlighted the perception of how cancer affects the entire family and how integrative medicine is still a difficult topic to integrative into modern medicine. Susan Hedlund, the director of patient and family services at the Knight Cancer Institute, values in-home programming for parents with dependent children because these parents often struggle to leave the home.

\section{Discussion}

With approximately a quarter of the people diagnosed with cancer being child rearing age, there is value in developing resources to support families through treatment. This project took place at the Knight Cancer Institute in the integrative medicine department. This 
organization conducted a needs assessment prior to the project taking place which revealed parent's needs when going through cancer. One of the areas to address is maintaining essential family routines. While there appears to be increasing programs and resources within the Portland community, there is an opportunity to expand services into the home. Occupational therapy has a strong role in supporting families in their home environment as the profession values therapy in the natural context. This project advocates for the role of occupational therapy in integrative medicine is to bridge services offered in the hospital setting to the home environment. This project concludes the need for an occupational therapist to provide home program which integrates mindfulness into daily routines within the natural environment. Occupational therapists approach the individual in a holistic, client-centered way that highlights their roles, routines, habits, values, and interests.

\section{Collaboration with Interdisciplinary Team}

Throughout the capstone experience, the doctoral student worked closely with a variety of disciplines involved in integrative medicine. A main objective of this project was to explore the various professionals involved in the care of an individual diagnosed with cancer and how occupational therapy is involved. According to Seely and colleagues (2012), implementation of successful integrative therapy programs requires strong leadership and collaboration across the interdisciplinary team. One strategy to improve communication was to strengthen the communication and collaboration between outpatient and inpatient services. An in-service was scheduled for March 2020 to the acute rehabilitation department at OHSU, however due to public health concerns, it has been postponed to an unknown date. The doctoral student will follow-up with hospital to reschedule when appropriate. 
A home program, "Healing at Home," has been developed by the doctoral student to provide a sample program that an occupational therapist could implement with newly diagnosed individuals and their families. This program consists of three sessions which incorporate meditation, yoga, journaling, and support for families with resources and childcare while a parent is going through treatment (See Appendix F).

This project had several limitations which impacted the methodology of the proposed capstone. The project was designed to gather information from newly diagnosed individuals about the impact of cancer, but due to a limited number of parents attending integrative therapy groups, this was not achieved. Additionally, due to a worldwide public health crisis, the planned in-service to the rehabilitation department at OHSU was postponed to an unknown date.

\section{Conclusion}

This project sought to understand the vast impact of a diagnosis of cancer on a parent and their family. Current literature supports the notion that a diagnosis of cancer and subsequent treatment can affect all areas of daily living, social engagement, sleep quality, family routines, and engagement in meaningful activities (Huizinga et al., 2011; Kim et al., 2006). Psychosocial symptoms secondary to cancer develop as treatment is established and progressed through. Integrative therapy programs are designed to complement the medical treatment plan by offering modalities to support symptoms of pain, anxiety, social isolation, and feelings of depression. While these programs are beneficial at any stage of treatment, they are often not accessed until individuals complete treatment. 


\section{References}

American Cancer Society. (2019). Cancer facts \& figures 2019. Retrieved from https://www.cancer.org/research/cancer-facts-statistics/all-cancer-facts-figures/cancerfacts-figures-2019.html

American Cancer Society. (2019). Cancer treatment \& survivorship. Retrieved from https://www.cancer.org/research/cancer-facts-statistics/survivor-facts-figures.html

American Occupational Therapy Association. (2011). The role of occupational therapy in oncology: Fact sheet.

https://www.aota.org/ /media/Corporate/Files/AboutOT/Professionals/WhatIsOT/RDP/F acts/Oncology $\% 20$ fact $\% 20$ sheet.pdf

Bower, J. E., Bak, K., Berger, A., Breitbart, W., Escalanta, C. P., Ganz, P. A., Hill Schnipper, H., Lacchetti, C., Ligibel, J. A., Lyman, G. H., Ogaily, M. S., Pirl, W. F., \& Jacobsen, P. B. (2014). Screening, assessment, and management of fatigue in adult survivors of cancer: An American Society of Clinical Practice guideline adaption. Journal of Clinical Oncology, 32(7), 1804-1851. https://doi:10.1200/JCO.2013.53.4495

Compas, B.E., Worsham, N.L., Epping-Jordan, J. E., Grant, K. E., Mireault, G., Howell, D. C., \& Malcarne, V. L. (1994). When Mom or Dad has cancer: Markers of psychological distress in cancer patients, spouses, and children. Health Psychology, 13(6), 507-515. https://doi.org/10.1037/10338-011

Coss, D. (2019). Occupational therapy interventions in cancer care. OT Practice, 24(7), 10-14.

Crespo, C., Santos, S., Canavarro, M., Kielpikowski, M., Pryor, J., \& Deres-Carneiro, T. (2013). Family routines and rituals in the context of chronic conditions: A review. International Journal of Psychology,48(5), 729-746. https://doi.org/10.1080/00207594.2013.806811 
Grabiak, B., Bender, C., \& Puskar, K. (2007). The impact of parental cancer on the adolescent: An analysis of the literature. Psycho-Oncology, 16, 127-137. https://doi.org/10.1002/pon.1083

Heiney, S., Bryant, L., Walker, S., Parrish, R., Provenzano, F., \& Kelly, K. (1997). Impact of parental anxiety on child emotional adjustment when a parent has cancer. Oncology Nursing Society, 24(4), 655-661.

Helseth S. \& Ulfsaet N. (2005). Parenting experiences during cancer. Journal of Advanced Nursing 52, 38-46. https://doi.org/10.1111/j.1365-2648.2005.03562.x

Huizinga, G. A., Visser, A., Zelders-Steyn, Y., Teule, J., Reijneveld, S., \& Roodbol, P. (2011). Psychological impact of having a parent with cancer. European Journal of Cancer, 47(3), S239-S246. https://doi.org/10.1016/S0959-8049(11)70170-8

Hunter, E. G., Gibson, R. W., Arbesman, M., \& D’Amico, M. (2017). Centennial TopicsSystematic review of occupational therapy and adult cancer rehabilitation: Part 2. Impact of multidisciplinary rehabilitation and psychosocial, sexuality, and return-to-work interventions. American Journal of Occupational Therapy, 71, 7102100040. https://doi.org/10.5014/ajot.2017.023572

Kim, Y., Baker, F., Spillers, R., \& Wellisch, D. (2006). Psychological adjustment of cancer caregivers with multiple roles. Psycho-Oncology, 15, 795-804. Flowhttps://doi.org/10.1002/pon.1013

Mackenzie, M. J., Carlson, L. E., Munoz, M., \& Speca, M. (2007). A qualitative study of selfperceived effects of mindfulness-based stress reduction (MBSR) in a psychosocial oncology setting. Stress and Health, 23, 59-69. https://doi.org/10.1002/smi.1120 
McCall, M.C., Ward, A., \& Heneghan, C. (2015). Yoga in adult cancer: A pilot survey of attitudes and beliefs among oncologists. Current Oncology, 22(1), 13-19. https://doi:10.3747/co.22.2129

Okamoto, I., Wright, D., \& Foster, C. (2011). Impact of cancer on everyday life: A systematic appraisal of the research evidence. Health Expectations, 15, 97-111. https://doi.org/10.1111/j.1369-7625.2011.00662.x

Peh, C. X., Kua, E H., \& Mahendran, R. (2016). Hope, emotion regulation, and psychosocial well-being in patients newly diagnosed with cancer. Support Cancer Care, 24, 19551962. https://doi.org/10.1007/s00520-015-2989-X

Portney, L. \& Watkins, M. (2015). Foundations of Clinical Research (3rd ed.). F.A. Davis Company.

Raub, J. A. (2002). Psychophysiologic effects of Hatha yoga on musculoskeletal and cardiopulmonary function: A literature review. Journal of Alternative and Complementary Medicine, 8(6), 797-812. https://doi.org/10.1089/10755530260511810

Seely, D. M., Weeks, L. C., \& Young, S. (2012) A systematic review of integrative oncology programs. Current Oncology, 19, e436-461. http://doi:10.3747/co.19.1182

Shah, B. K., Armaly, J., \& Swieter, E. (2017). Impact of parental cancer on children. Anticancer Research, 37, 4025-4028. https://doi:10.21873/anticanres.11787

Sleight, A. G., \& Duker, L. I. S. (2016). The issue is-Toward a broader role for occupational therapy in supportive oncology care. American Journal of Occupational Therapy, 70, 7004360030. https://doi.org/10.5014/ajot.2016.018101 
Smith, J., Richardson, J., Hoffman, C., \& Pilkington, K. (2005). Mindfulness-based stress reduction as supportive therapy in cancer care: Systematic review. Journal of Advanced Nursing, 52(3), 315-327. https://doi.org/10.1111/j.1365-2648.2005.03592.x

Taylor, R. (2017). Kielhofner's Model of Human Occupation: Theory and application (5 ${ }^{\text {th }}$ ed.) Lippincott, Williams and Wilkins.

Tolson, A., Lowrie, D., Chand, A., \& Marsh, J. (2017). Occupational disruption among people with haematological cancer during treatment isolation. International Journal of Therapy and Rehabilitation, 24(9), 394-402. https://doi.org/10.12968/ijtr.2017.24.9.394

Visser, A., Huizinga, G., Van der Graaf, W., Hoekstra, H., \& Hoekstra-Weebers, J. (2004). Supportive care - The impact of parental cancer on children and the family: A review of the literature. Cancer Treatment Reviews, 30, 683-694.

https://doi.org/10.1016/j.ctrv.2004.06.001 


\section{Appendix A: Participant Consent Form}

I voluntarily agree to participate in this interview for the purpose

of gathering information as part of a needs assessment conducted by Riley Harrold, doctoral student.

- I understand that even if I agree to participate now, I can withdraw at any time or refuse to answer any question without any consequences of any kind.

- I understand that I can withdraw permission to use data from my interview within two weeks after the interview, in which case the material will be deleted.

- I have had the purpose and nature of the needs assessment explained to me in writing and I have had the opportunity to ask questions about the project.

- I understand that participation involves an hour-long interview regarding experiences and responsibilities in their various roles and how cancer has impacted them.

- I agree to my interview being audio-recorded.

- I understand that all information I provide for this study will be treated confidentially.

- I understand that in any report on the results of this research my identity will remain anonymous. This will be done by changing my name and disguising any details of my interview which may reveal my identity or the identity of people I speak about.

- I understand that disguised extracts from my interview may be quoted in a final capstone paper, conference presentations, and other forms of dissemination.

- I understand that if I inform the researcher that myself or someone else is at risk of harm they may have to report this to the relevant authorities - they will discuss this with me first but may be required to report with or without my permission.

- I understand that signed consent forms and original audio recordings will be retained in a password protected laptop until April 2020 when the final dissemination of results will be analyzed.

- I understand that a transcript of my interview in which all identifying information has been removed will be retained until April 2020.

- I understand that under freedom of information legalization I am entitled to access the information I have provided at any time while it is in storage as specified above.

- I understand that I am free to contact any of the people involved in the research to seek further clarification and information.

Thank you so much for your participation!

Riley Harrold, OTDS

University of St. Augustine for Health Sciences

Signature of participant: Date:

Signature of doctoral student: Date: 


\section{Appendix B: Letter to Staff of Knight Cancer Institute}

To whom it may concern,

THANK YOU for assisting me in distributing this screening tool. This information is part of my doctorate of occupational therapy capstone project which is exploring the impact of cancer on an individual with minor (dependent) children. I am hoping to gather some preliminary information to help develop resources for parents with cancer. This survey was specifically developed for the purpose of this project and the information provided by the individuals will not be shared outside this project. The purpose of this tool is to identify possible individuals to follow-up with a more in-depth interview.

Please only have people who meet ALL of the following criteria to complete the screening tool:

- Individual who has a diagnosis of cancer

$\circ$ Any type

$\circ$ Any stage (newly diagnosed, in treatment, survivorship, etc.)

- Has minor (dependent) children

This survey will be distributed from January 2020, through February 2020.

Please don't hesitate to contact me if you have any questions.

Best,

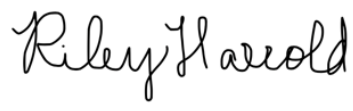

Riley Harrold, OTD student

r.harrold@usa.edu

r.harrold.ot@gmail.com

University of St Augustine for Health Sciences 


\section{Appendix C: Occupational Disruption Survey for Parents}

The purpose of this tool is to identify patients who are parents of dependent (18-years-old and younger) children. The information gathered will be part of a doctoral student project.

\begin{tabular}{|l|l|}
\hline Name: & Diagnosis: \\
\hline Stage of treatment: & Referral/Service: \\
\hline
\end{tabular}

Are you a single parent? $\quad$ Yes No

Are you currently working? Yes No

Are you driving? Yes No

How old is/are your child(ren)?

Please rate how following statements apply on a scale of $1-5$.

( 1 = strongly disagree, $2=$ disagree, $3=$ neutral, $4=$ agree, $5=$ strongly agree)

\begin{tabular}{|c|c|c|c|c|c|}
\hline My daily routine is impacted by pain or fatigue. & 1 & 2 & 3 & 4 & 5 \\
\hline $\begin{array}{l}\text { I have enough energy to do all the things I need and want to do each } \\
\text { day. }\end{array}$ & 1 & 2 & 3 & 4 & 5 \\
\hline Pain often impacts my ability to do the things I need and want to do. & 1 & 2 & 3 & 4 & 5 \\
\hline I am satisfied with the quality and amount of sleep I get each night. & 1 & 2 & 3 & 4 & 5 \\
\hline It is difficult to complete my daily routine. & 1 & 2 & 3 & 4 & 5 \\
\hline I have responsibilities to care for people other than myself. & 1 & 2 & 3 & 4 & 5 \\
\hline I have fear surrounding my health. & 1 & 2 & 3 & 4 & 5 \\
\hline I have adequate support from family and friends. & 1 & 2 & 3 & 4 & 5 \\
\hline I have the physical ability to accomplish what I need and want to do. & 1 & 2 & 3 & 4 & 5 \\
\hline $\begin{array}{l}\text { There are resources available to help me overcome barriers to getting } \\
\text { things done. }\end{array}$ & 1 & 2 & 3 & 4 & 5 \\
\hline I worry about my children being taken care of. & 1 & 2 & 3 & 4 & 5 \\
\hline $\begin{array}{l}\text { I find it difficult to care for my children due to symptoms such as } \\
\text { pain, fatigue, or depression. }\end{array}$ & 1 & 2 & 3 & 4 & 5 \\
\hline Exercise and physical activity are important to me. & 1 & 2 & 3 & 4 & 5 \\
\hline I need assistance to physically care for myself. & 1 & 2 & 3 & 4 & 5 \\
\hline I am able to do activities that bring me joy. & 1 & 2 & 3 & 4 & 5 \\
\hline $\begin{array}{l}\text { It is hard for me to complete household tasks such as meal prep, } \\
\text { laundry, or cleaning. }\end{array}$ & 1 & 2 & 3 & 4 & 5 \\
\hline Anxiety impacts my ability to do the things I want and need & 1 & 2 & 3 & 4 & 5 \\
\hline
\end{tabular}




\section{Appendix D: OCAIRS Sample Interview Questions}

\section{OCAIRS Mental Health Interview (Form 1) Questions}

\section{Roles}

What do you do? What are your major responsibilities? (Parent? Spouse? Worker? Student? Homemaker?)

Do you belong to any groups?

(For each role mentioned) How important is to you? Do you enjoy __ ?

How well are you able to (for each role mentioned)?

What else do you do? What other roles do you fill?

\section{Habits}

Describe a typical weekday (before you began treatment/ this program/were hospitalized).

Describe a typical weekend day (before you began treatment/this program/were hospitalized).

Does your daily schedule let you do the things you need and want to do?

Has your daily routine changed (over the last 6 months/ since your accident/since your divorce etc_-pick some pivotal event if possible)? How?

Are you satisfied with your current daily routine?

\section{Interests}

Is your major occupational role such as, worker, student, volunteer, caretaker something you enjoy? What about it interests or satisfies you?

What do you like to do with your time outside of (work or major occupational role)?

Do you have any other interests or hobbies?

(For interests mentioned) How often do you __ ? Are you satisfied with the amount of time you are able to spend ?

\section{Values}

What do you value most in your life? (What is most important to you?)

What are other things or ideals that you value (are important to you)?

How important are these to you?

What about your life reflects these values? Are you able to live life in ways that fit with the values you think you should have or try to live up to?

Is there anything about your life that you feel goes against your values?

\section{Social Environment}

Do you spend a lot of time alone? Who do you spend most of your time with?

Who are the most important people in your life right now?

Does what they expect from you match what you like or would like to do?

Would you describe your (work, school, community) setting as supportive?

Do the people or situations in your life place limits on you?

If you need help/support, can you count on family/friends/ community? 
Appendix E: Integrative Therapy Program Report

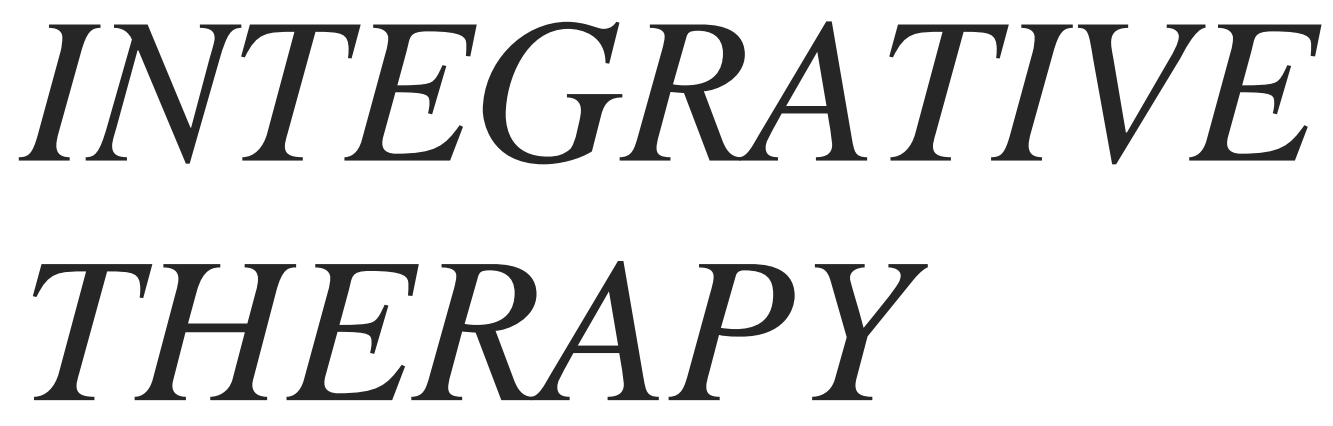

PROGRAM

REPORT

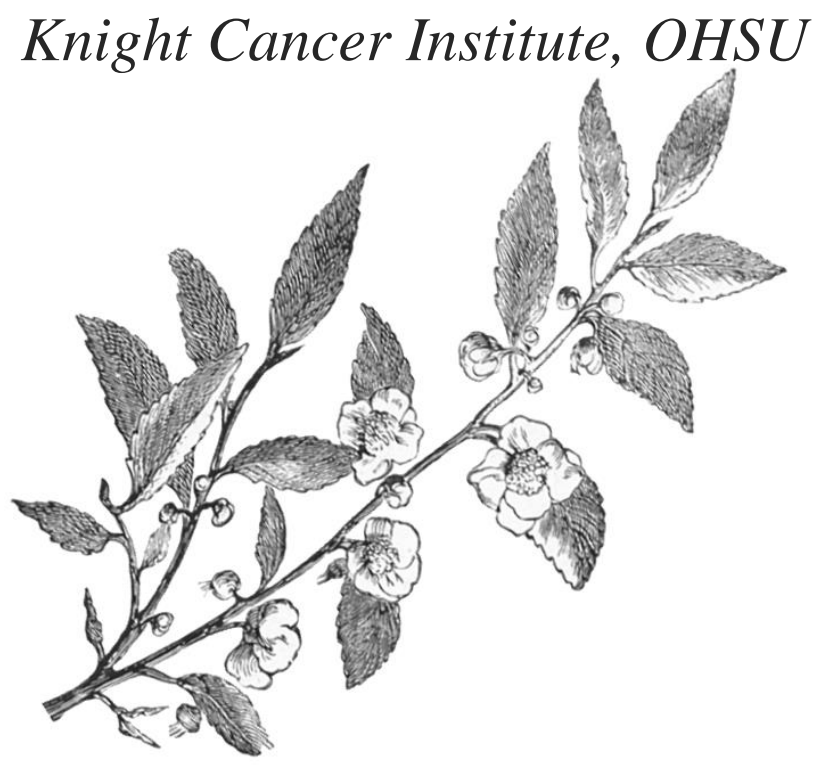

Riley Harrold, OTD student

University of St Augustine for Health Sciences | April 2020 


\section{Introduction}




\section{Introduction}

My time at the Knight Cancer Institute has been invaluable. Less than a year ago, I met Susan Hedlund at the Integrative Therapy Conference hosted by OHSU. There, I learned from the amazing program instructors and heard from patients about their experiences being involved in the groups. With my background research being in oncology, I was quickly drawn to the foundations of integrative medicine. With Susan's help, I was able to connect my project with the programs that are offered through the Knight Cancer Institute. After meeting with Susan, we developed some mutual goals for me to accomplish by the end of my capstone in April 2020.

I began my information-gathering by attending some of the wellness groups offered for cancer patients and caregivers. Starting in November 2019, I attended and participated in the gentle yoga class, the women's writing group, and mindfulness breath-by-breath weekly. Regularly attending these groups allowed me to broaden my understanding of the foundations of each of these therapeutic modalities. I began to build rapport with the participants with the goal of interviewing parents who have young children. My focus demographic for my capstone project is newly diagnosed individuals with minor (dependent) children. I quickly learned that there are not many parents attending these groups, so I had to shift my focus, as we often have to do when conducting a needs assessment. I ultimately wanted to understand why parents were not attending. My intention was to identify barriers for participant attendance, to understand how parents can integrate these therapeutic modalities at home, and strategize ways to enhance programming. I decided to approach my overall objectives in a new way: retrospectively. Instead of interviewing newly diagnosed individuals, I saw the value in learning from the program instructors and parents who are out of treatment. The program instructors have years of 
experience both personally with cancer and professionally working with people at all stages through a variety of modalities.

I strongly believe that we need more interdisciplinary collaboration, especially when working with cancer patients and their families. Cancer impacts many areas of our lives, and there is great benefit in sharing our expertise in our respective fields to best care for the patient. One of my goals during my time at OHSU has been to share the role of occupational therapy in cancer care and learn how to better work with other disciplines within integrative medicine. The more we understand each other's profession, the more we can work together to enhance our patient care.

This report is meant to serve as a summary of the interviews that were conducted between December 2019 - February 2020. By interviewing staff, I was able to identify four themes that highlight the impact of a cancer diagnosis, the need for education on integrative therapy, program access, and the value to in-home services. I hope you and your team find this helpful for future programming and patient recruitment. Please don't hesitate to contact me if you have any questions.

Sincerely,

$$
\text { Riley Havold }
$$

Riley Harrold

OTD Student

Harrold.riley@gmail.com

(541)948-5683

University of St. Augustine for Health Sciences 


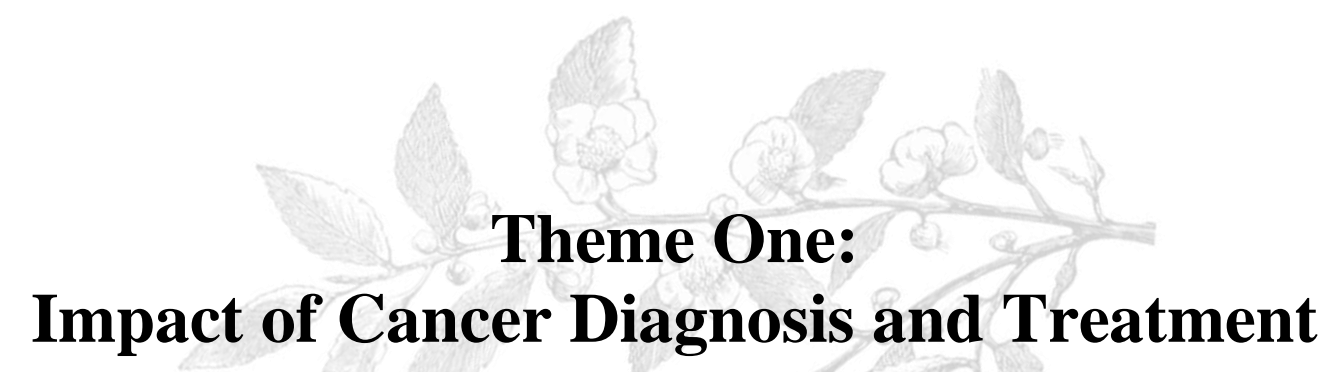




\section{Theme One: \\ Impact of Cancer Diagnosis and Treatment}

The impact of a diagnosis of cancer and subsequent treatment is broad. The staff who work with these individuals and their families are aware of the rippling effect cancer has on what they do and how they do it. When a parent is diagnosed with cancer, there are aspects of the family that will change. Susan Hedlund, the director of patient and family services at the Knight Cancer Institute, shares her experience working with parents who have young children: A cancer diagnosis always has a ripple effect across the whole family's system. It isn't just a disease of one person; it has an impact on anybody who cares about them, whether it is their partner or their parents or their siblings or friends. It can be so disruptive, with everything from not being able to continue to work, to not being able to do normal parenting. That's that thing I heard the most from young parents is that they were so worried about the cancer disrupting normal developmental tasks for their children, yet they often lack the energy to do the kinds of things that they would normally be doing like playing sports with them or coaching their teams or volunteering in the classroom. And there is often this real struggle between taking care of themselves as somebody with cancer and taking care of their families, in particular, the needs of their kids.

Some roles are shared across family members, while habits and routines might change over time.

Kimberly Carson, the meditation mindfulness instructor, shares her perspective on the impact of cancer treatment.

In many different ways I have seen it bring families closer together, but I have also seen roles become less trusted. I have seen parents who don't trust themselves to be an optimal parent because their system is struggling so much. They lose confidence in that. There is also sometimes an enhanced tenderness 
and fear around outcome because of the concern for the children. It's different if you're in your 70s, and you've had a long, productive life. It still can be very scary, and people still want to be able to live longer rather than not, but it's a different lens if there are kids at home. The depth of that responsibility has a different pull.

Parents are in a unique situation as they take on the "patient" role. The needs of their family often come before their own, and the shift in normal becomes difficult to cope with. Cancer and subsequent treatment can cause physical and emotional symptoms such as anxiety, fatigue, pain, and social isolations. Carson shares:

When people are finished with radiation, finished with surgeries, there are so many ways in which tissue can be compromised going through treatment or through disease process itself. Being able to have appropriate range of motion exercise where you're keeping the system moving as functional as possible is really helpful.

People going through cancer treatment might not have the insight into the fact their body is changing. Elaine Cohn, the instructor of gentle yoga, explains how cancer can impact the body and how she works with people to adapt to their limitations.

I talk to each person before they start and find out what is going on with them, their energy, their limitations, problems, soreness, etc. And I observe. And if I see they are having trouble, I can make adaptations. They always have the option. It's not right or wrong. I think that's really important, so they don't feel like a failure.

When someone is diagnosed with a chronic condition, that person can feel isolated, especially if treatment causes them to reside in the home. If secondary effects of treatment impact the ability 
to work or drive, it could cause the individual to become disconnected from their instrumental activities of daily living. Cohn explains:

I've learned with cancer survivors what's most valuable is to be around other cancer survivors and talk, to feel normal, to do normal things, to share. 


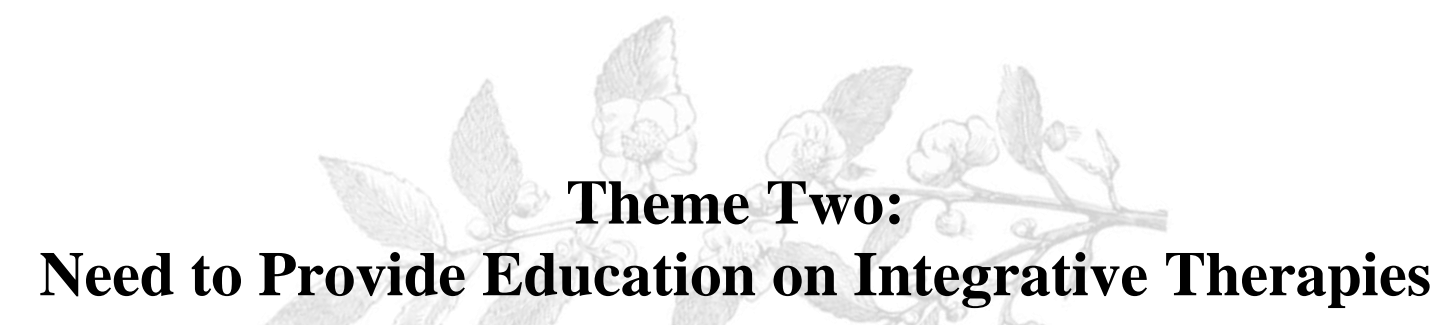




\section{Theme Two: Need to Provide Education on Integrative Therapies}

As integrative medicine, also known as complementary or alternative therapy, becomes more popular in Western medicine, there is an increased need to educate the community on the benefits of these modalities. Integrative therapies in the cancer setting are designed to work with the patient's medical plan of care to augment support across all domains. While chemotherapy and radiation might address the physical dimensions of cancer, integrative therapy programs provide tools to address the psychosocial symptoms that develop over time. One tool is mediation mindfulness practice. Kimberly Carson further explains:

Part of what mindfulness training does, it's very explicit in its origin. It's working with the reality of impermanence, that everything that arises has its song and dance and then dissolves. In moment to moment, that's happening. It's happening with breath. It's happening with thought, sensation, emotion, conversation, always every single moment. As we become more comfortable with the reality of that, then the willingness to be here and embrace here, rather than ongoing worry about what could be, what will be. It's like that whole process is a completely different way to live. Just here.

Mindfulness training can be a strong tool for anyone to bring awareness and acceptance to our life challenges. In the context of a chronic condition, mindfulness can help reduce anxiety by allowing the mind space to process. Carson continues:

It's about recognizing that all of us get pulled into different patterns of thought and different patterns of emotional responding. Sometimes those patterns of thoughts and feelings can end up driving physiology and how little or how much at ease we feel in our systems. Mindfulness can really help bring clarity 
and some light to what those patterns might be and then allow some transformation of those so that people suffer less.

Meditation mindfulness practice is used to bring awareness to how our thoughts and feelings can impact our physical bodies. This practice provides an opportunity to reduce feelings of anxiety and bring awareness to our senses. There is a stigma around this type of therapy. In Eastern medicine, these practices have been used for hundreds of years. Until more recently, Western culture has begun to accept these practices in the treatment of cancer. It takes a while for change to take place in the medical field. Carson shares the difficulty:

This is a real challenge. And part of it, too, is the institutional training. It's a culture shift, which is never easy. If we truly had healthcare teams that recognized the value of this and would encourage patients whatever way they are able to step into the self-care work, and then it's getting told by the doctor, by the nurse, somebody else that's a stakeholder in their care, then I think it becomes something totally different than a piece of paper.

In addition to the culture of the medical institution, there is an education component that is needed for the community. These services must be presented in a way that highlights the value and benefit to the patient and their family. Carson confirms:

It has to be in the culture of the family as well as the culture of the healthcare team. It has to been in both because the patient is just trying to survive. Literally.

Yoga and positioning can be used to alleviate symptoms of pain, fatigue, and can help reduce anxiety. Contrary to traditional yoga, gentle yoga for cancer patients is designed to provide range of motion and light movement in a relaxing environment. Hatha and Kripala are 
types of yoga that specifically cater to the individual and their current abilities. Elaine Cohn further explains:

How it differs from other types of yoga is that it is really accepting of where you are at and learning to love and accept where you're at, who you are, what your body can do, and nurturing that instead of comparing yourself to others. It's tuning into your body, to the sensations, the feelings.

Cohn continues to describe how gentle yoga approaches the participants with a $70 \%$ effort guideline which will keep the person safe. Cohn explains:

It's a way people can still benefit but less likely to injure themselves. It's also where they can feel some positive feelings. When we go beyond 80, 90, 100\%, which we learn so much in our community, in our society, in America, to go full out. It's like... people start to hate what they are doing, they dread it. For some, it's about relearning not just to move in yoga but maybe even move in the world. Everything doesn't have to be $100 \%$. We may be hurting ourselves and missing out on some joy. It can still be effective.

It can be difficult to help someone else gauge what $70 \%$ effort is to them. Part of what Cohn does is work with the participants to identify their safe range when engaging in these poses.

And $70 \%$ is a good thing because I don't know what is going on inside. They are the best gauge. I can look at their faces. If they are straining, I can say, 'Can you breathe and bring more ease to the pose?' Notice their breath. Encourage that deep belly breath to keep them more relaxed and aware what their breathing is like. 'Is your chest breathing fast?' 


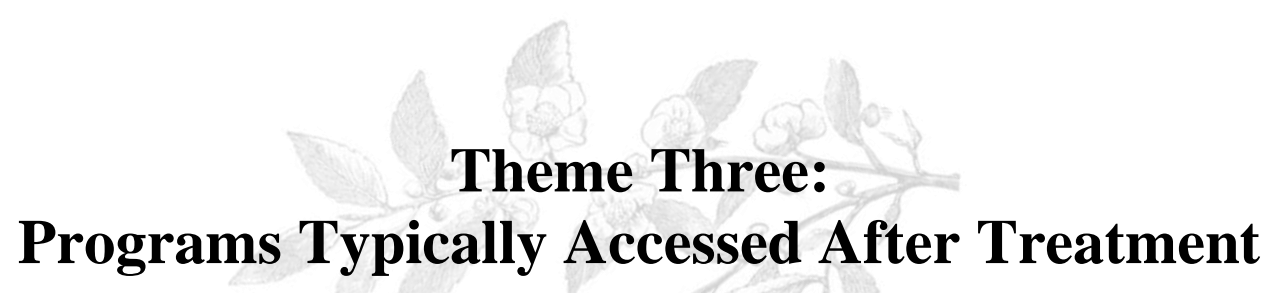




\section{Theme Three: \\ Programs Typically Accessed After Treatment}

The integrative therapy programs at the Knight Cancer Institute are introduced when an individual is diagnosed. However, with the overload of initial information following a diagnosis, it is not often a priority. Many patients are in survival mode working with their oncology team to develop a treatment plan. Susan explains how patients are more likely to access therapeutic programs after active treatment because they are emotionally ready to make lifestyle changes. Susan continues:

People are so ripe for these services at the end of treatment while they already have the emotional wherewithal and the physical energy more often. Secondly, they are highly motivated to make lifestyle changes.

When people are accessing integrative therapies post treatment, they are working to improve symptoms secondary to cancer treatment. Hedlund further explains how integrative medicine addresses the secondary impacts of cancer when the individual is finished with their medical plan of care:

It's a time where people are often coming up for air and thinking, 'Whew! What have I been through and how do I stay safe?' So integrative therapies I think do several things, not only relieve particular side effects and symptoms of the disease like fatigue and neuropathies, anxiety and stress, but they also give people back a sense of control and mastery, which is something that cancer takes away from people.

From the point of diagnosis, there are psychosocial concerns that begin to arise. Emotions are heightened as things begin to change with their health. Kimberly Carson explains how important it is to address these symptoms early in the process to prevent further suffering. She shares: 
Another way these tools help, especially with pain, with anxiety, nausea, is teaching how to learn to work with those sensations. If the trajectory of the disease goes in the direction where the body is not able to fight it off and the medication and treatment is not able to fight off the disease, that's really important so that we are empowering folks early for however things unfold. Whatever rolls out.

Currently, the majority of people accessing the services offered through the Knight Cancer Institute are post treatment. However, individuals diagnosed with cancer, their partners, and their families all experience some degree of secondary psychosocial symptoms throughout the disease and treatment process. 


\section{Theme Four: Value of In-Home Services}




\section{Theme Four: \\ Value of In-Home Services}

Cancer is considered a chronic condition and treatment extends beyond the hospital setting and into the home environment. When individuals are in the middle of treatment, they are often home for longer periods of time because of their fluctuating physical symptoms and changes in emotions. Some individuals are not able to drive or work during this time, which impacts them engaging in their normal roles and routines. Parents with dependent children have extended responsibilities in the home to care for their children. Susan Hedlund explains her perception of how parents are driven to fight cancer because of their children. She shares:

People are highly motivated to make lifestyle changes, whether it is to stop smoking or to eat healthier, to lose some weight or to get active. And that's a real pivotal point and much of that could and should occur in the home.

The Knight Cancer Institute currently offers these services on their main campus. If individuals are not able to participate in the groups in person, there is presently no alternative. Instead of disregarding these modalities, individuals can engage in these programs at home. Kimberly Carson describes the benefit of finding time in your daily routine to practice mindfulness. But it's really helpful to find a time of day that's somewhat reliable. With kids, that's tricky, so sometimes it means you have to get up before they do. Sometimes people are worried that if they get up earlier, they are going to be more fatigued, and they are going to lose out on the benefit of sleep. But what most meditators will attest to is there is a deeper rejuvenation that comes from practice even than comes from sleep. It has its own nourishing capacity. It may be the last thing at night, after the kids go to bed. It may have to be during the day if somebody is working. Maybe it's 10 minutes in your office in which you 
close the door. Sometimes you have to get creative, but most importantly it's to make the commitment and do it.

By providing opportunities for parents to engage in these programs at home allows for them to include their family. Carson further explains the benefit of incorporating the children into the conversation surrounding cancer. Depending on the children's developmental level, keeping communication open can help reduce anxiety in the home. One way meditation mindfulness practice can be taught to children in the home is to introduce how we identify the different senses. Carson explains:

We did a little thing where we talked about the hungry ghost, that insatiable hunger, that desire for something different than what's here. So we would play with how do we bring the wisdom and the insight that comes from mindfulness training in ways that are more playful. But that's a whole different approach than adult learning.

By educating parents how to incorporate mindfulness practice at home, they can engage with their children to alleviate any fear and allow them a space to understand how they are feeling. She continues:

Being able to feel the body and helping children really come into the sensate realm and be able to see the difference from what they are experiencing versus what they are thinking about what they are experiencing. To be able to just see that and be reinforced for that recognition would be probably the most skillful way to bring this to kids, not having them sit still and need them to be able to focus on their breath for 20 minutes. 


\section{Program Overview:}

At the Knight Cancer Institute, the programs are graciously funded through philanthropic support and grants. Through many avenues of fundraising, these programs are offered to patients and caregivers affected by cancer. Unlike many other institutions, this organization is grateful to have the support it does and the ability to grow these services. Overall, each program has welleducated staff that are dedicated to providing the best services they can. The foundations of these activity-based groups provide individuals who normally wouldn't attend a traditional support group a way to engage with others with similar experiences.

Although funding is a main barrier, it is important to have solid goals to work toward as the programs continue to expand. A group specifically for spouses has been identified as a future possibility as well as one for parents and their children. Other organizations in the Portland area have similar offerings. Telehealth is rapidly expanding in the medical field and is a platform to provide live-streaming services of groups. This is a method for individuals and their families to access the instructors and classes in real time.

To market these services to a broader audience, it is recommended to expand methods of recruitment. One way to do this would be to have the instructors of the programs introduce the other offerings at the beginning of their sessions. This way someone who normally attends the yoga class will be educated about the writing group. Additionally, using methods that engage the individual in the waiting room, for instance, could be more effective in getting their attention. 
Program: Strengths:

Mindfulness

Breath-By- individuals outside

Breath of the Knight

Cancer Institute

-Offered twice a

week and at no

cost

-Option to attend more structured practice through MBSR

Gentle Yoga

-Current has extensive training in oncology-based

yoga, contraindications to positions, and safe practices

-Available to patients and caregivers at no cost for the first year

-Space and equipment provided

\begin{tabular}{l|l}
$\begin{array}{l}\text { Inpatient } \\
\text { Massage }\end{array}$ & -It's FUNDED! \\
& $\begin{array}{l}\text {-Services are } \\
\text { offered inpatient } \\
\text { and outpatient }\end{array}$ \\
& $\begin{array}{l}\text {-Therapists value } \\
\text { authentic } \\
\text { connection with } \\
\text { each patient or } \\
\text { family member }\end{array}$
\end{tabular}

\section{Challenges:}

-Strong educational

component to faculty and community on foundations and benefit of practice in this setting

-Bringing visibility to the services offered

\section{Recommendations:}

-Develop guided meditations for parents to access at home

-Offer regular guided meditations to oncology physicians and nurses to reduce stress and educate on patient programs
-The least attended class in all of the integrative therapy programs

-Limited awareness and marketing to the cancer community

\author{
-Reaching past patients \\ who attended prior \\ classes \\ -Development of home \\ program for patients \\ who are not able to \\ attend \\ -Trial a morning class, \\ possibly on the \\ weekend to increase \\ attendance
}

-Development of a handout for the massage therapists to provide to patients and caregivers in the inpatient and outpatient settings

-Educating the nursing staff, cancer care team, and rehab department on board with the massage service that is offered for oncology patients
-Develop home program "10-minute Comfort Care Massage" 


\begin{tabular}{|c|c|c|c|}
\hline & $\begin{array}{l}\text {-Oncology } \\
\text { massage therapists } \\
\text { are highly trained } \\
\text { in cancer care } \\
\text { massage }\end{array}$ & & \\
\hline $\begin{array}{r}\text { Women's } \\
\text { Writing } \\
\text { Group }\end{array}$ & $\begin{array}{l}\text {-Women's writing } \\
\text { instructor has years } \\
\text { of experience with } \\
\text { using writing as a } \\
\text { tool for healing } \\
\text {-The group } \\
\text { respects and } \\
\text { upholds the ground } \\
\text { rules to assure } \\
\text { participants are in } \\
\text { a safe space } \\
\text {-Group meets } \\
\text { weekly and is } \\
\text { available to } \\
\text { individuals } \\
\text { affected by cancer } \\
\text { and caregivers in } \\
\text { the community }\end{array}$ & $\begin{array}{l}\text {-Reaching a new audience of } \\
\text { patients and caregivers } \\
\text {-Extending services beyond } \\
\text { the clinical setting }\end{array}$ & $\begin{array}{l}\text {-Developing an activity } \\
\text { to engage community } \\
\text { members and educate } \\
\text { about writing groups } \\
\text { offered through the } \\
\text { integrative medicine } \\
\text { program (See attached) }\end{array}$ \\
\hline
\end{tabular}




\section{WRITING IN \\ community}

Everyone has a story to tell.

Pick up a card and share yours.

OHSU CANCER WRITING CLASSES:

WOMEN HEALING FROM CANCER I TUESDAYS, 10-12PM

$\mathrm{CHH} 2$, Floor 12, Conference room

Dawn Thompson, dawnrenethompson@gmail.com

MEN HEALING FROM CANCER । FRIDAYS, 1-3PM

$\mathrm{CHH} 2$, Floor 11, Room 11010

Ryan Voelker, voelkerr@ohsu.edu

YOUNG ADULTS HEALING FROM CANCER । WEDNESDAY 6:30-8:30PM

CHH2, Floor 12, Conference room

Dawn Thompson, dawnrenethompson@gmail.com

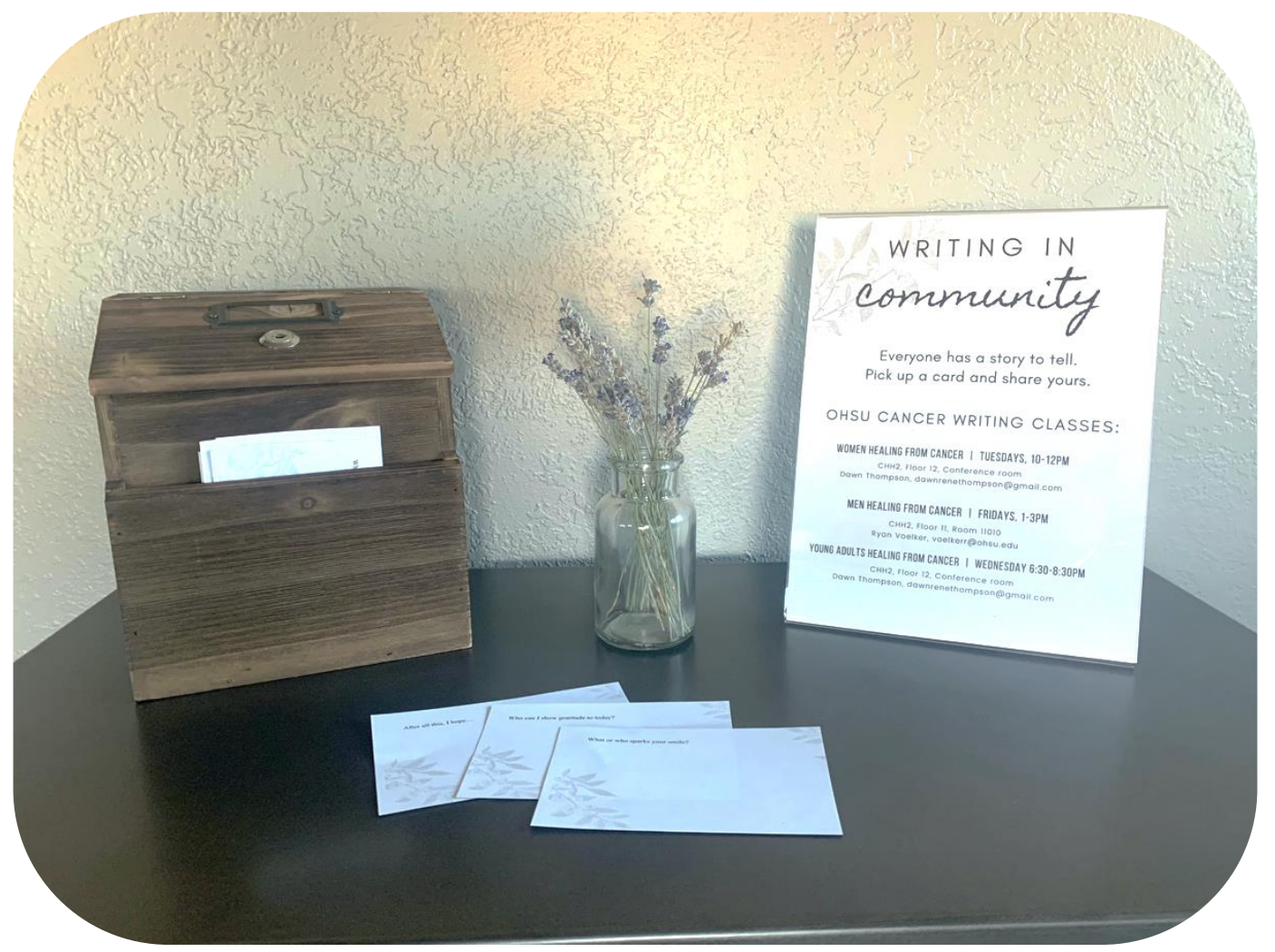


Appendix F: Occupational Therapy Program: "Healing at Home"

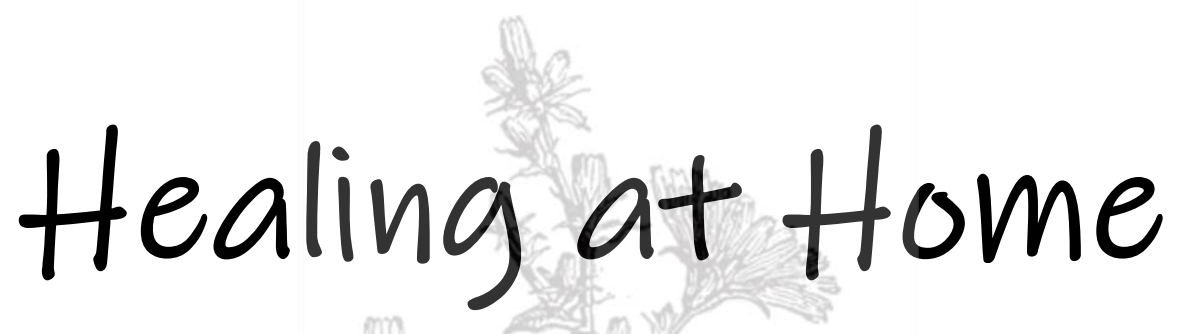

Supporting the Mind and Body During Cancer Treatment

Riley Harrold, OTD student

University of St Augustine for Health Sciences | April 2020 


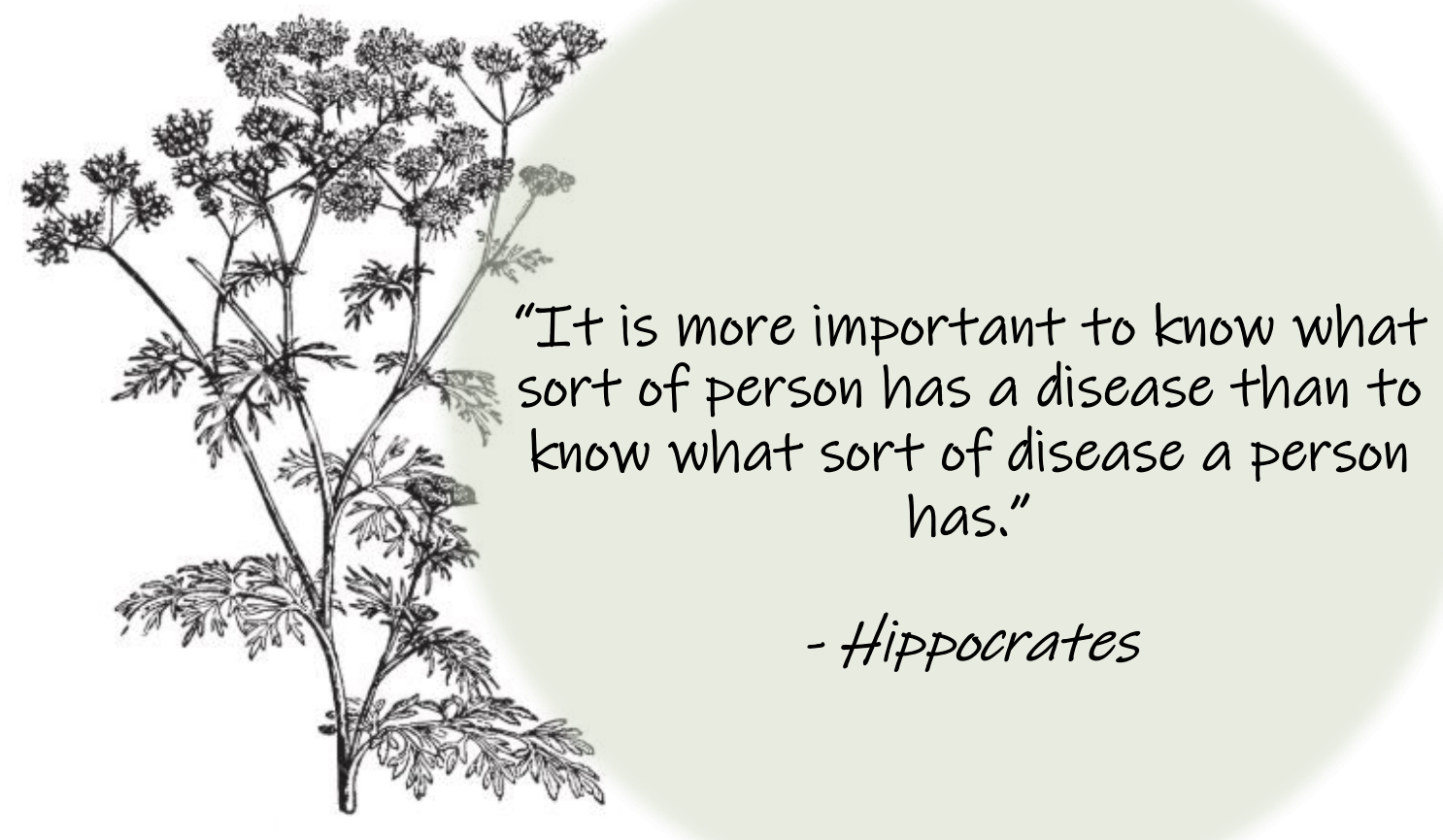




\section{Supporting the Mind \& Body During Cancer Treatment}

Cancer diagnosis and treatment will bring a lot of changes to you and your family. Integrative medicine, also known as complementary or alternative treatment, works with your medical plan to support the whole person. Along with your treatment plan, this home program is designed to support your physical and emotional well-being while in the comfort of your home.

During cancer treatment, it is common to have changes in mood or fluctuating energy levels. Some people experience changes in the amount or quality of sleep each night. It is also expected to have roles and routines impacted during this time. To help address these new challenges, this program will support you and your family by offering meditation and gentle yoga sessions throughout treatment as well as resources to address important family routines. 


\section{Program Description}

Over the next three sessions, you will be introduced to meditation, breath work, yoga, and journaling activities and will be provided resources to help support your family during your cancer treatment.

This program is designed to support your physical and emotional well-being while going through treatment. All these activities are suggestions and your occupational therapist will work closely with you to determine the best recipe for you.

Each session will introduce a new set of yoga poses. You will find additional poses and series at the back of this program. 


\section{Session One:}

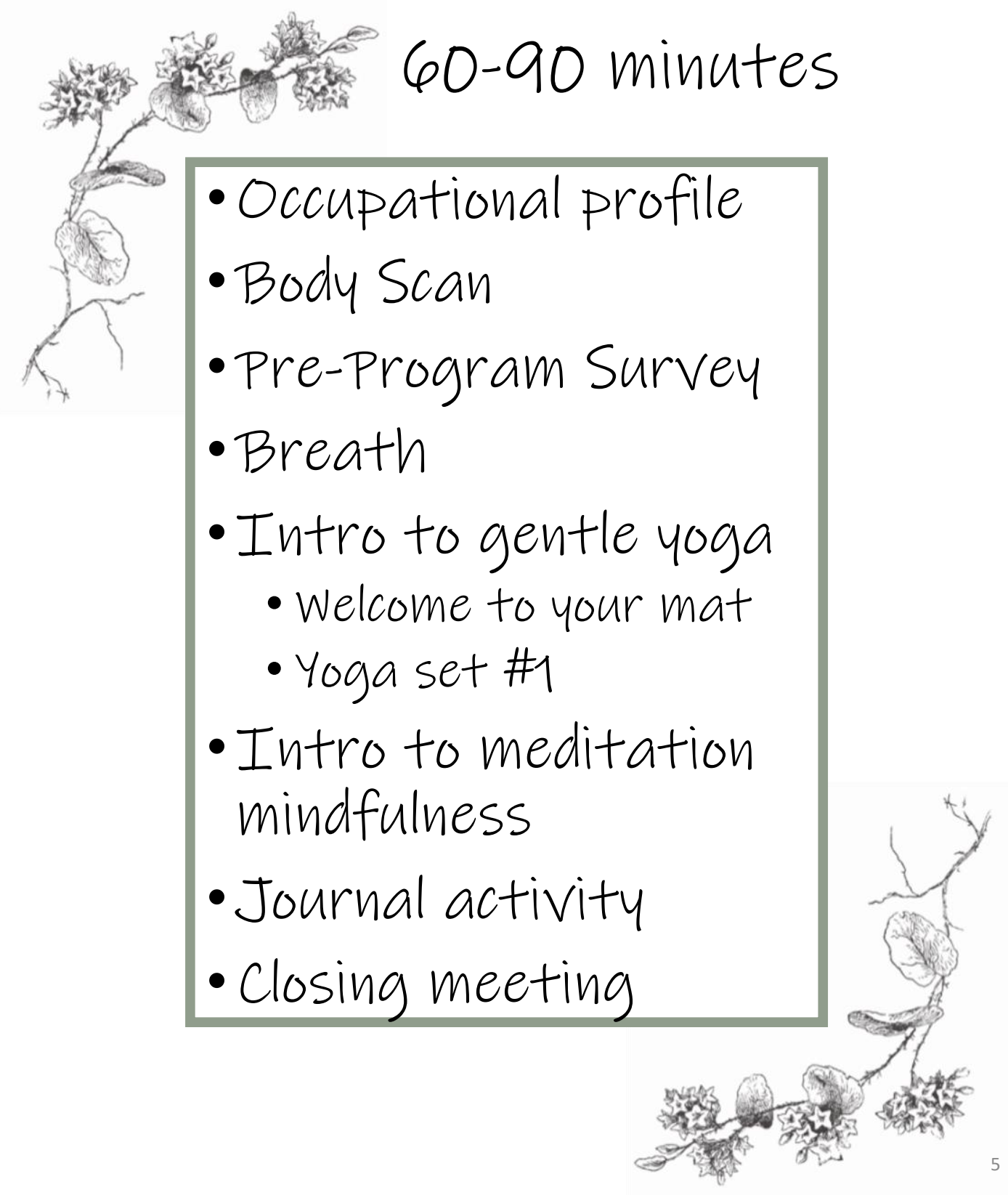




\section{Occupational Profile}

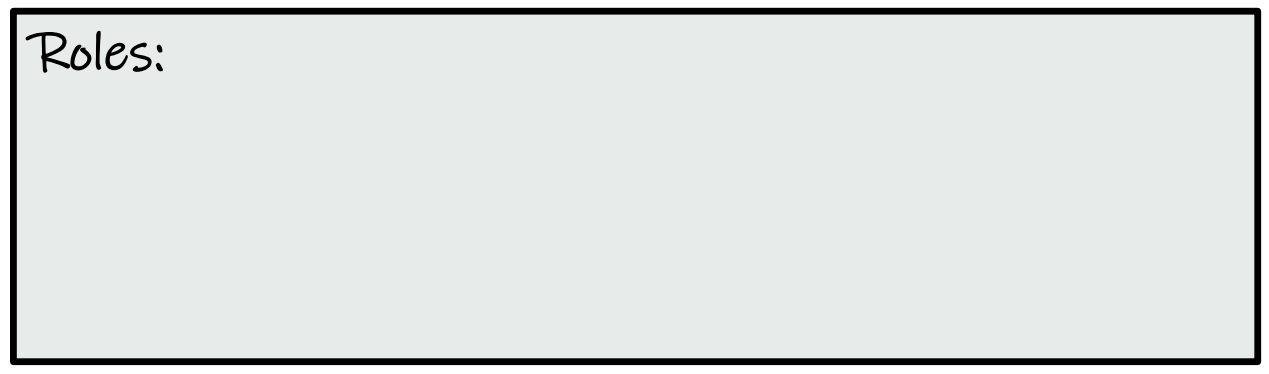

Routines/Habits:

Interests/Values:

Support System: 


\section{Body Scan:}

Take this opportunity to focus on your body.

Identify any limitations such as pain, injuries, post-surgical sites, wounds.

- Is one side weaker than the other?

- Do you have range of motion restrictions?

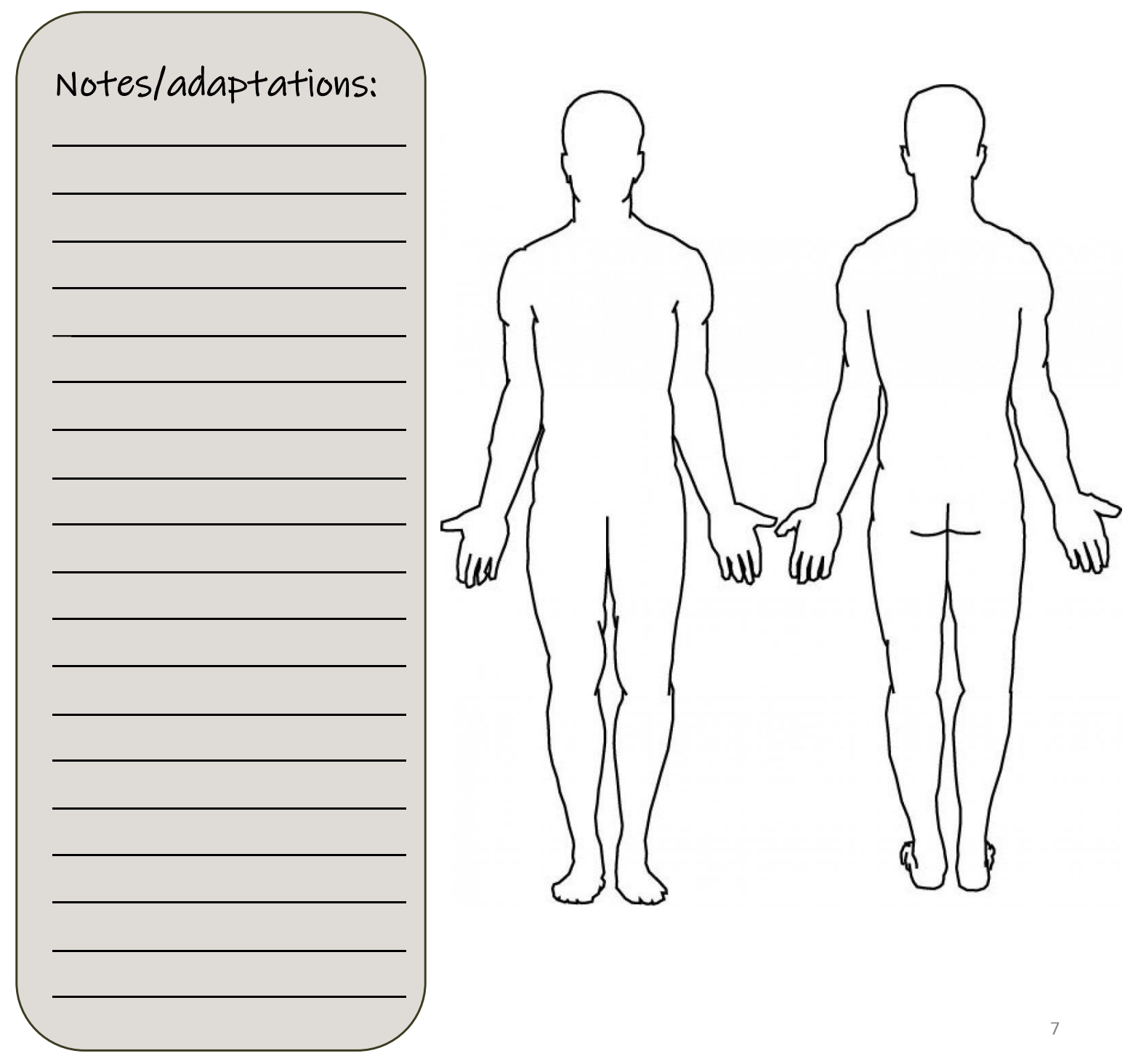




\section{Pre-program Survey}

please rate how following statements apply on a scale of $1-5$.

(1=strongly disagree, 2 =disagree, 3=neutral, 4=agree, 5=strongly agree)

\begin{tabular}{|c|c|c|c|c|c|}
\hline My daily routine is impacted by pain or fatigue. & 1 & 2 & 3 & 4 & 5 \\
\hline $\begin{array}{l}\text { I have enough energy to do all the things I } \\
\text { need and want to do each day. }\end{array}$ & 1 & 2 & 3 & 4 & 5 \\
\hline $\begin{array}{l}\text { Pain often impacts my ability to do the things } \\
\text { I need and want to do. }\end{array}$ & 1 & 2 & 3 & 4 & 5 \\
\hline $\begin{array}{l}\text { I am satisfied with the quality and amount of } \\
\text { sleep I get each night. }\end{array}$ & 1 & 2 & 3 & 4 & 5 \\
\hline It is difficult to complete my daily routine. & 1 & 2 & 3 & 4 & 5 \\
\hline $\begin{array}{l}\text { I have responsibilities to care for people other } \\
\text { than myself. }\end{array}$ & 1 & 2 & 3 & 4 & 5 \\
\hline I have fear surrounding my health. & 1 & 2 & 3 & 4 & 5 \\
\hline $\begin{array}{l}\text { I have adequate support from family and } \\
\text { friends. }\end{array}$ & 1 & 2 & 3 & 4 & 5 \\
\hline $\begin{array}{l}\text { I have the physical ability to accomplish what } \\
\text { I need and want to do. }\end{array}$ & 1 & 2 & 3 & 4 & 5 \\
\hline $\begin{array}{l}\text { There are resources available to help me } \\
\text { overcome barriers in getting things done. }\end{array}$ & 1 & 2 & 3 & 4 & 5 \\
\hline I worry about my children being taken care of. & 1 & 2 & 3 & 4 & 5 \\
\hline $\begin{array}{l}\text { I find it difficult to care for my children due to } \\
\text { symptoms such as pain, fatigue, or depression. }\end{array}$ & 1 & 2 & 3 & 4 & 5 \\
\hline $\begin{array}{l}\text { Exercise and physical activity are important to } \\
\text { me. }\end{array}$ & 1 & 2 & 3 & 4 & 5 \\
\hline I need assistance to physically care for myself. & 1 & 2 & 3 & 4 & 5 \\
\hline I am able to do activities that bring me joy. & 1 & 2 & 3 & 4 & 5 \\
\hline $\begin{array}{l}\text { It is hard for me to complete household tasks } \\
\text { such as meal prep, laundry, or cleaning. }\end{array}$ & 1 & 2 & 3 & 4 & 5 \\
\hline $\begin{array}{l}\text { Anxiety impacts my ability to do the things I } \\
\text { want and need to do. }\end{array}$ & 1 & 2 & 3 & 4 & 5 \\
\hline
\end{tabular}




\section{Breath}

Learning to control our breath is an important tool to bring awareness to the present. When we slow down our breath, we decrease the oxygen demand to our system which requires less energy. Slow, controlled breathing can decrease symptoms of anxiety and help control pain. See pg. 88 for a breathing activity for kiddos!

Diaphragmatic breathing uses the large domeshaped muscle below your lungs to bring power to the inhale and exhale.

1. Sit comfortably, with your knees bent and your shoulders, head and neck relaxed.

2. Place one hand on your upper chest and the other just below your rib cage. This will allow you to feel your diaphragm move as you breathe.

3. Breathe in slowly through your nose so that your stomach moves out against your hand. The hand on your chest should remain as still as possible.

4. Tighten your stomach muscles, letting them fall inward as you exhale through pursed lips. Try to keep the hand on your upper chest as still as possible.

Constriction breathing is used to build heat within the body. This technique is used in yoga to align breath with movement. With constricting the back of the throat, slowly and deeply breathe in and out of your nose. In yoga tradition, it's called "ujayii pranayama."

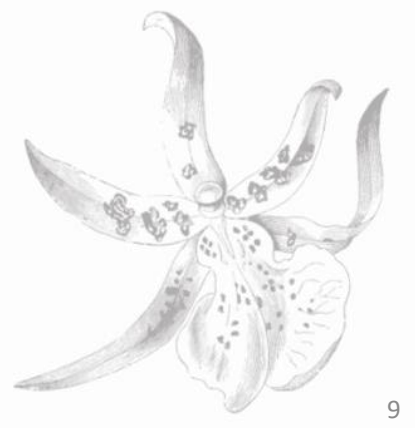




\section{Welcome to Your Mat}

During this program, you will be introduced to a variety of poses. Everybody's body is unique, so some positions might look a little different for you, and that's okay. This time is for you to connect with your body and move within a comfortable range. your occupational therapist will work with you to adjust poses as needed.

More engagement: For a more difficult variation, there will be options to upgrade the pose.

More ease: For a more restorative variation, there will be options to downgrade the pose.

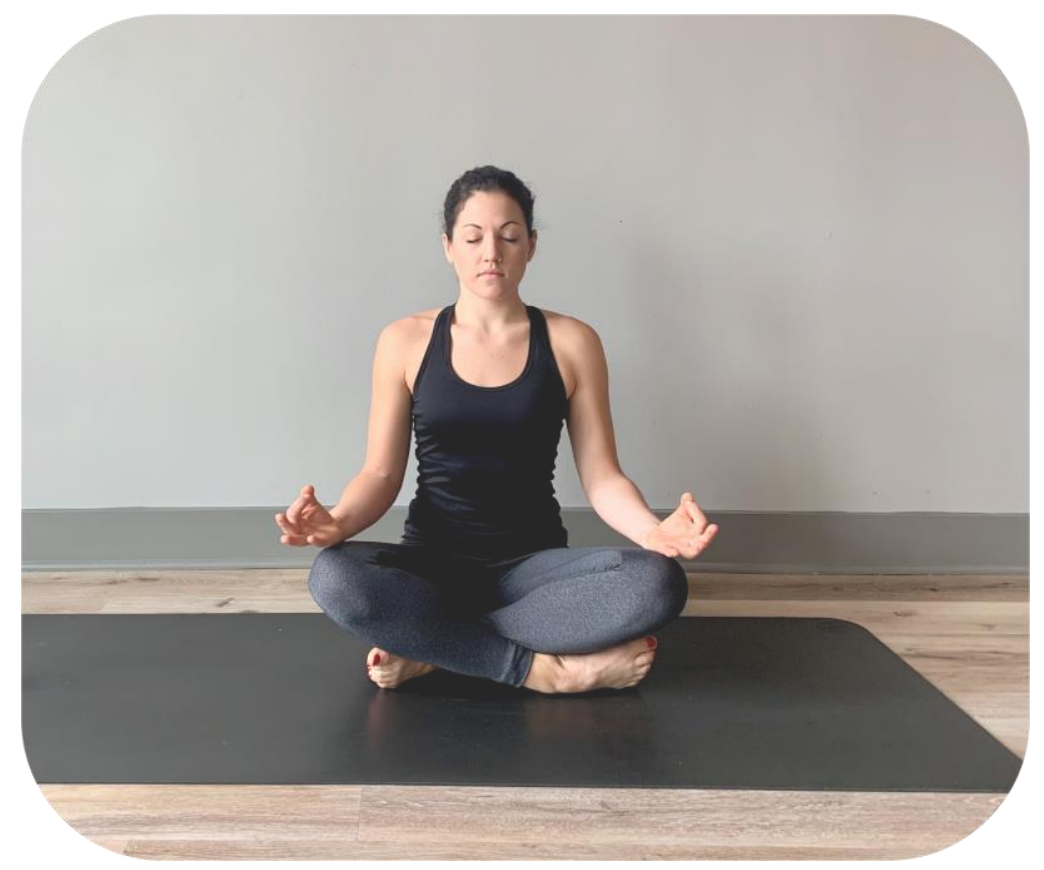




\section{Yoga Se+ 1:}

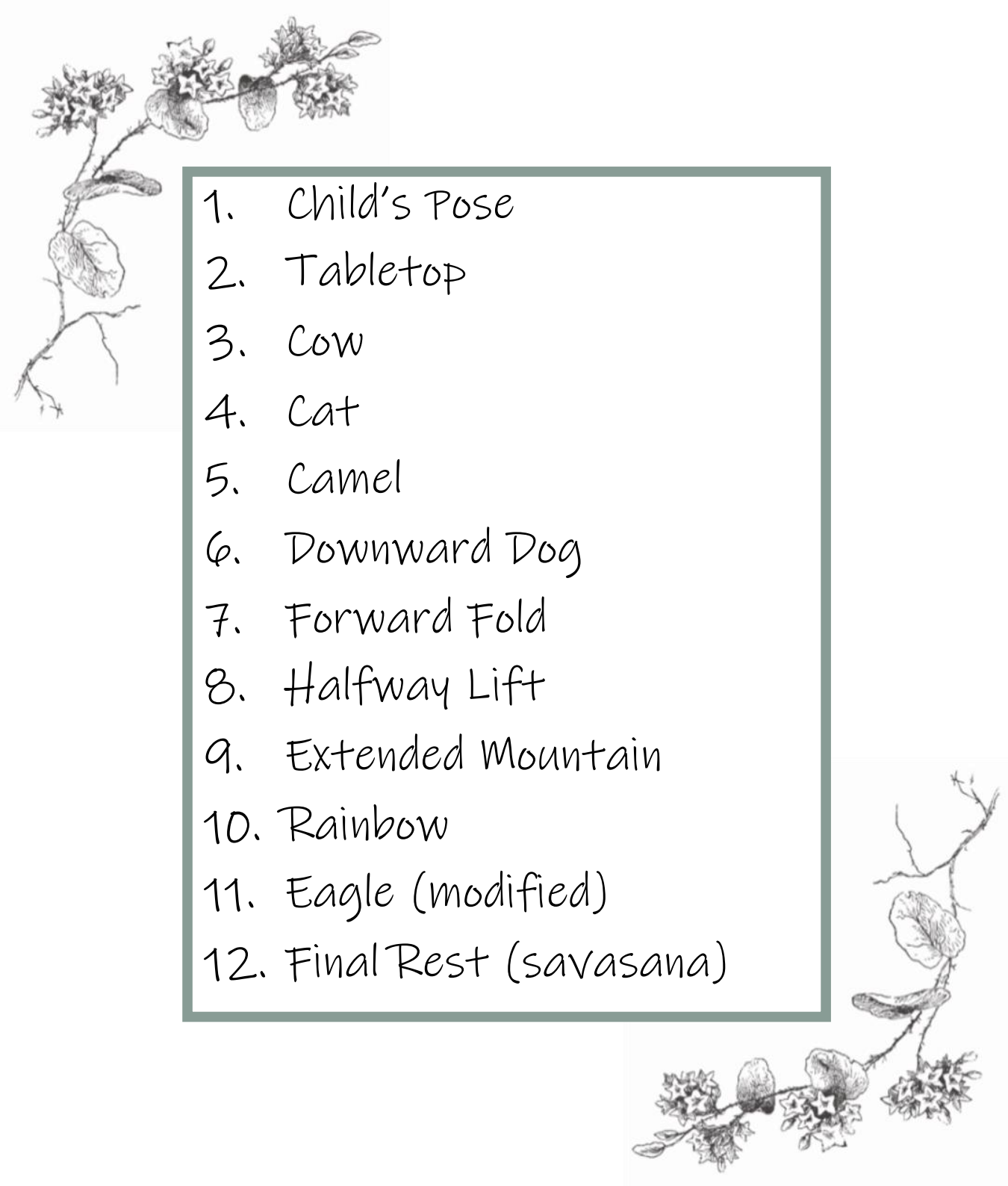




\section{Child's Pose}

1. Beginning with knees out wide, move big toes toward each other

2. Reach arms out long, rest forehead on mat, pillow, or block

3. Tuck tailbone down, draw belly into spine

4. Breathe in... breathe out...

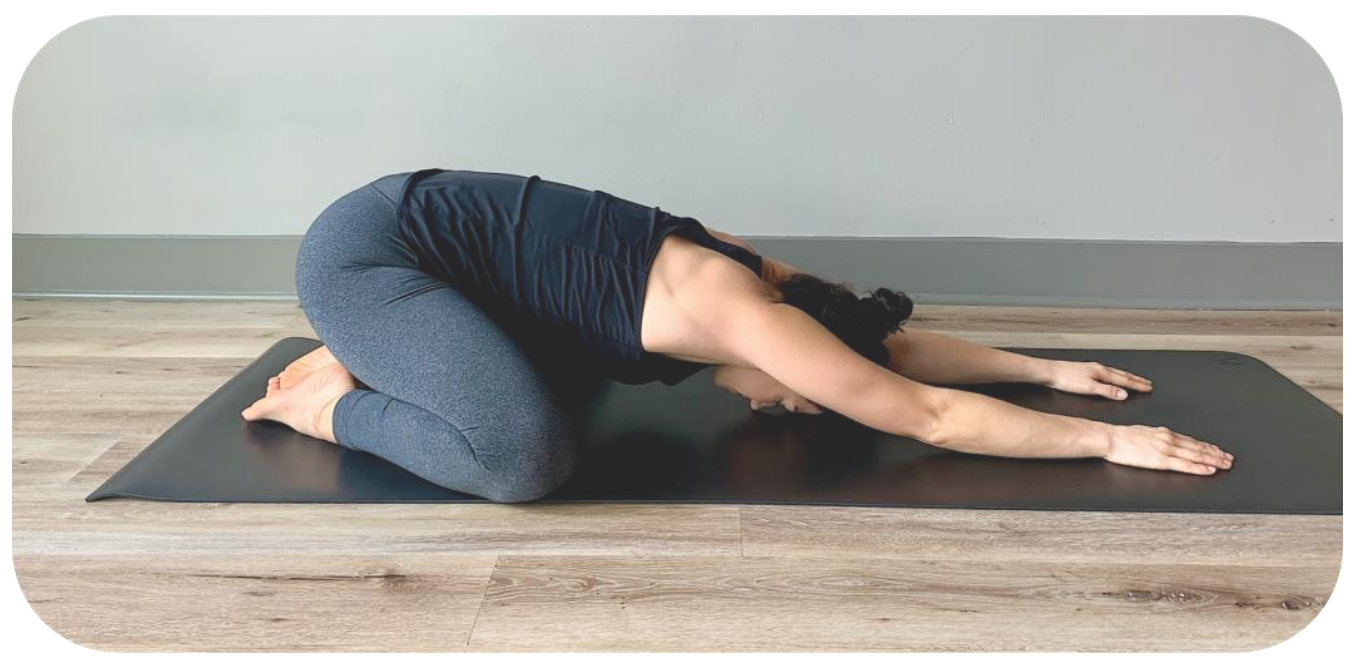

Notes/adaptations: 


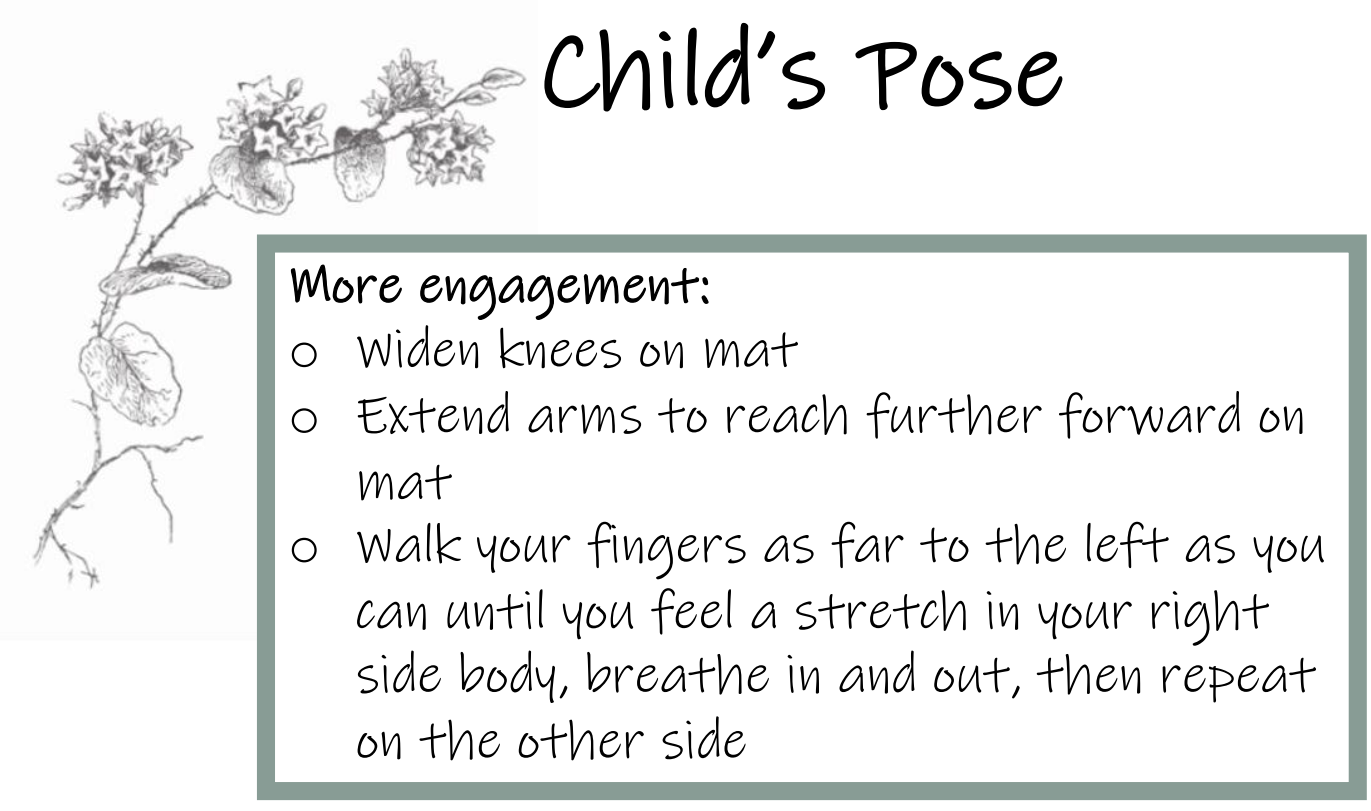

\section{More ease:}

- Bring knees closer together on mat

- Reduce the distance arms are reaching, bring closer to body

\section{Special considerations:}

- Injuries to joints such as knees or shoulders might impact this position

- Individuals with tight hips should move slowly with caution

- Post-mastectomy individuals should consider their range of motion restrictions 


\section{Tabletop}

1. Stack your shoulders over your wrists and your hips over your knees

2. Draw your belly in and press the ground away from you while gazing down with a neutral neck

3. Breathe in... breathe out...

Notes/adaptations:

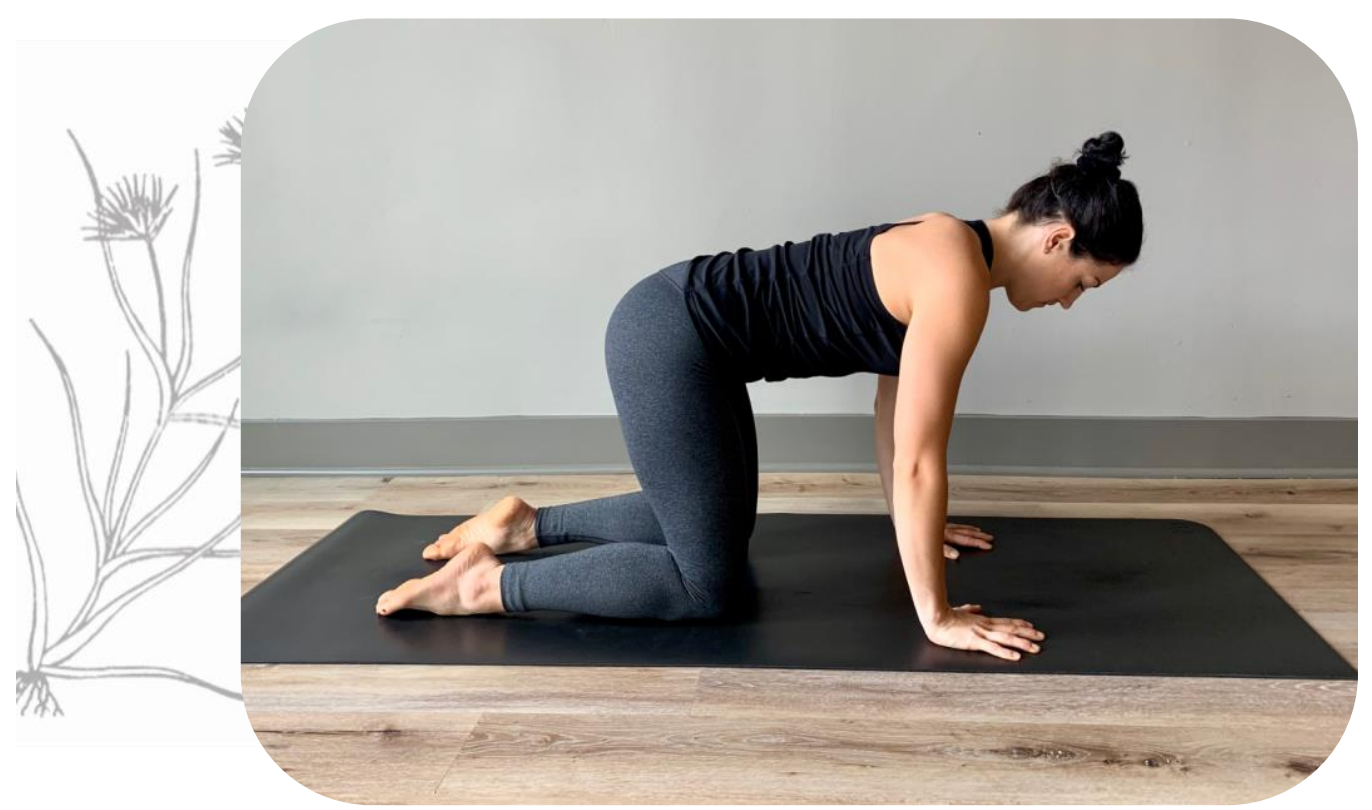




\section{Tabletop}

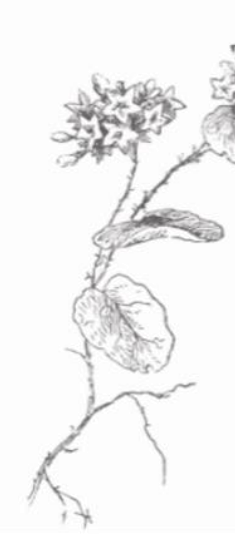

\section{More engagement:}

- Tuck toes under, hover knees 2 inches above mat

- Extend right arm out long, level with shoulder, extend left leglong at hip height

- Keep ankle flexed

o *repeat on other side*

\section{More ease:}

- Using a chair, sitting up tall, knees bent at 90 degrees, extend arms straight out from shoulders

\section{Special considerations:}

- Injuries to joints such as knees, shoulders, or wrists might impact this position

- Post-mastectomy individuals should consider their range of motion restrictions 


\section{Cow}

1. Breathe out...

2. Arch back, gaze up

3. Shoulders open

4. Breathe in... breathe out...
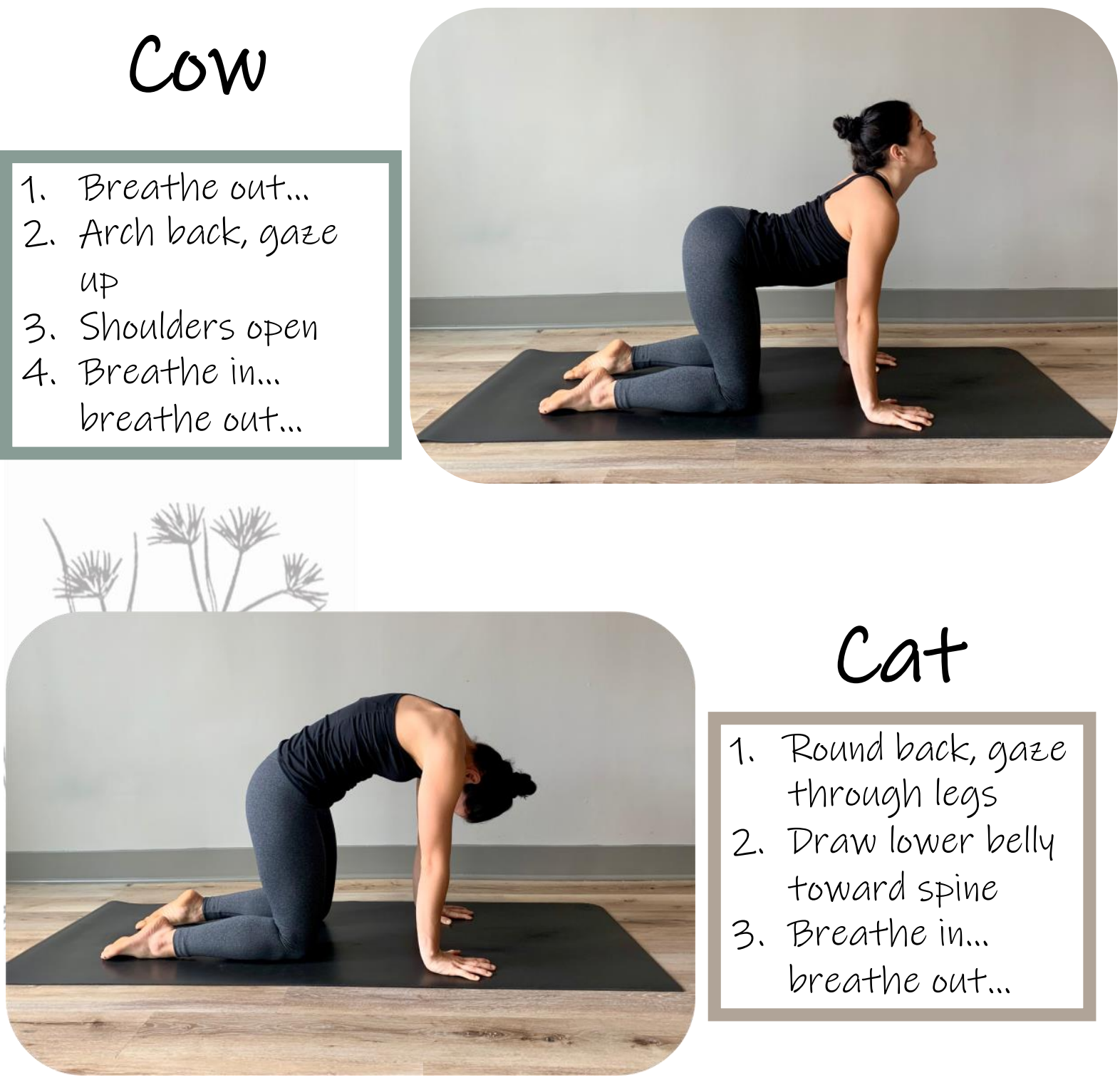

\section{Cat}

1. Round back, gaze through legs

2. Draw lower belly toward spine

3. Breathe in... breathe out...

Notes/adaptations: 


\section{cow + Cat}

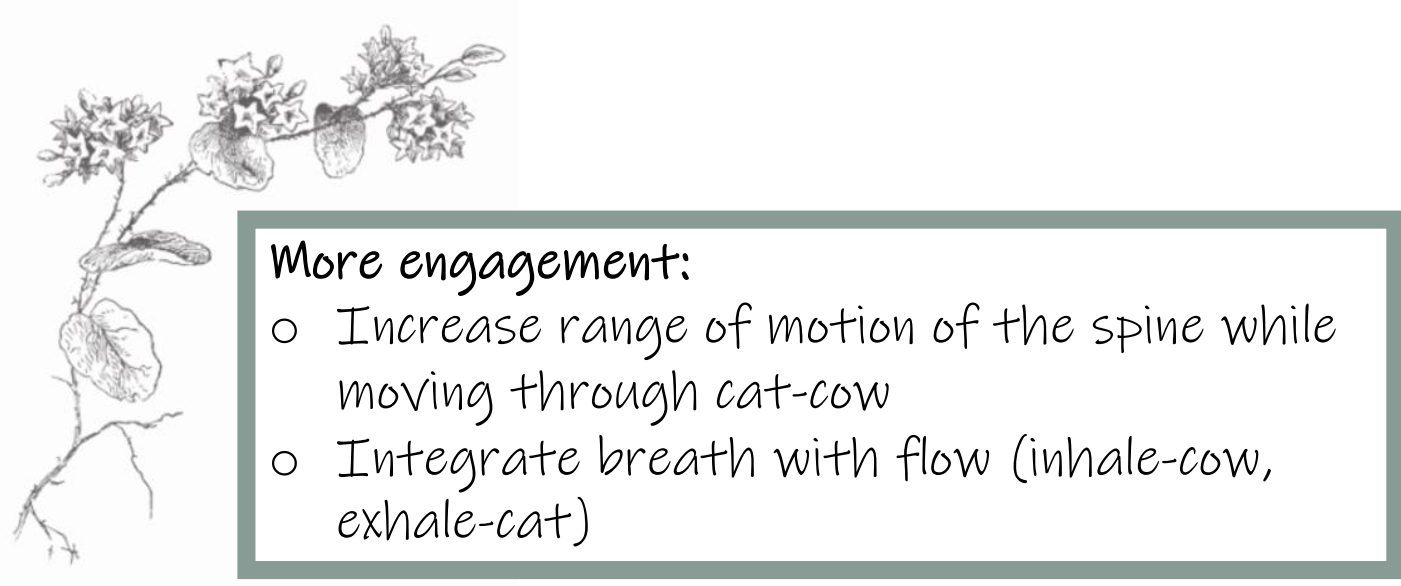

More ease:

- Decrease range of motion of the spine while moving through cat-cow

\section{Special considerations:}

- Injuries to joints such as knees, shoulders, or wrists might impact this position

- Post-mastectomy individuals should consider their range of motion restrictions 


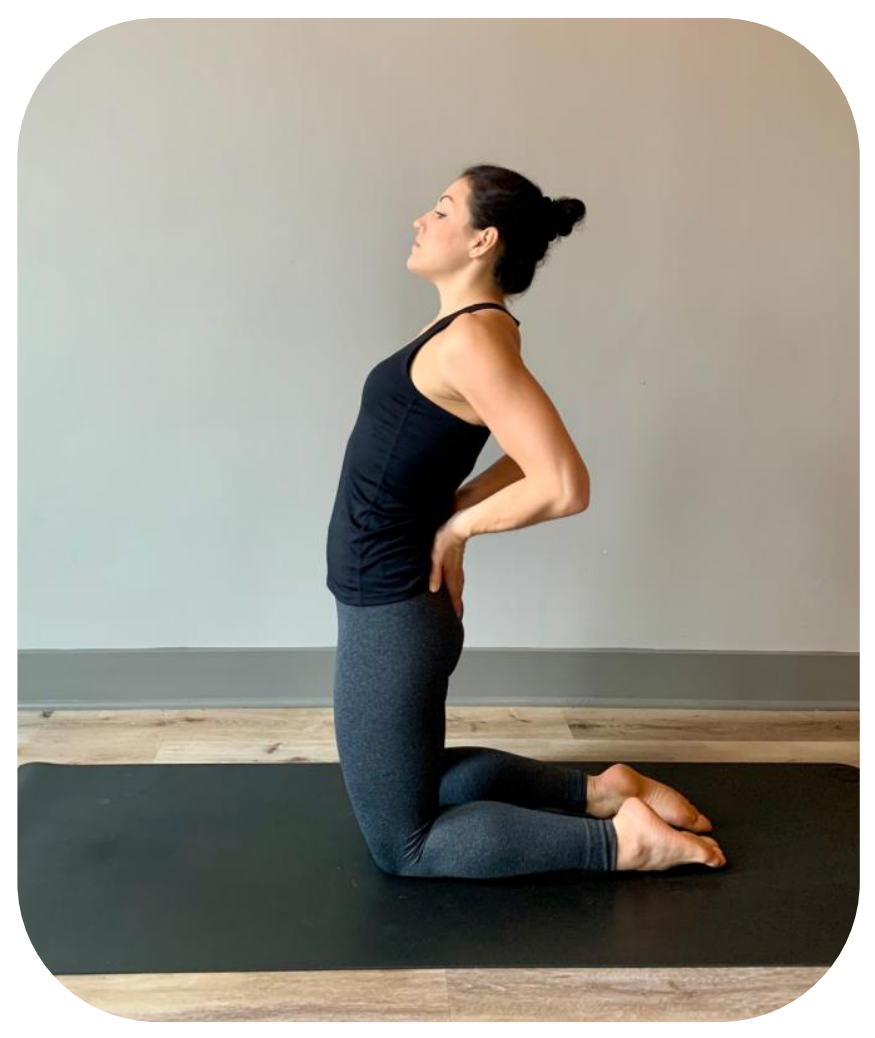

Notes/adaptations:

1. With knees under hips, gently place hands on lower back or pelvis

2. While hips move forward, slowly and gently lean back

3. Draw belly into spine to protect back 4. Breathe in... breathe out...

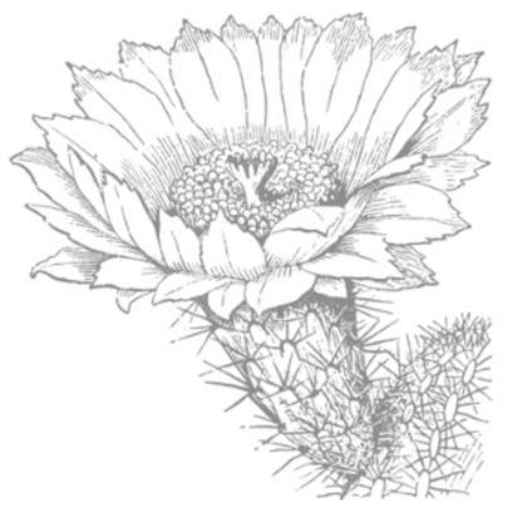

\section{camel}




\section{camel}

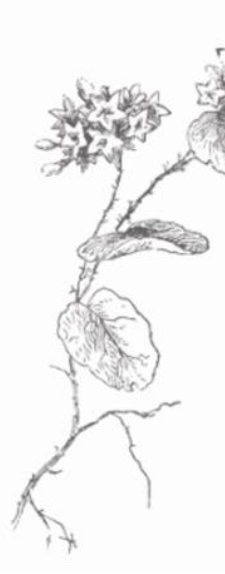

\section{More engagement:}

- Increase range of motion in spine while bending back

- Gently and slowly extend neck back

- Bring hands to heels

\section{More ease:}

- Decrease range of motion in spine while bending back

- Keep neckneutral

\section{Special considerations:}

- If attempting the full engagement of the pose, pay careful attention to releasing your head back slowly so as to protect your neck

- Injuries to joints such as knees or hips might impact this position

- If you have injuries in the low back and neck, the full engagement of the pose should be avoided

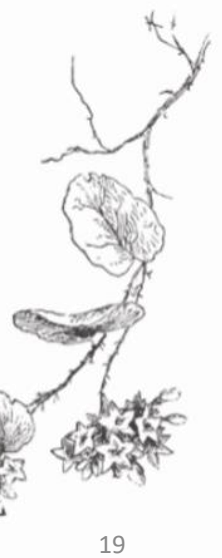




\section{Downward Dog}

1. Start in tabletop, extend legs and reach hips toward ceiling

2. Arms slightly wider than shoulder, fingertips push into mat

3. Neutral spine

4. Lightly bend knees to release spine

5. Reach ankles toward floor, draw lower belly into spine 6. Breathe in... breathe out...
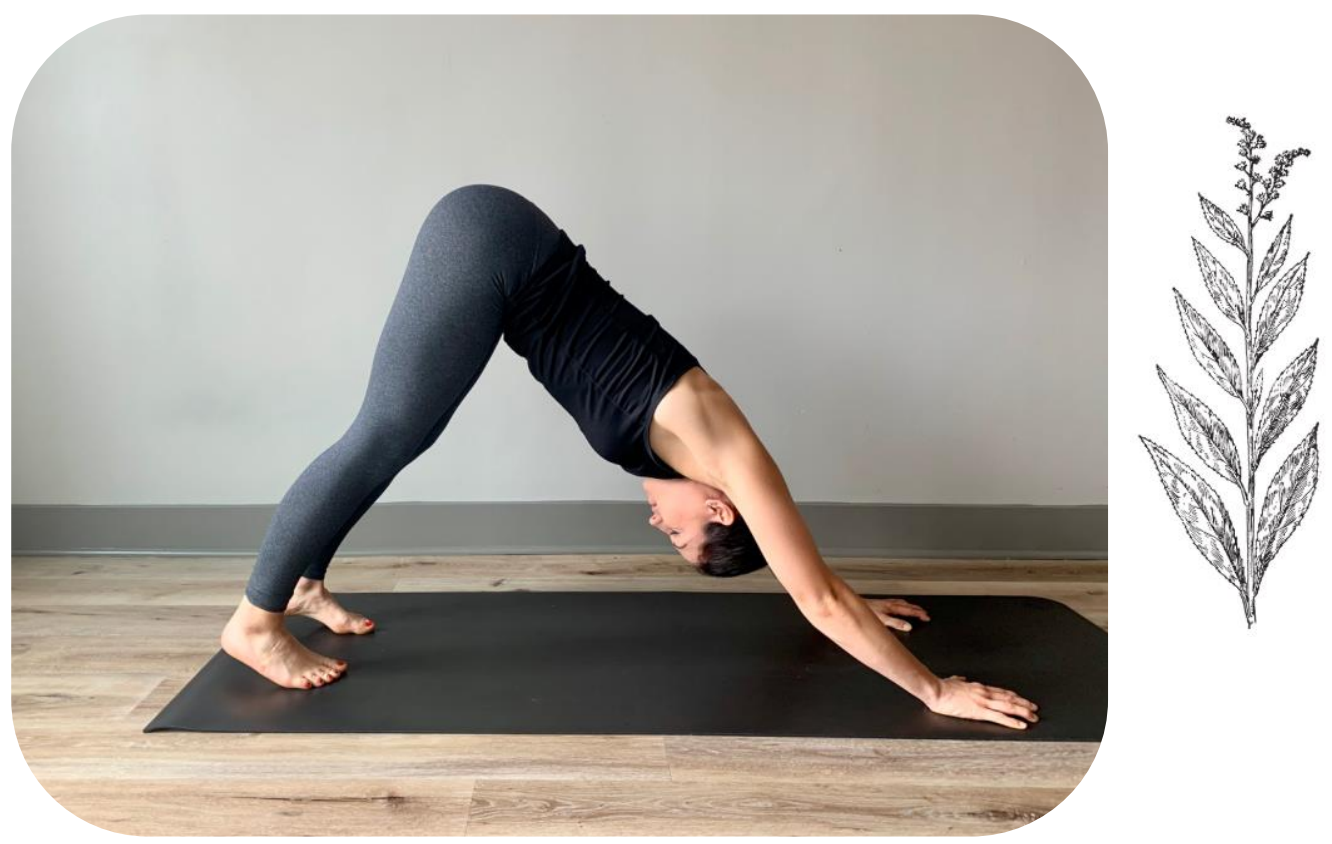

Notes/adaptations: 


\section{Downward Dog}

More engagement:

- Release bend in knees to extend ankles to the floor, push through shoulders

- pedal out ankles, bring movement to joints to loosen up muscles

\section{More ease:}

- While standing facing a wall, extend arms out long to touch surface

- walk feet backward until you begin to feel a stretch in shoulders and hamstrings

\section{Special considerations:}

- Injuries to joints such as knees, shoulders, or wrists might impact this position

- Post-mastectomy individuals should consider their range of motion restrictions 


\section{Forward Fold + Halfway Lift}

1. Breathe in...

2. Bring big toes to touch

3. Fold chest over thighs

4. Bring as much bend in your knees as you need

5. Rotate tailbone to the ceiling

6. Breathe out...
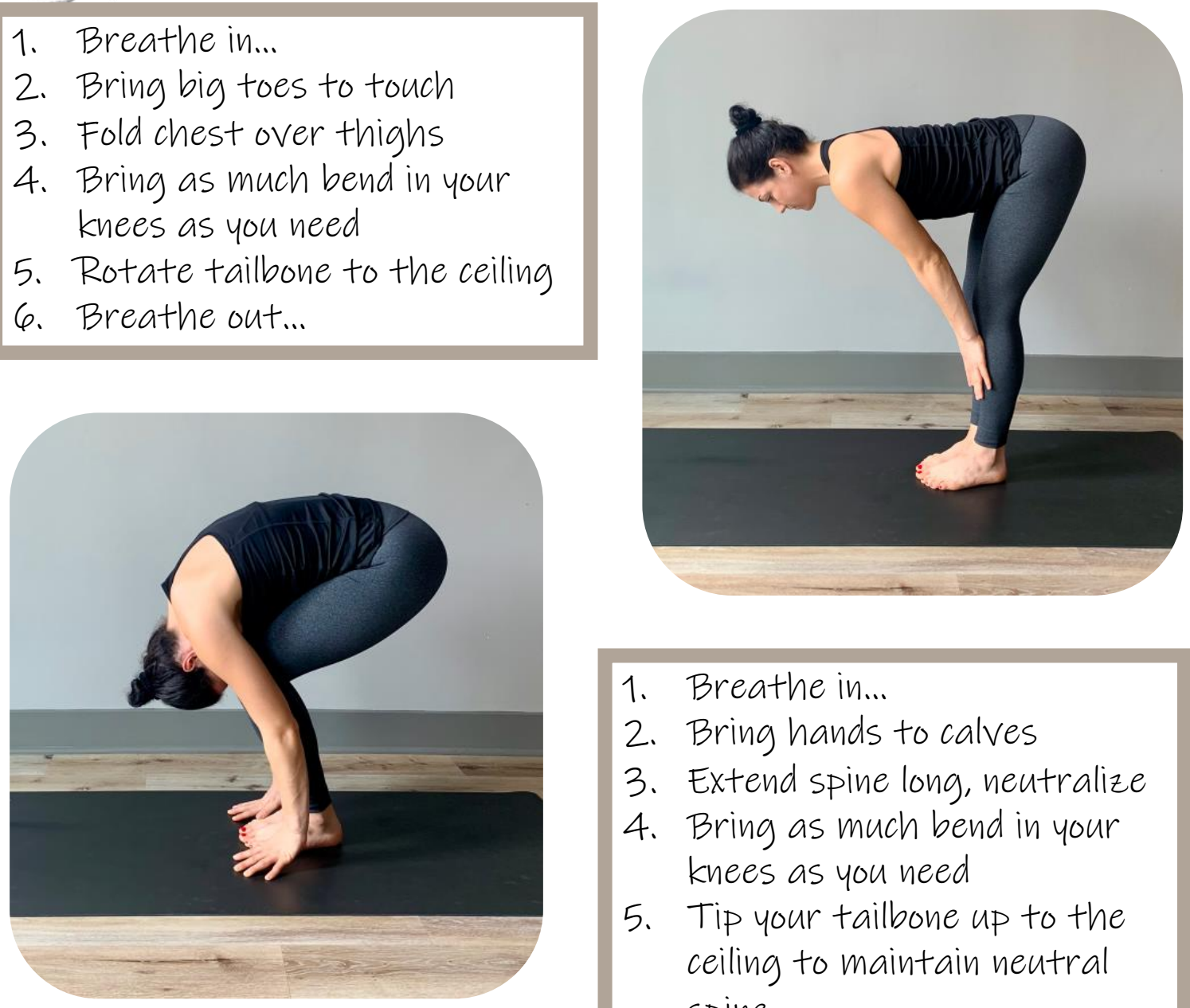

1. Breathe in...

2. Bring hands to calves

3. Extend spine long, neutralize

4. Bring as much bend in your knees as you need

5. Tip your tailbone up to the ceiling to maintain neutral spine

Notes/adaptations: 


\section{Forward Fold + Halfway Lift}

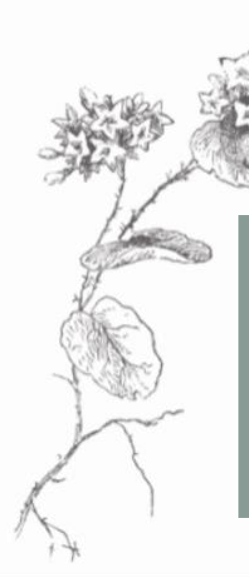

More engagement:

- Increase amount of bend in spine

- Extend legs while rotating tailbone to ceiling

\section{More ease:}

o While sitting in chair with legs bent at 90 degrees, forward fold over thighs

- Sitting on the floor with legs extended, fold over thighs. Bring as much bend to your knees as you need while keeping your spine neutral

\section{Special considerations:}

- This position can cause strain on the lower back

- Move through poses slowly, especially when standing up 


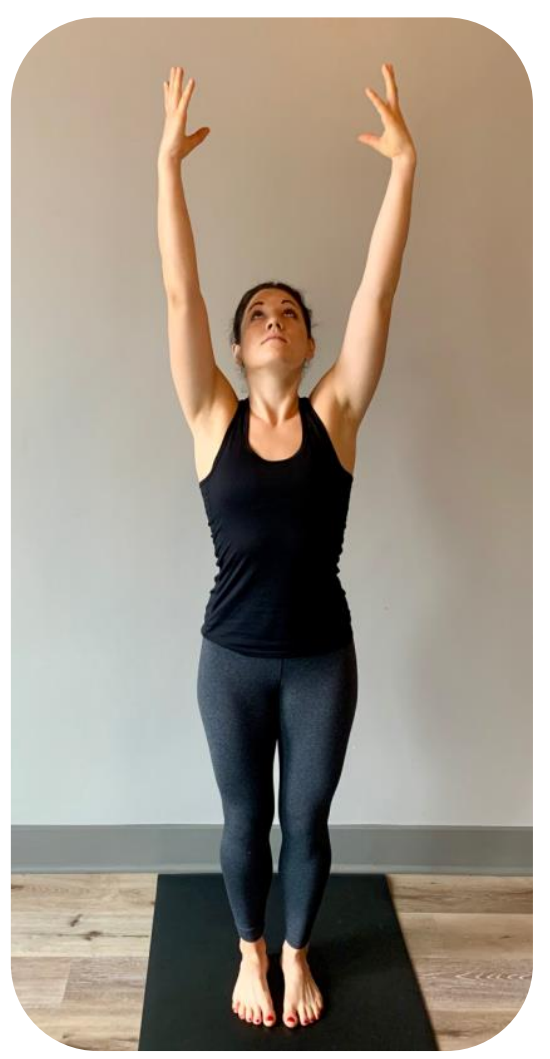

\section{Notes/adaptations:}

1. Standing standing with arms by your aides

2. Extend arms up and turn pinkies in to allow shoulders to slide down your back

3. Bring softness to knee joints

4. Neutral pelvis and spine

5. Gaze up at hands

6. Breathe in... breathe out...

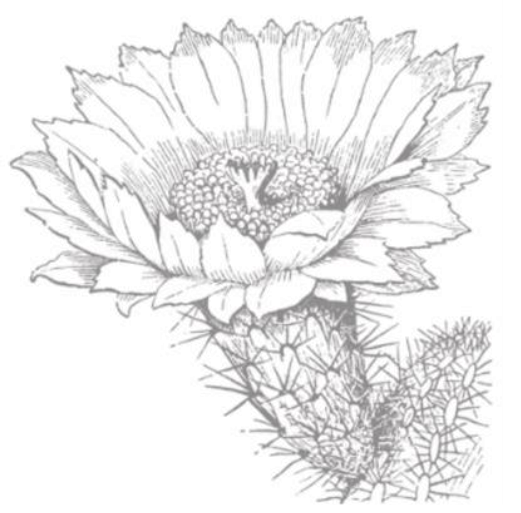

\section{Extended}




\section{Extended Mountain}

More engagement:

- cactus arms and extend back slightly

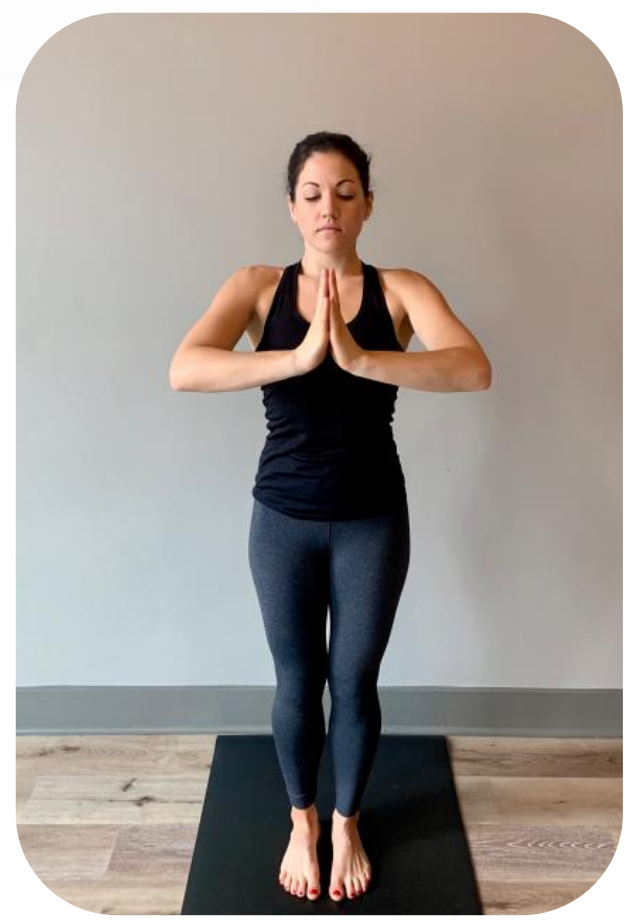

More ease:

- Bring hands to heart center

- While sitting in a chair, extend arms up, gaze to follow

\section{Special considerations:}

- When flowing from low to high, move slowly to start to allow proper blood flow to the body

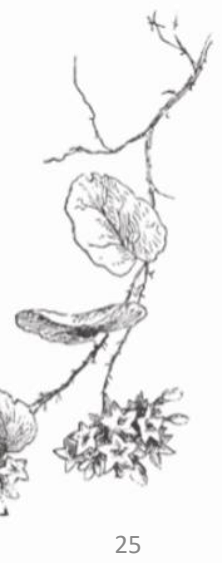




\section{Rainbow \\ (standing side stretch)}

1. With arms extended up, bring left hand to right wrist

2. Extend spine toward right

3. Breathe in... breathe out...

4. *Repeat on other side*

Notes/adaptations:
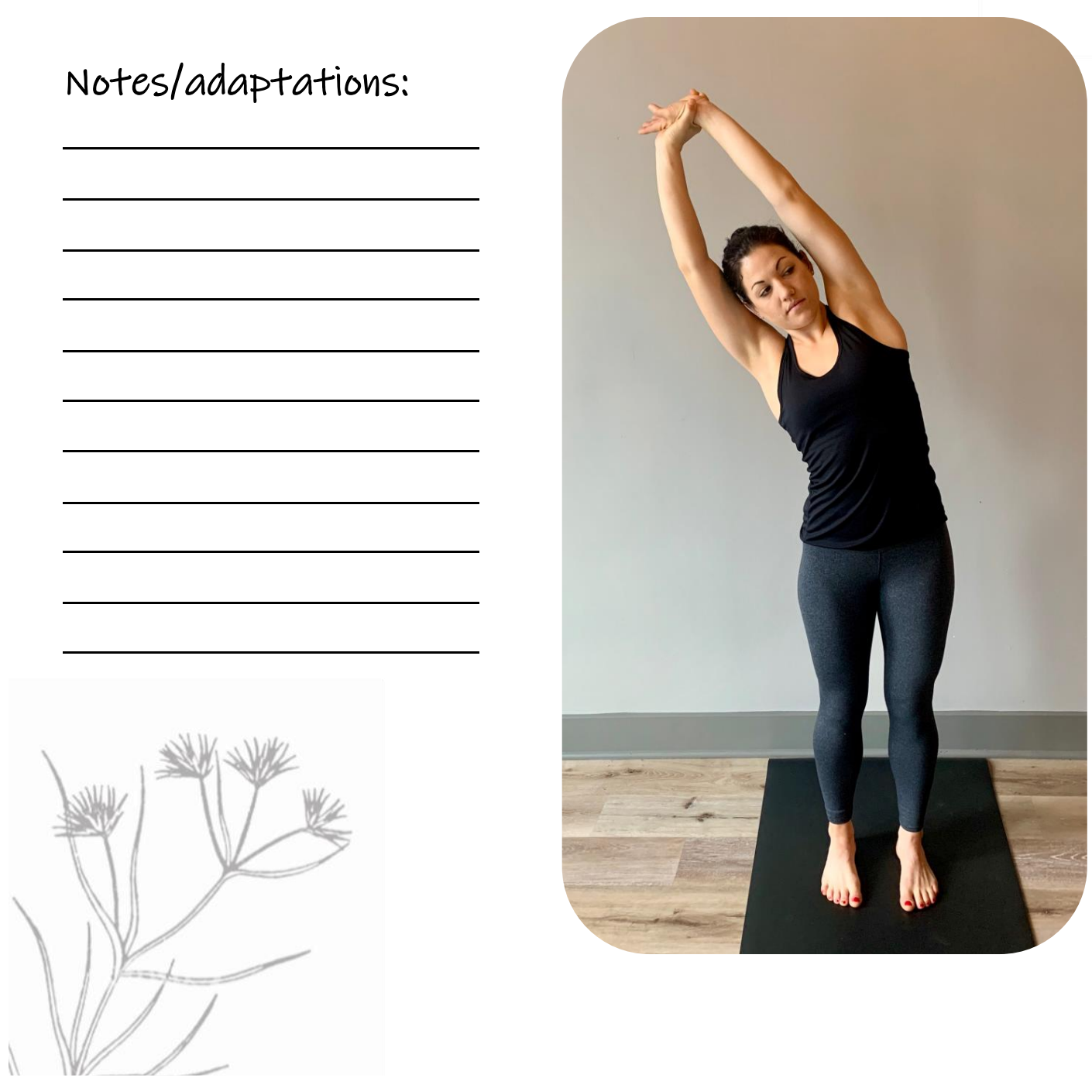

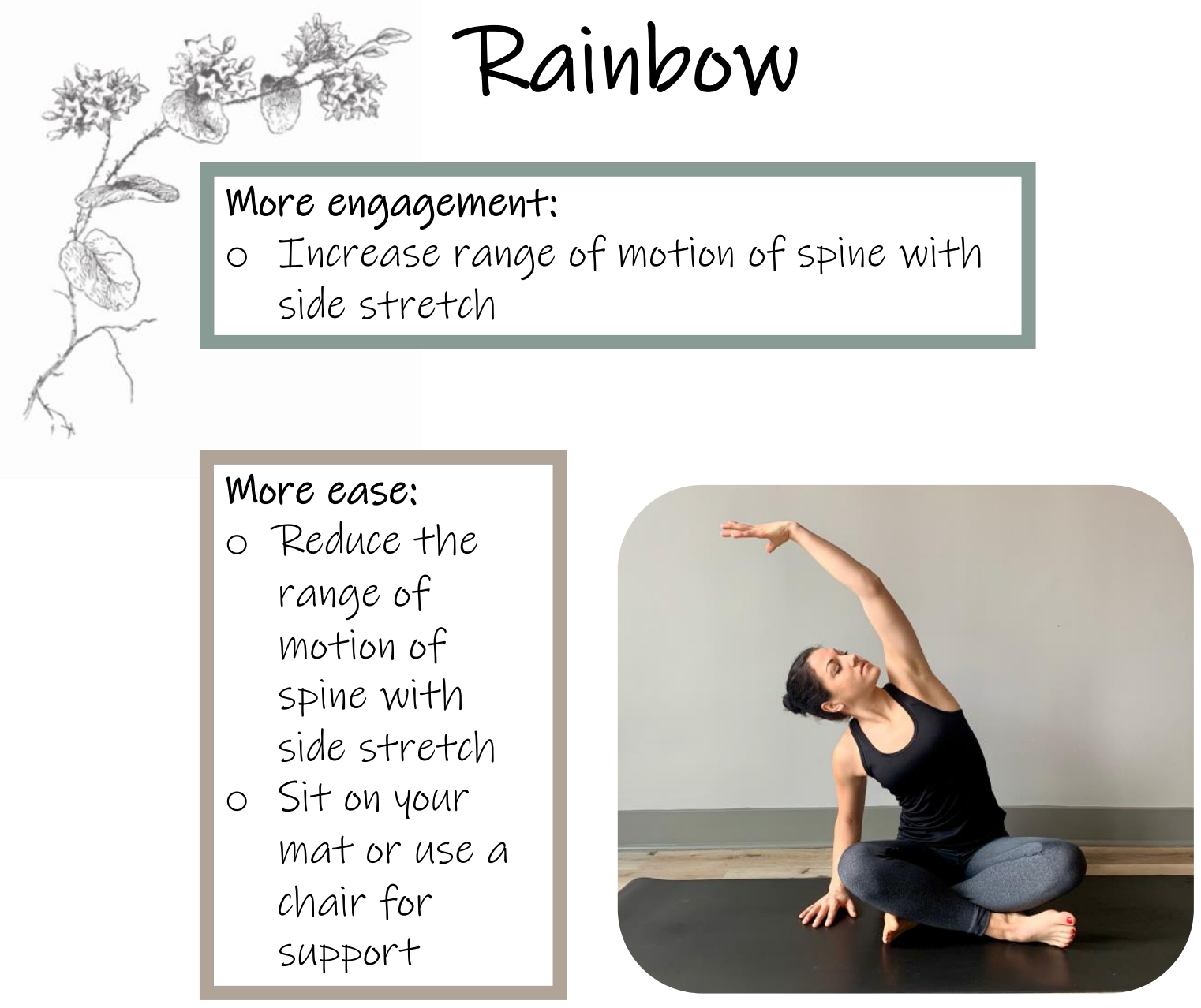

\section{Special considerations:}

- Be sure to slowly lean into this stretch to avoid injuries

- Post-mastectomy individuals should consider their range of motion restrictions

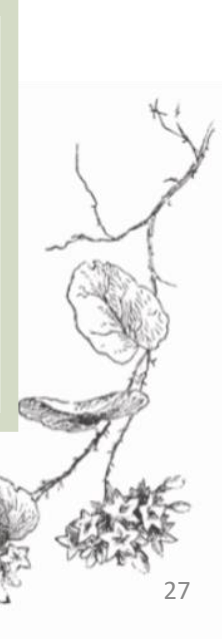




\section{Eagle (modified)}

1. Start standing, bring right arm under left, reach for opposite shoulders

2. cross right leg over left

3. Draw belly into spine

4. Bring slight bend to standing knee

5. Keep spine neutral

6. Tuck pelvis in

7. Focus gaze up

8. Breathe in... breathe out...

9. *Repeat on other side*

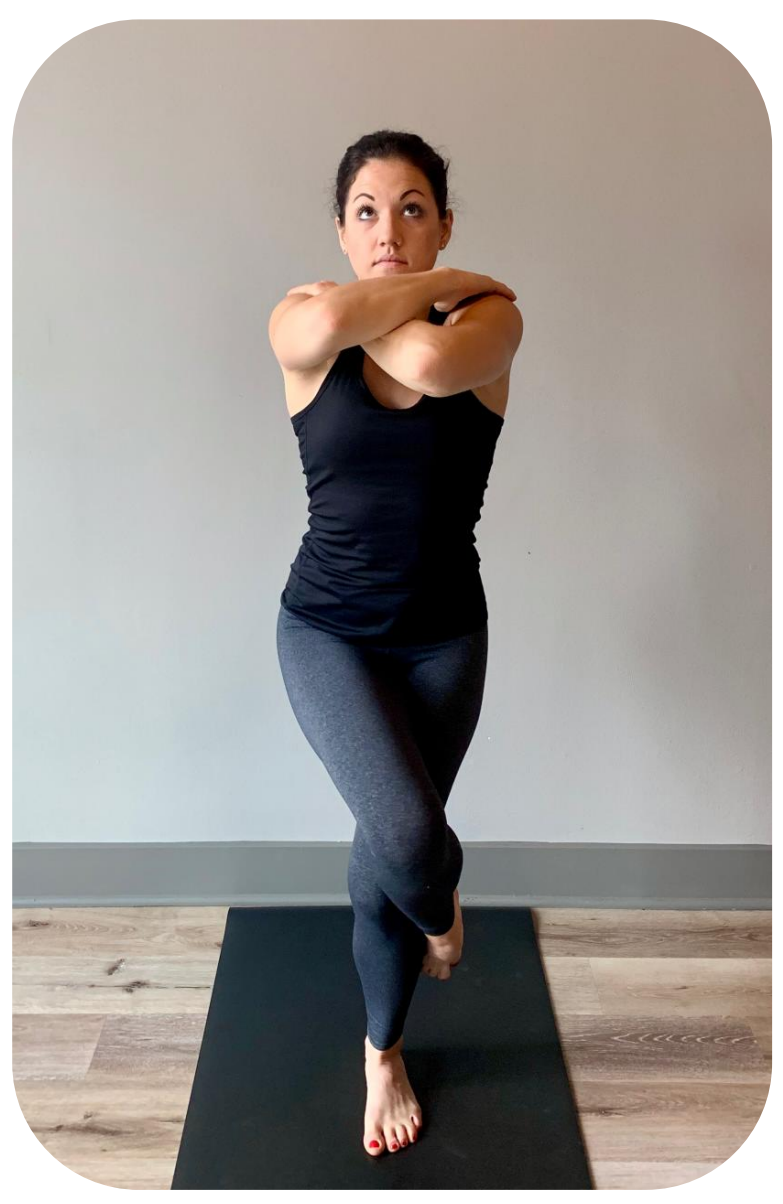

Notes/adaptations: 


\section{Eagle (modified)}

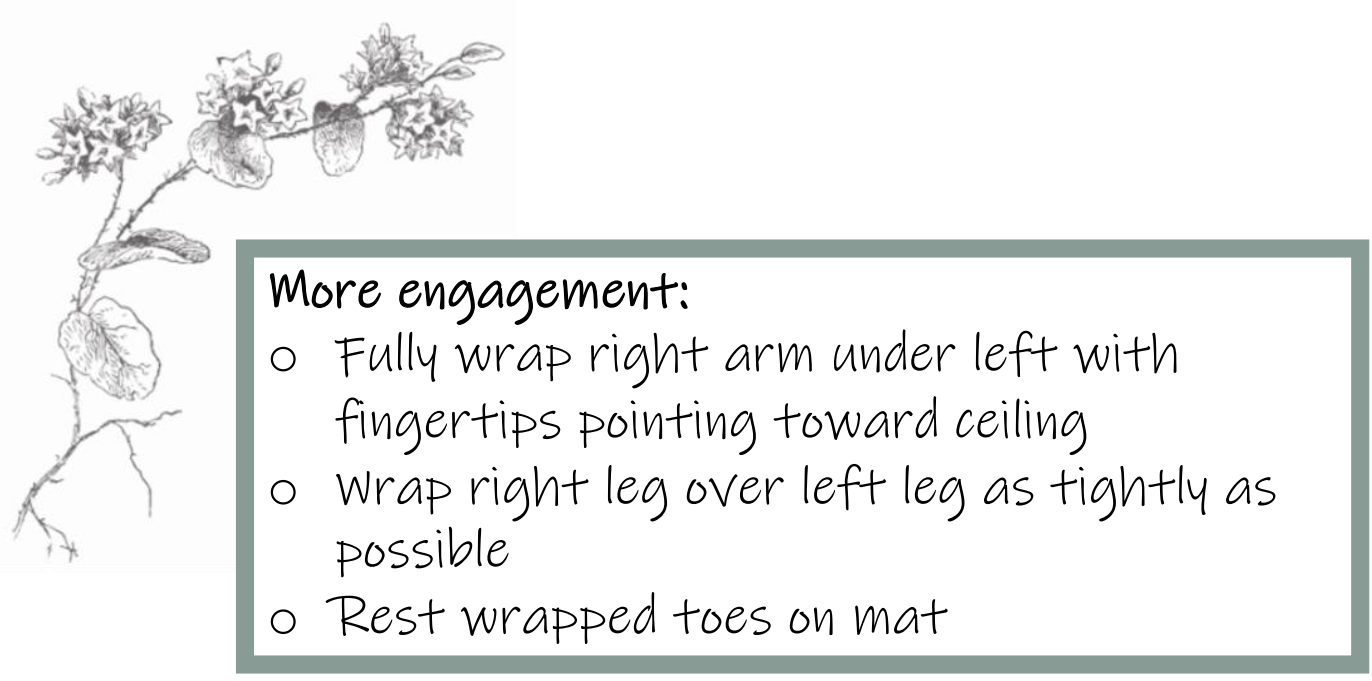

More ease:

- Reduce the bend in standing knee

- Focus on upper body first, then lower body

\section{Special considerations:}

- Men or people with broad shoulders should consider modifying by holding onto opposite shoulders

- Post-mastectomy individuals should consider their range of motion restrictions 


\section{Final Rest (savasana)}

"Savasana" is considered the most important pose of yoga. It is when all the benefits of the practice are absorbed by the body. In ancient times, yogis tanght the purpose of the physical practice of yoga was to release all the tension and pent up energy in the body so that at the end of the physical practice the body could be fully at rest, prepared for sitting mediation.

1. Extend legs long

2. Bring palms up and close your eyes

3. Relax your breathing

4. Rest for 3-5 minutes
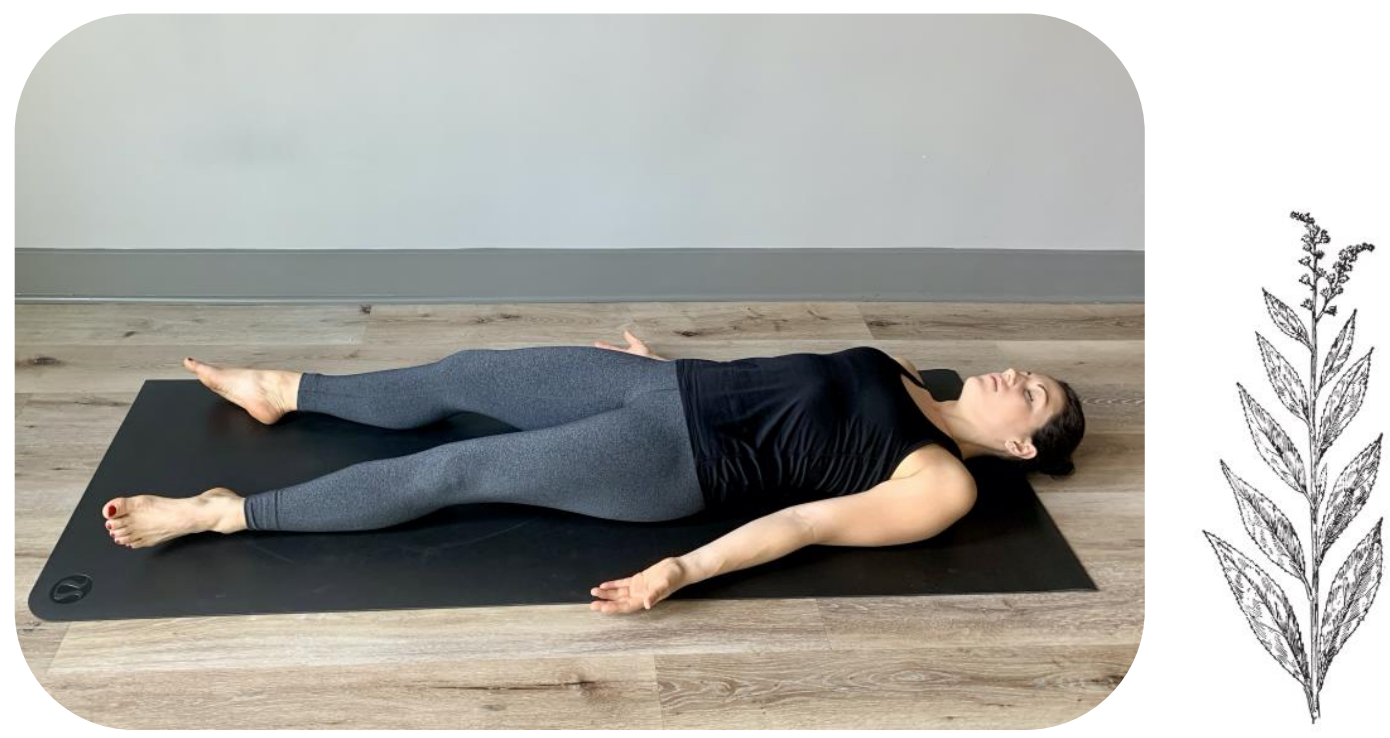

Notes/adaptations: 


\section{Introduction to Meditation Mindfulness}

Mindfulness practice is simply bringing awareness to the present through intentional focus. This practice opens space for our patterns of thought to arise. The intention is to allow thoughts and ideas to move through the mind, in a free and non-judgmental way. In other words, by bringing awareness to how we are emotionally responding to our thought patterns, we can begin to understand how we react to situations. Meditation brings an understanding of how our emotions drive our physiology and how this translates to how much ease or stress we feel within our system.

This practice works with the reality of impermanence. In our lives, everything arises, has its "song and dance" and then dissolves. From moment to moment, it's happening with everything. With breath, thought, sensation, emotion, conversation, everything. Mindfulness practice allows space for the connection of mind and body.

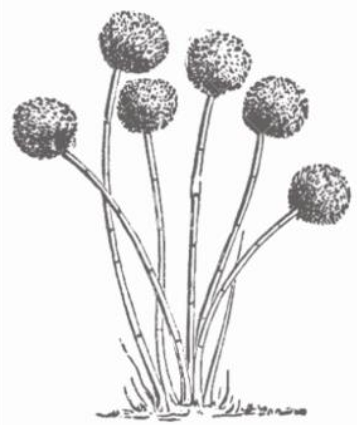




\section{creating a Quiet Space in your Home}

\section{Lighting:}

- Natural lighting

- Soft lighting

- candles

\section{Sound:}

- Light music or silence

- Guided practice or self-driven

\section{Space:}

- In chair or on cushion with supportive back

- Free from distraction (if possible)

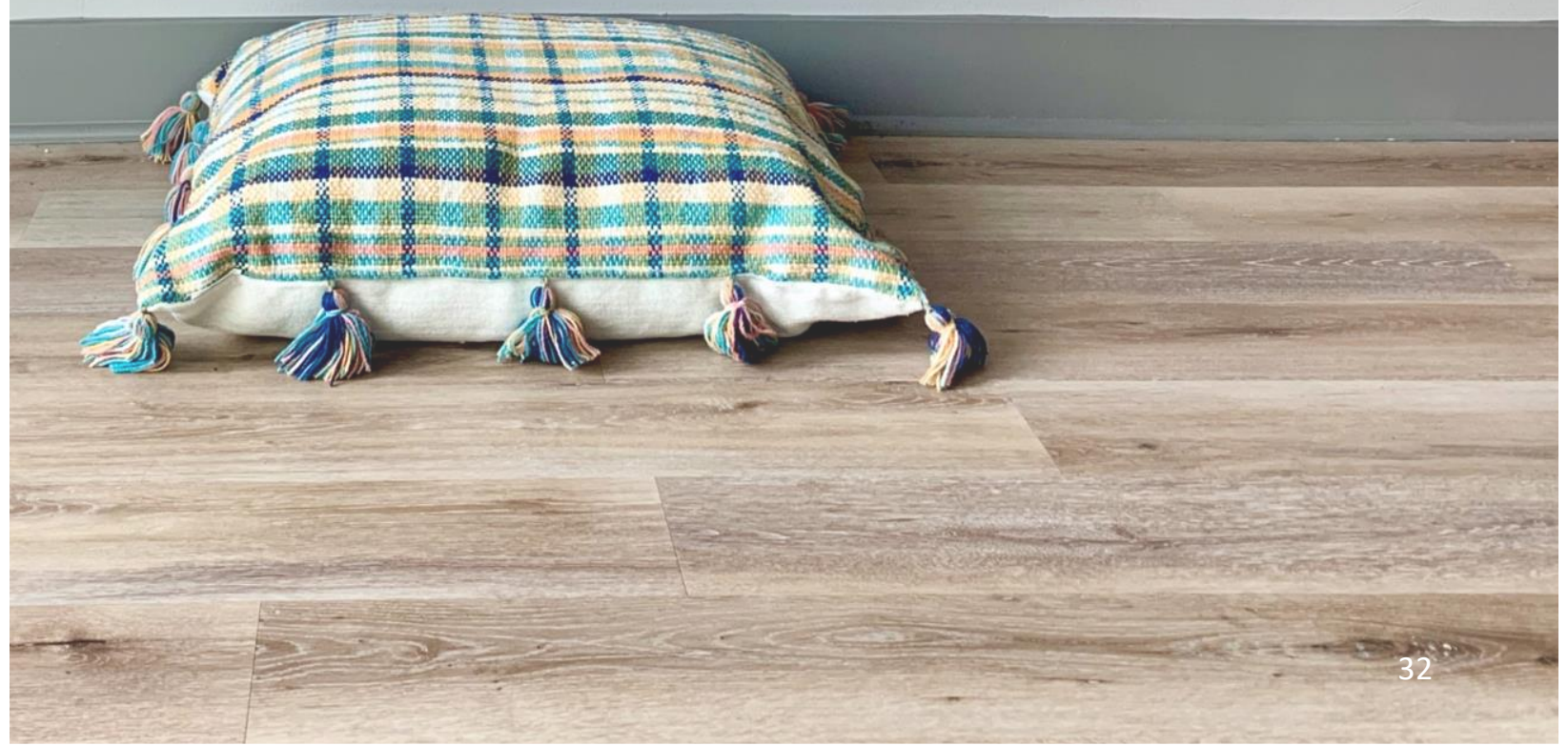




\section{Write and Release}

How does your body feel?

What thoughts come to the mind?

What are you grateful for in this moment?

What needs more attention or support? 


\section{Session Two:}

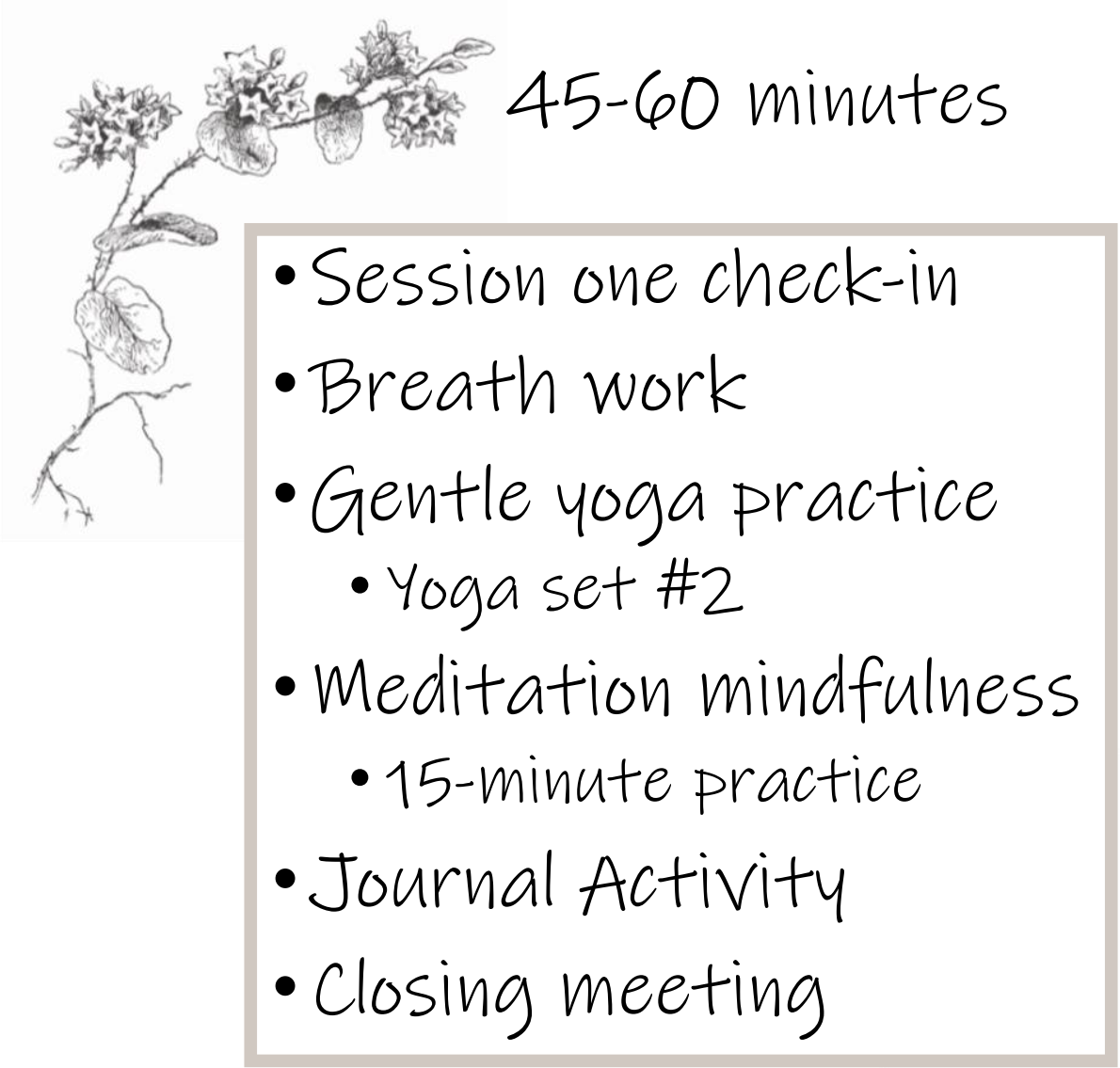




\section{Yoga Set 2:}

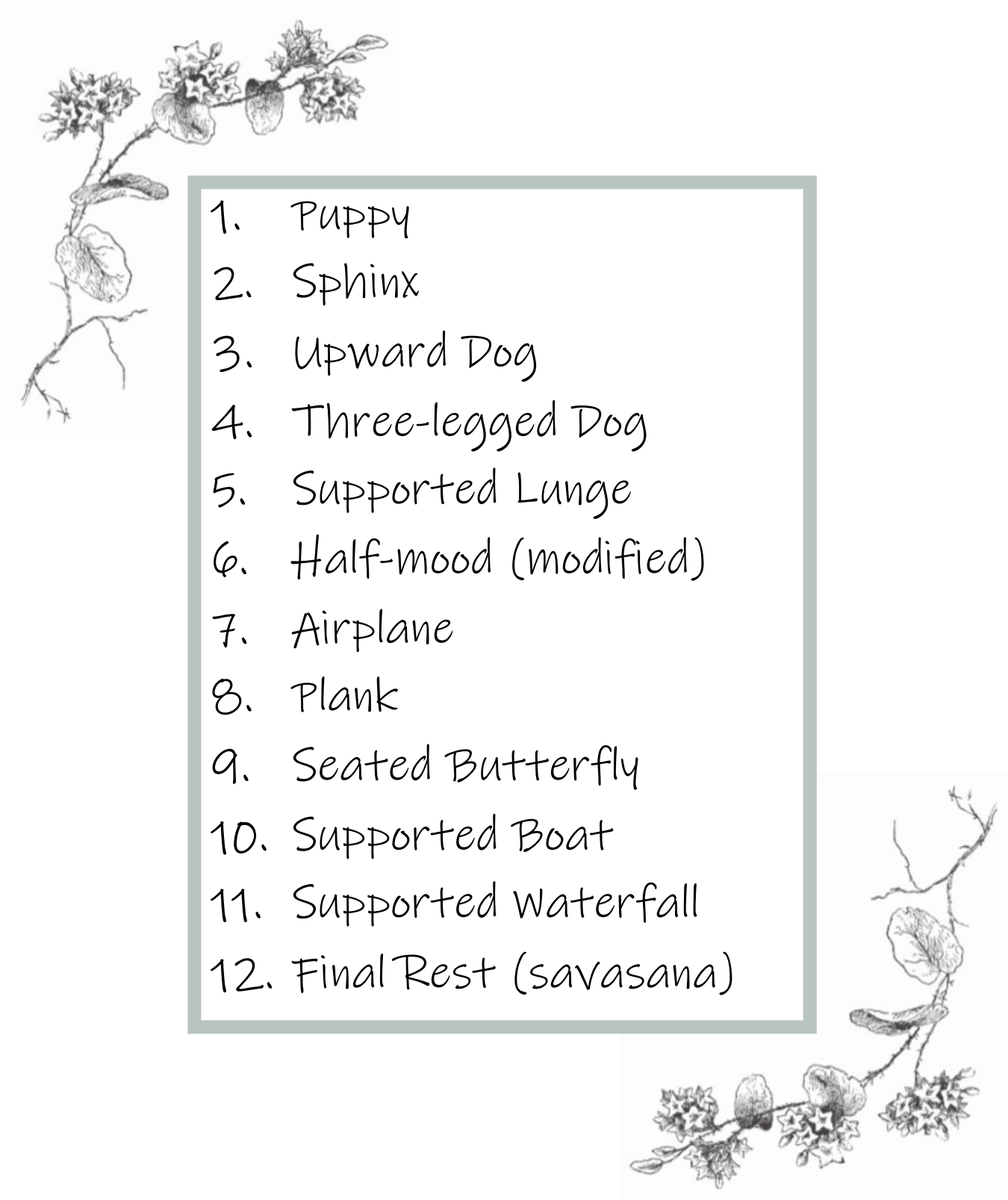




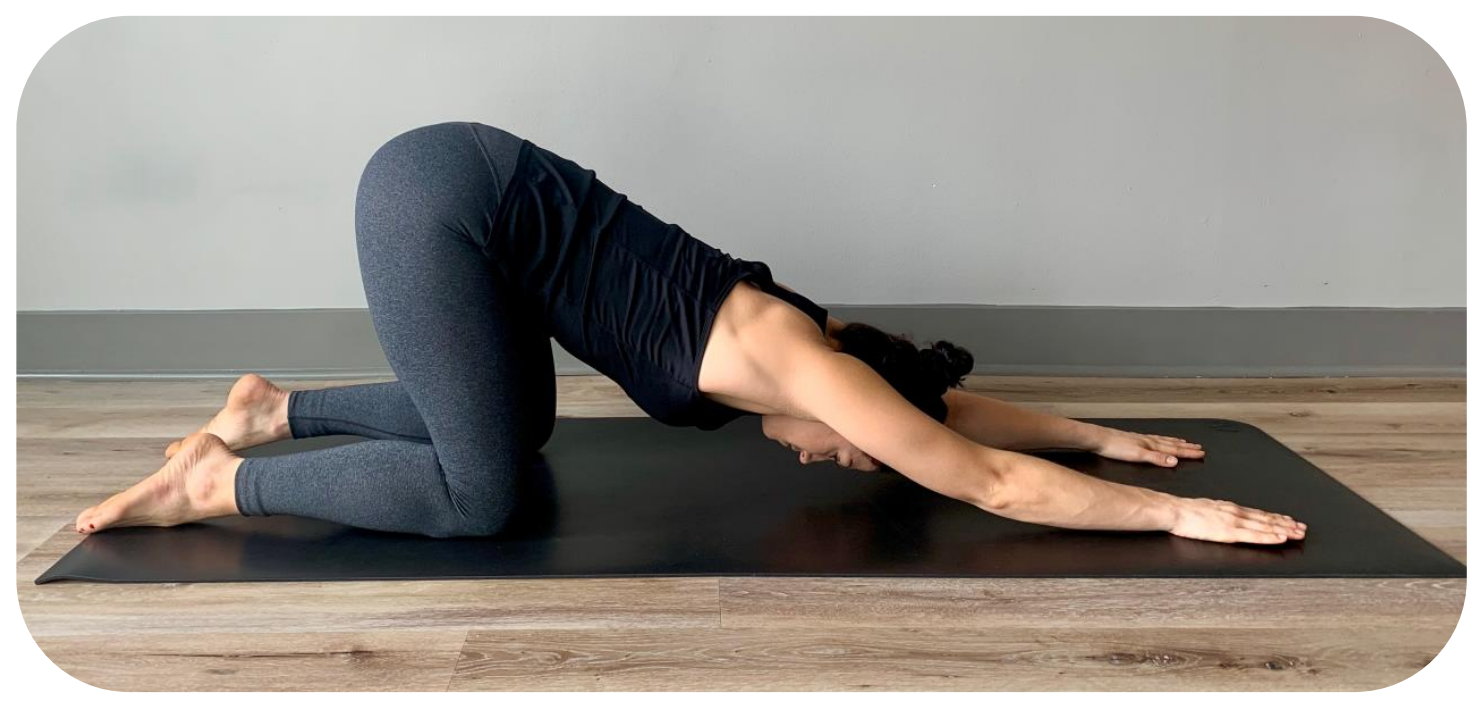

Notes/adaptations:

1. Stand on your knees and bend at the hips, stacking hips directly over knees

2. place palms on the floor in front of you

3. With a neutral spine, draw belly in, stretch through shoulders

4. Breathe in... breathe out...

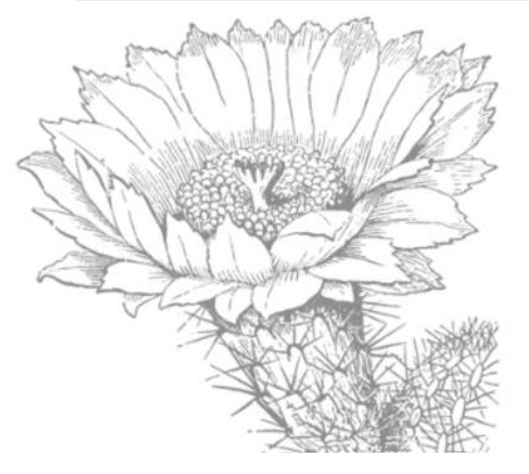

\section{PUPPY}




\section{PUPPY}

More engagement:

- Place hands in prayer position and bend at the elbows toward the back of the room

- Thread one arm under for spinal twist (see below)

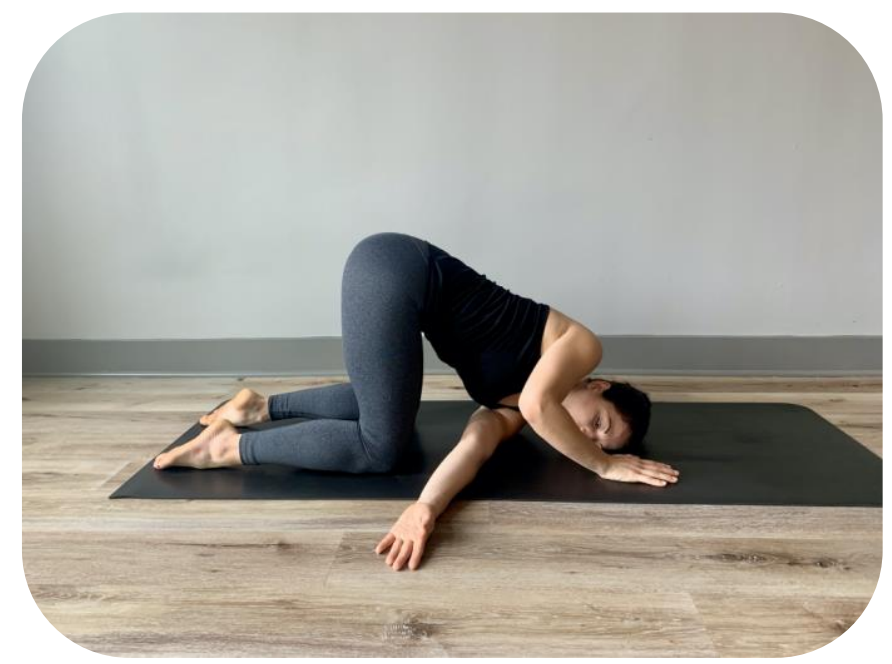

\section{More ease:}

- Reduce the distance your arms reach in front of you

\section{Special considerations:}

- Injuries to joints such as knees or shoulders might impact this position

- Post-mastectomy individuals should consider their range of motion restrictions 


\section{Sphinx}

1. Place arms shoulder width distance, palms flat on mat

2. Stack shoulders directly over elbows

3. With legs long and rested on mat, push into forearms

4. Keep neck neutral, gaze down at mat

5. Breathe in... breathe out...

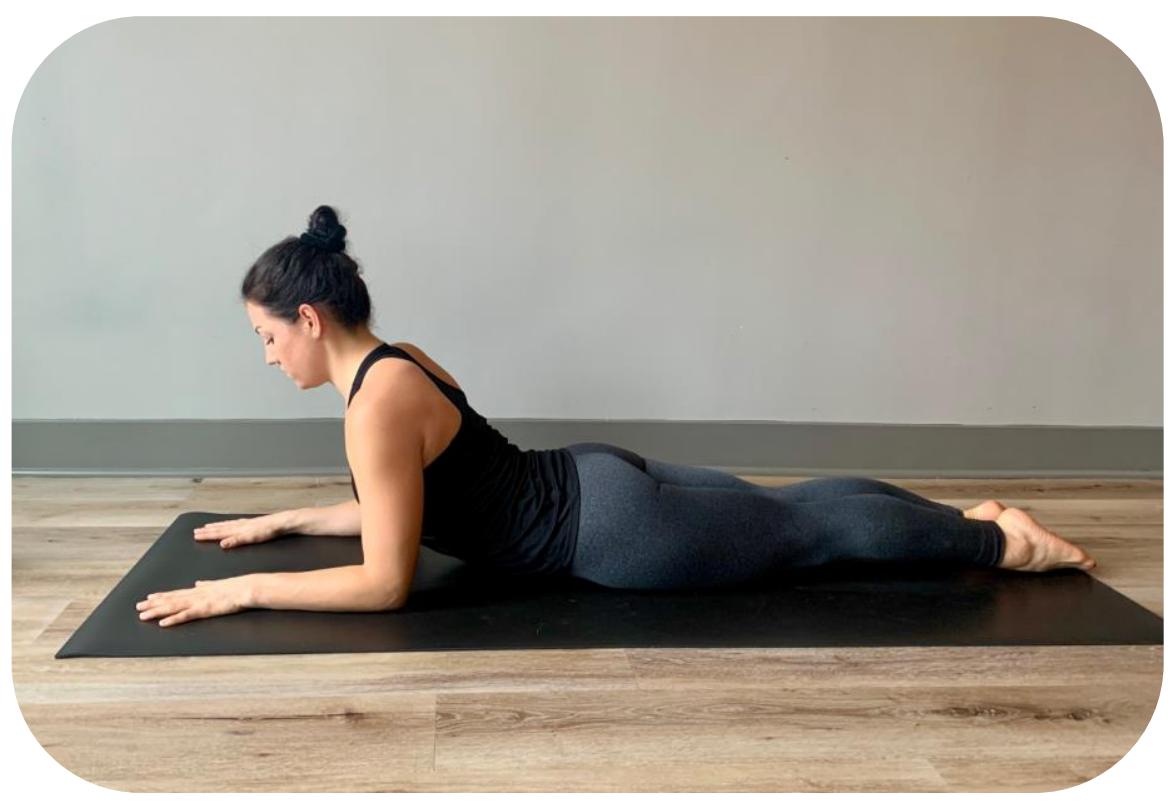

Notes/adaptations: 


\section{Sphinx}

More engagement:

- Slightly increase the amount of pressure you place through your forearms onto your mat

- walk palms wider on mat for seal pose

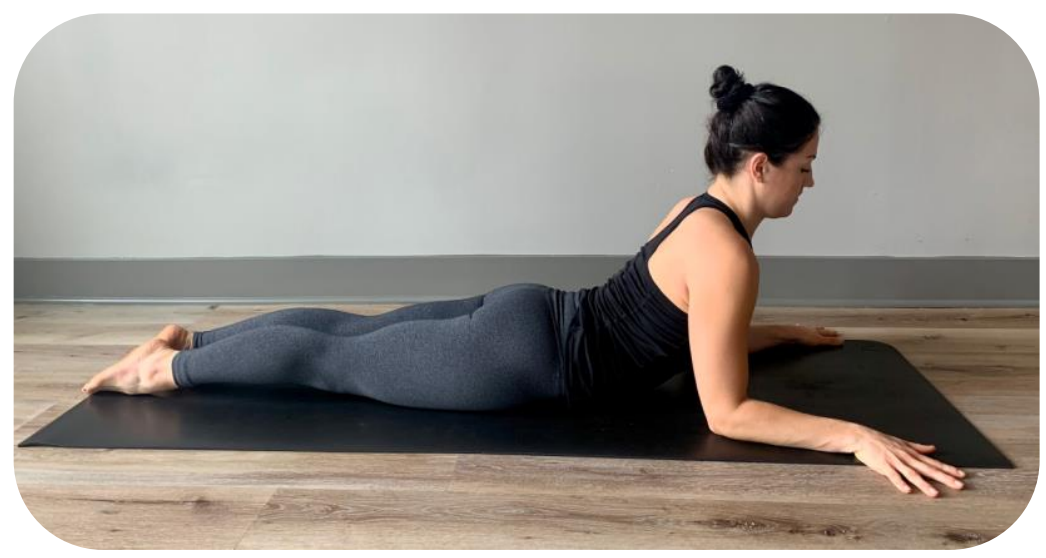

\section{More ease:}

- Reduce the amount of pressure you place through your forearms onto your mat

\section{Special considerations:}

- Injuries to shoulders or neck might impact this position

- Post-mastectomy individuals should consider their range of motion restrictions

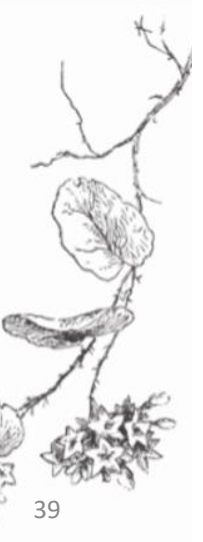




\section{Upward Dog}

1. Place palms next to your hips

2. Push into your mat, opening your chest

3. Move slowly and be sure to engage belly muscles to prevent strain in the lower back

4. With neutral neck, gaze forward

5. Squeeze thighs, hover knees off mat

6. Breathe in... breathe out...

Notes/adaptations:

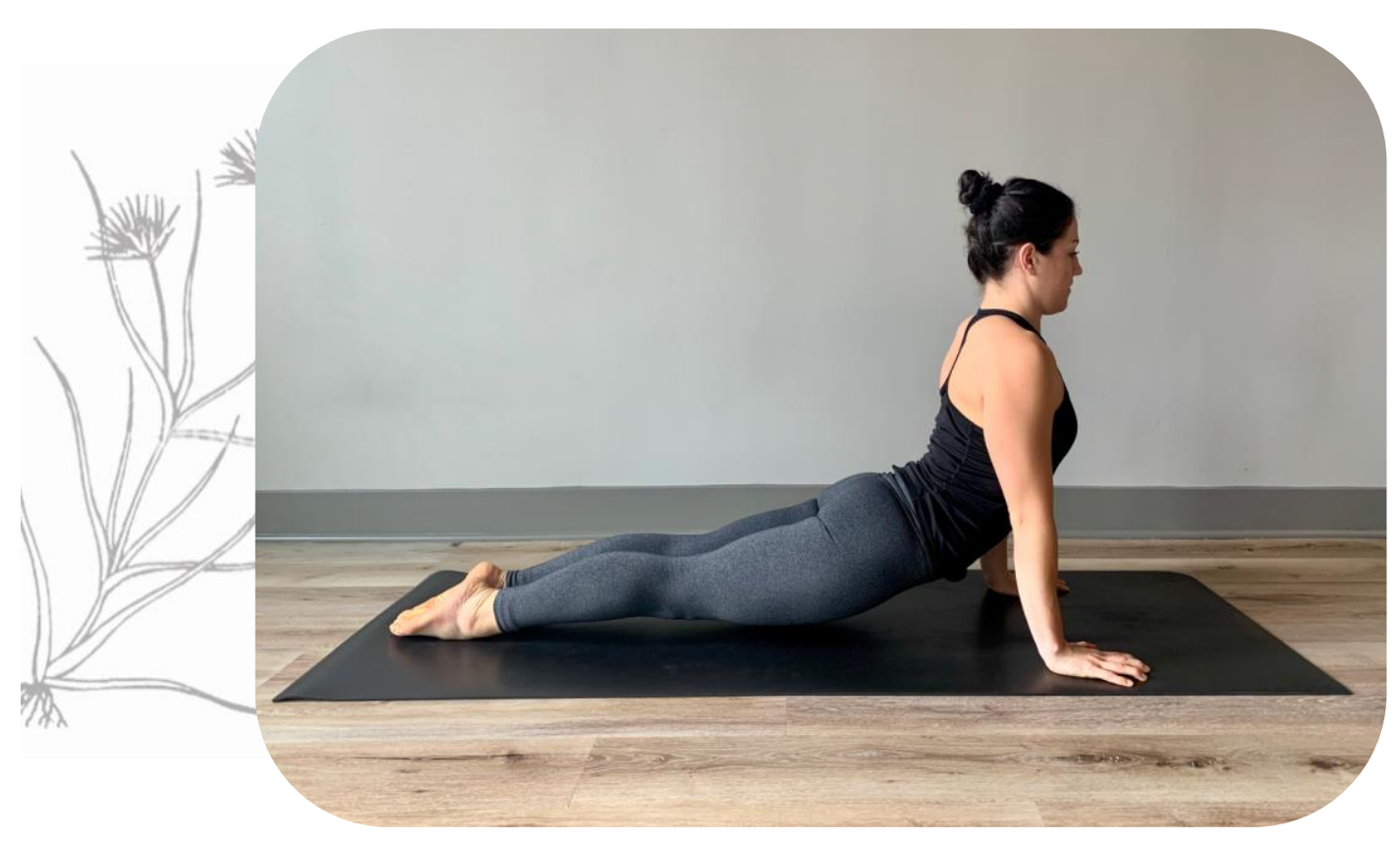




\section{Upward Dog}

More engagement:

- Increase opening through chest, externally rotate shoulders

More ease:

- Bring knees to mat

- Reduce the amount of pressure through your palms

\section{Special considerations:}

- Injuries to joints such as knees, shoulders, or wrists might impact this position

- Post-mastectomy individuals should consider their range of motion restrictions

- Move slowly to reduce the strain on your lower back

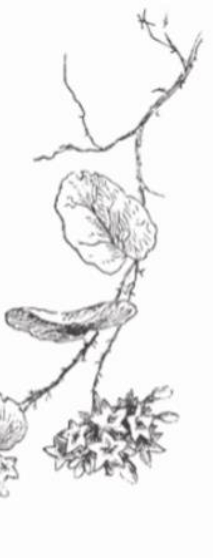




\section{Three-legged Dog}

1. Beginning in downward dog (refer to pg. 22)

2. Reach right leg high, keeping ankle flexed

3. Push your heel toward the back wall

4. Open through chest, push into palms

5. Nentral spine, draw belly in

6. Breathe in... breathe out....

7. *Repeat on other side*
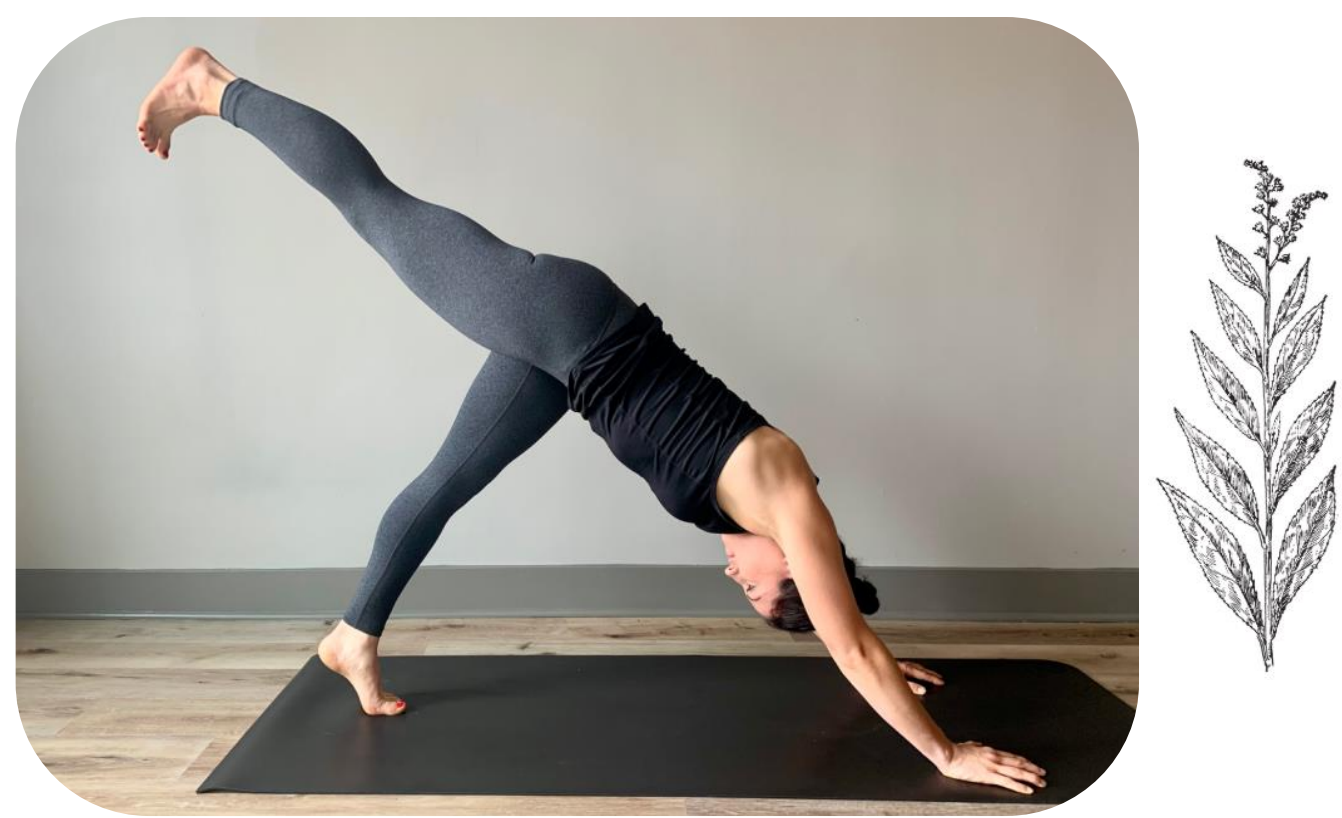

Notes/adaptations: 


\section{Three-legged Dog}

More engagement:

- Bend your knee and open your hip up to the side of the room

More ease:

- Reduce the height of the lifted leg

- Place blocks under wrists for increased support

\section{Special considerations:}

- Injuries to shoulder joints or wrists might impact this position

- Post-mastectomy individuals should consider their range of motion restrictions 
Notes/adaptations:
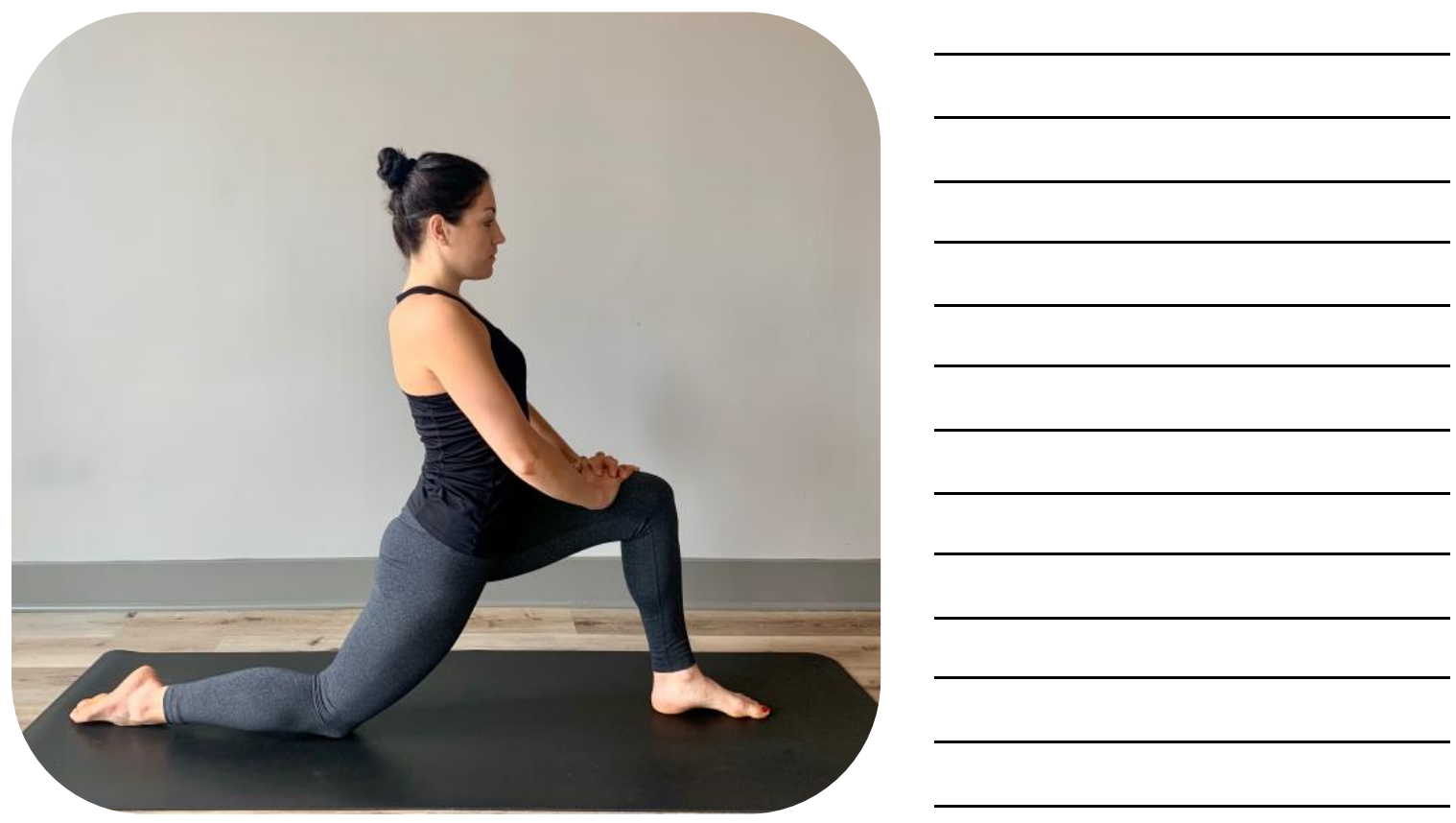

1. Start on knees, bring your right leg forward

2. Bring knee to mat, place palms on thigh

3. Slowly lean into forward leg

4. Breathe in... breathe out...

5. *Repeat on other side*

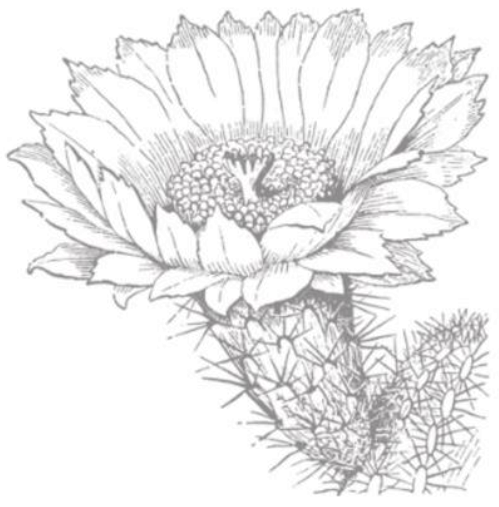

\section{Supported}

\section{Lunge}




\section{Supported Lunge}

\section{More engagement:}

- Move hands into different variations (prayer, cactus, reaching up)

- Lift knee off mat

- Bring hands to heart center, and twist toward the side of leading leg for a 'prayer twist'

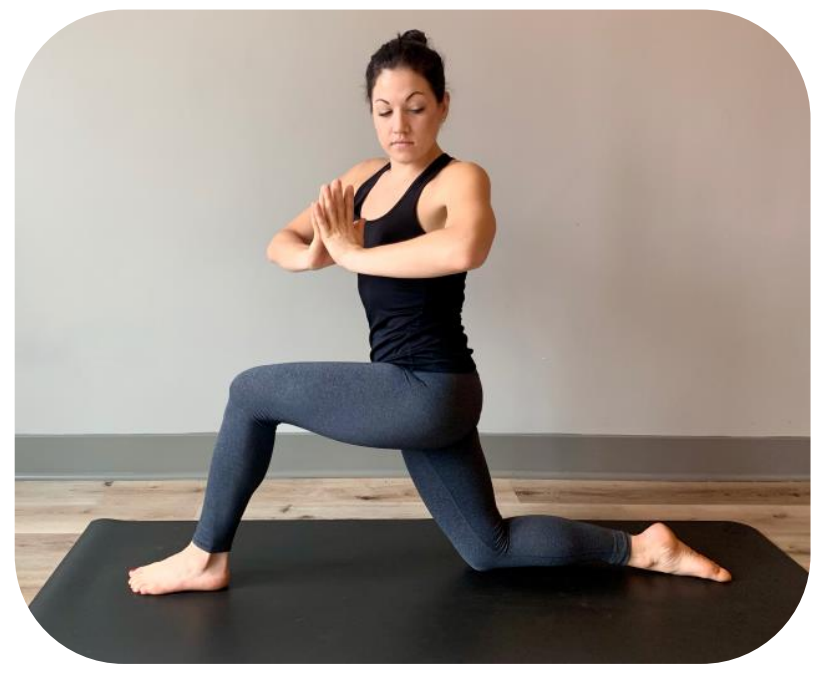

More ease:

- Place blocks on either side of body, hold to reduce the weight on lower body

Special considerations:

- Injuries to knees may impact this position 


\section{Half-moon (modified)}

1. Bring feet together, facing front of mat

2. Bring one arm to block, raise opposite arm and leg

3. Open hip toward side of room

4. Gaze forward, neutral spine

5. Flex ankle, draw belly in

6. Breathe in... breathe out...

7. *Repeat on other side*

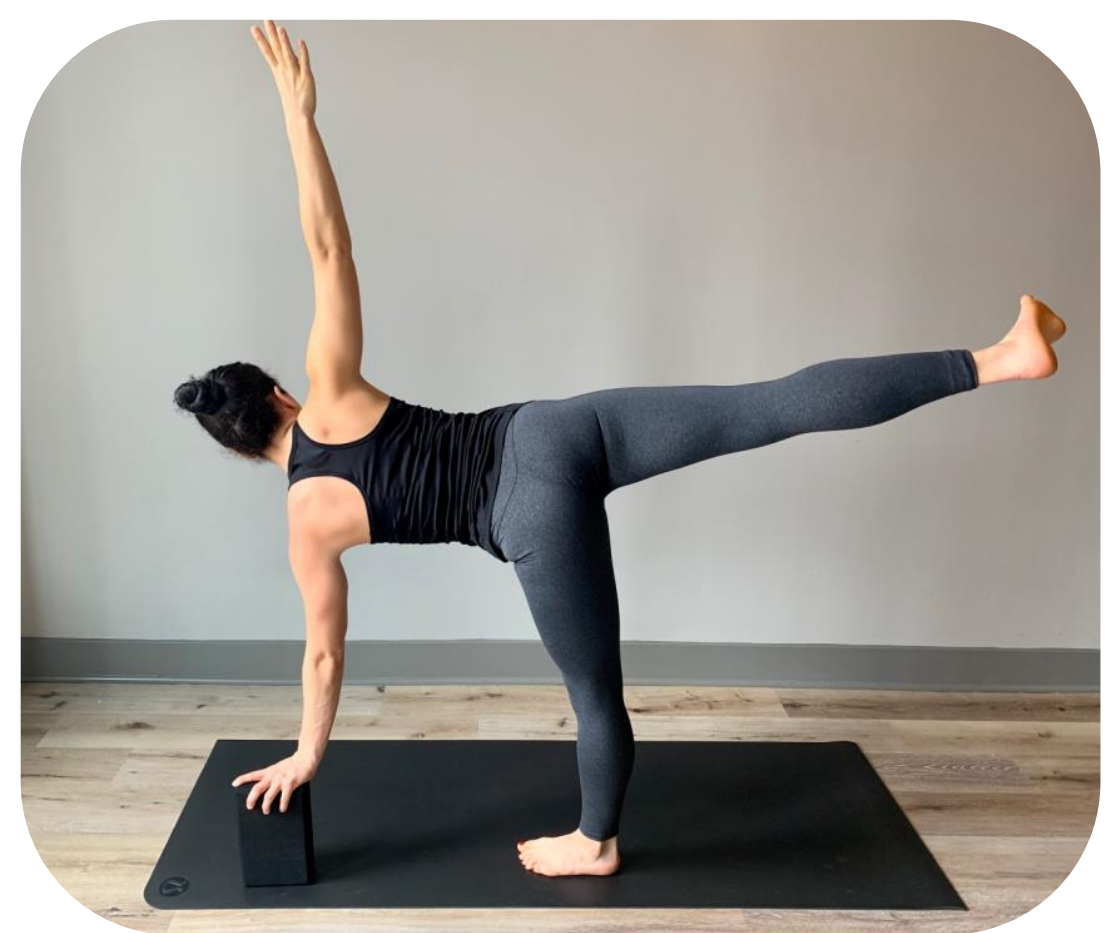

Notes/adaptations: 


\section{Half-moon (modified)}

\section{More engagement:}

- Raise lifted leg higher

- Try lifting support arm off block for a few seconds

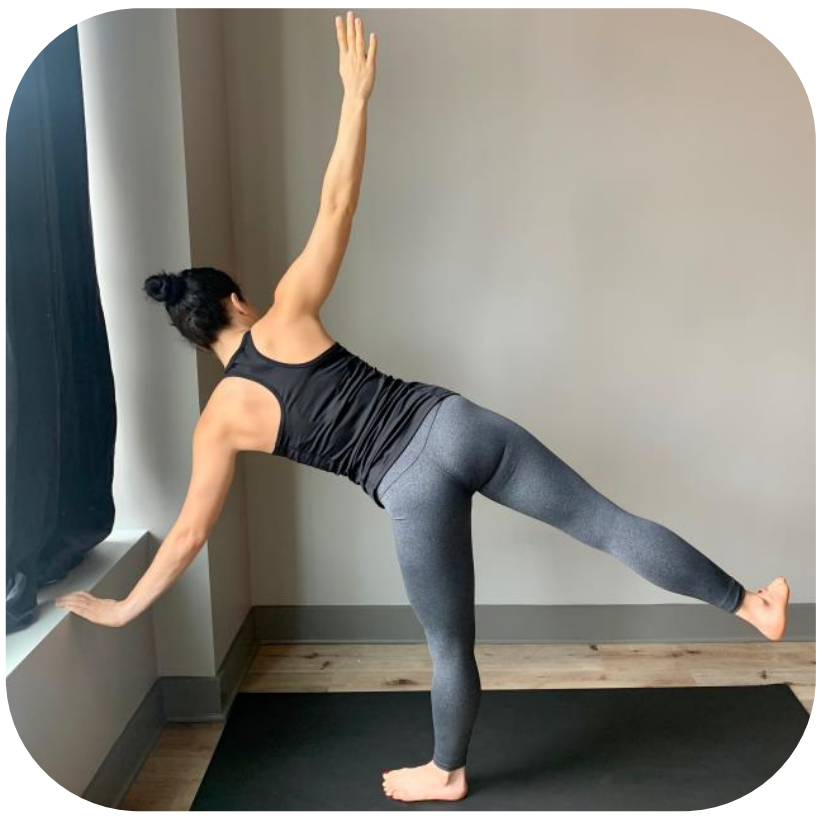

More ease:

- Use a counter or windowsill for extra support

- Lower lifted leg

\section{Special considerations:}

- Injuries to joints such as knees or shoulders might impact this position

- Post-mastectomy individuals should consider their range of motion restrictions

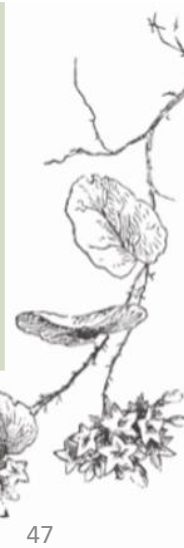




\section{Airplane}

1. Raise one leg behind, flexed ankle

2. Extend arms back, palms down

3. Open chest, gaze forward

4. Focus on one point to help with balance

5. Draw belly into spine

6. Breathe in... breathe out...

7. *Repeat on other side*

Notes/adaptations:

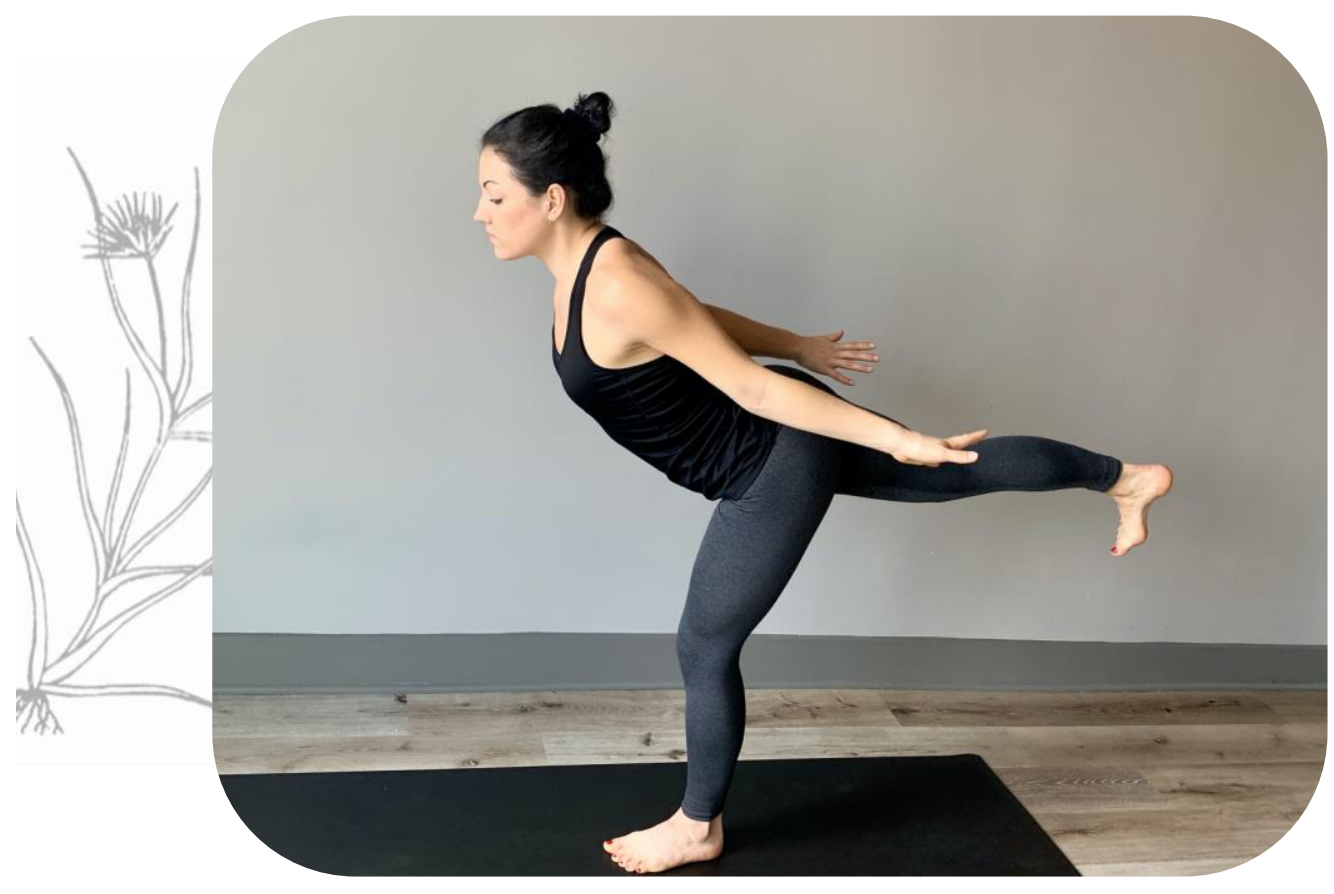




\section{Airplane}

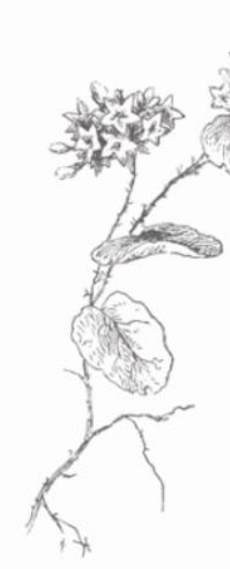

More engagement:

- Increase lift in back leg

- Increase lift in chest

More ease:

- Facing a wall, extend arms out in front for wall support

- Decrease the lift in back leg

Special considerations:

- Remember to bring softness to the knee joint in your standing leg 


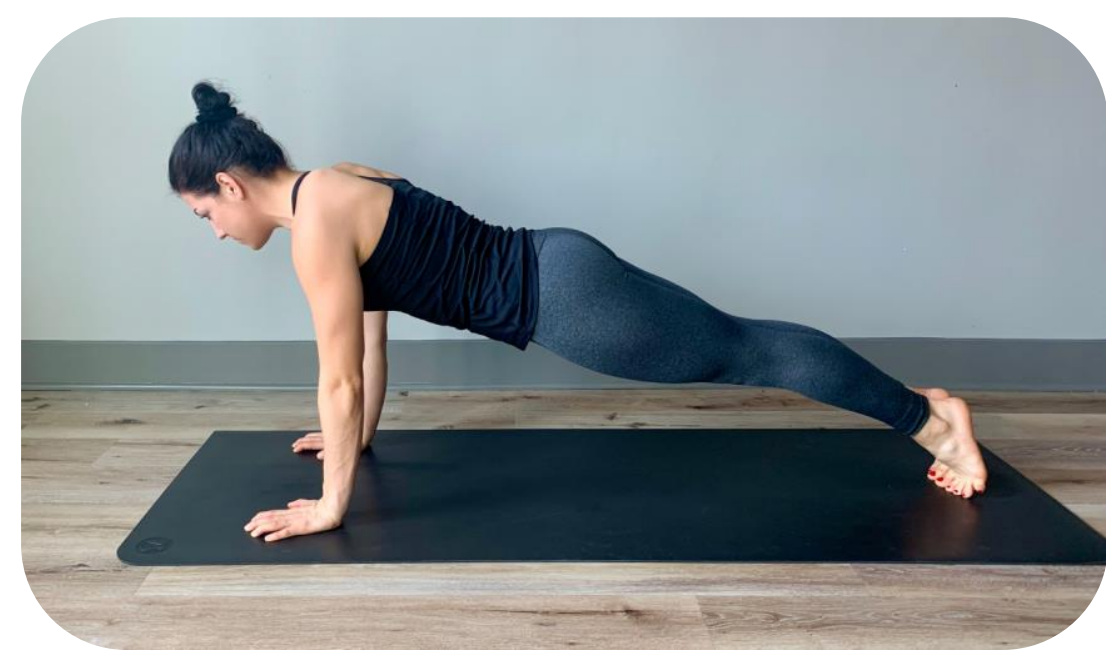

1. Starting in tabletop (refer to pg. 16)

2. Extend legs long, raising knees off mat

3. Draw belly in, keep spine neutral

4. Gaze about two inches above mat

5. Breathe in... breathe out...

Notes/adaptations:

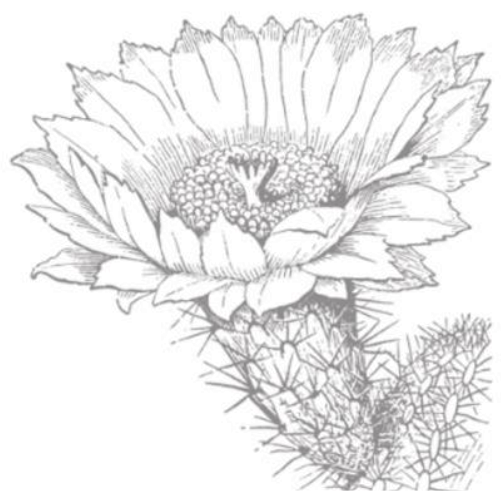

Plank 


\section{Plank}

\section{More engagement:}

- Lift one foot two inches above mat for a few breaths (repeat on other side)

- Bring forearms to mat, figure 11

\section{More ease:}

- Bring knees to mat

- Use blocks under wrists for extra support

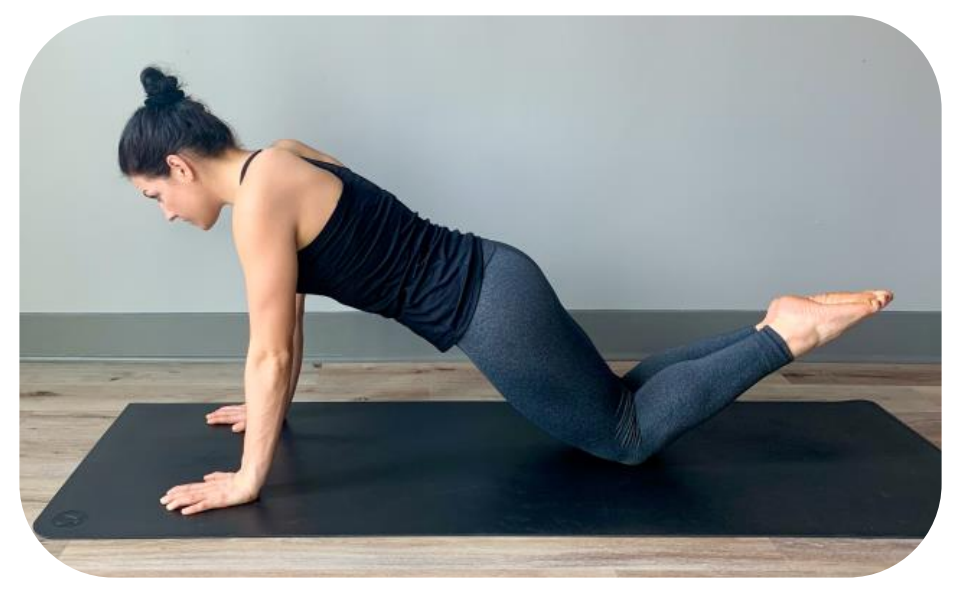

Special considerations:

- Injuries to shoulder, knee, or wrist joints might impact this position

- Post-mastectomy individuals should consider their range of motion restrictions

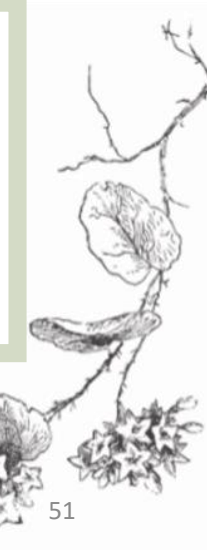




\section{Seated Butterfly (supported)}

1. Bring feet to touch, knees ont wide

2. Draw lower belly in

3. Gently bend over feet

4. Use blocks to support head or place under knees

5. Breathe in... breathe out...

Notes/adaptations:

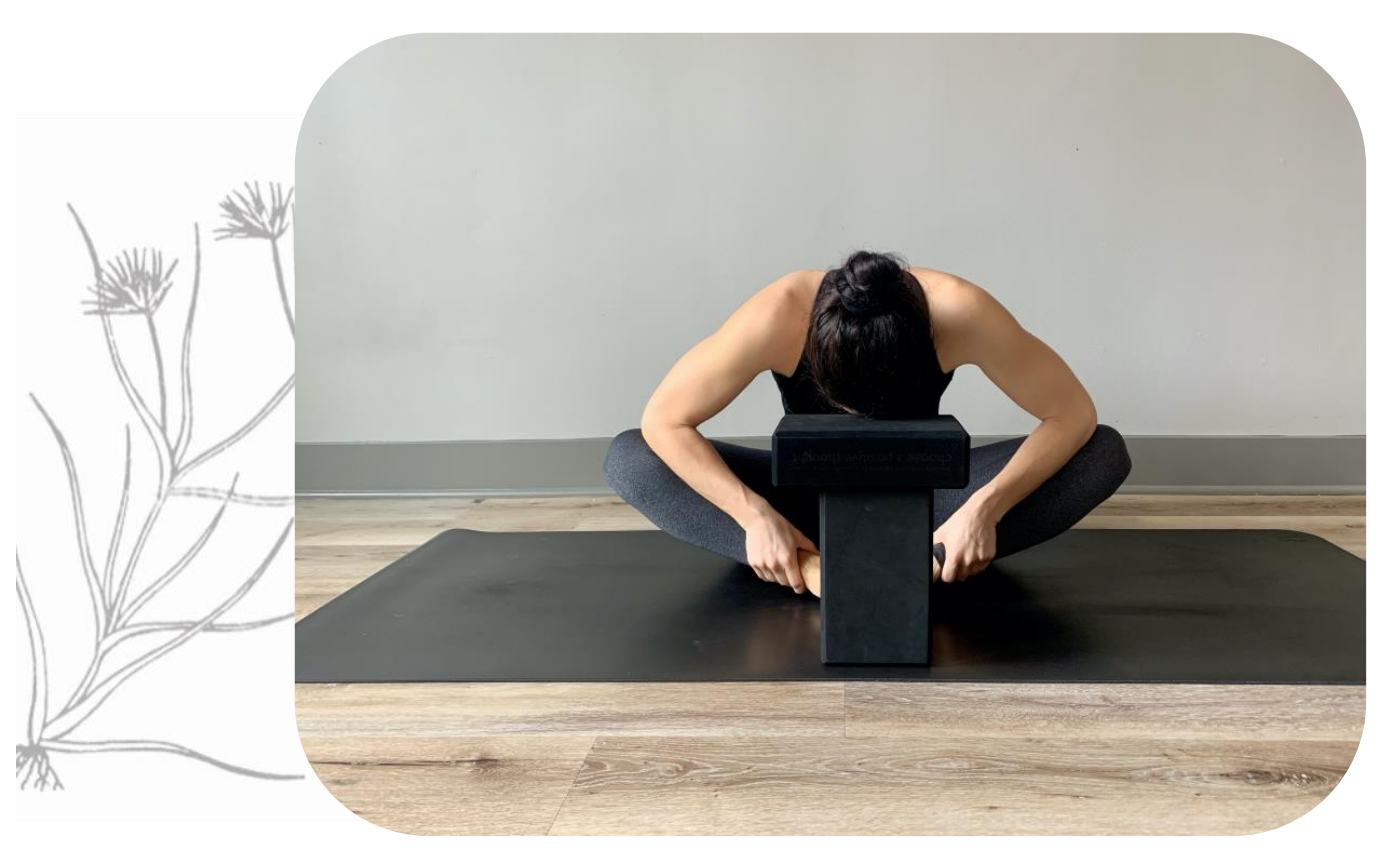




\section{Seated Butterfly}

More engagement:

- Remove blocks

- Fold over feet with neutral spine

\section{More ease:}

- Increase the height of blocks

- Move ankles farther away from body

\section{Special considerations:}

- For a restorative breathing position, bring feet to touch, knees wide, and lie on your back Bring one hand to your heart, and the other to your belly, breathe in... breathe out...
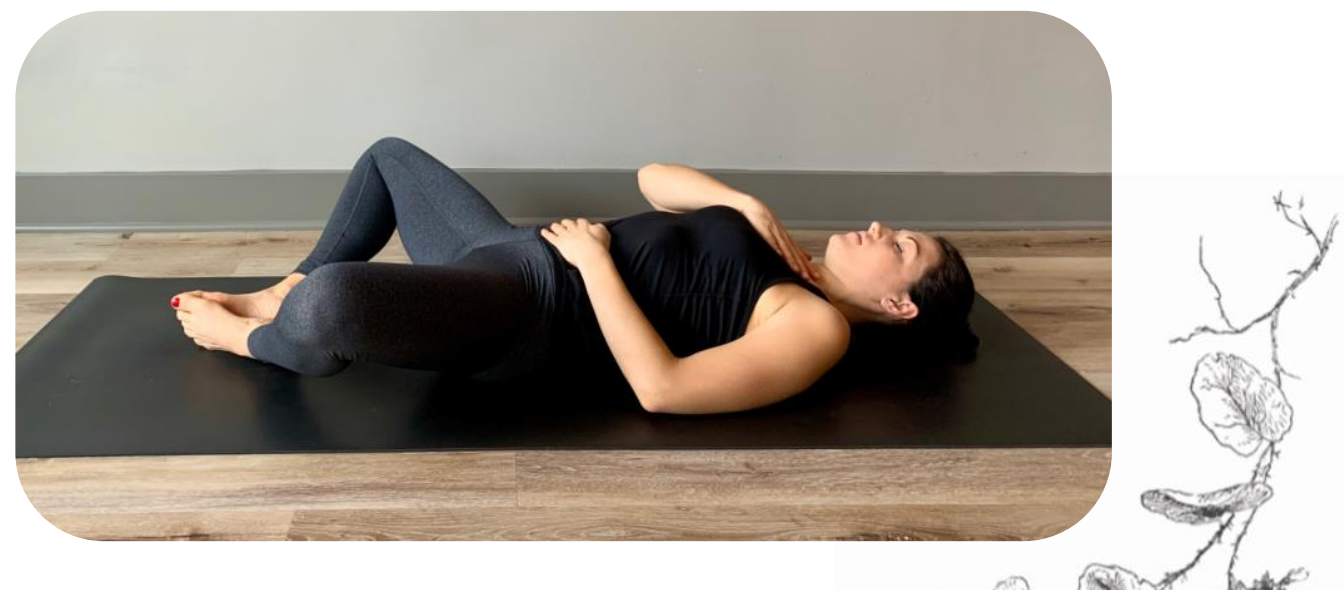


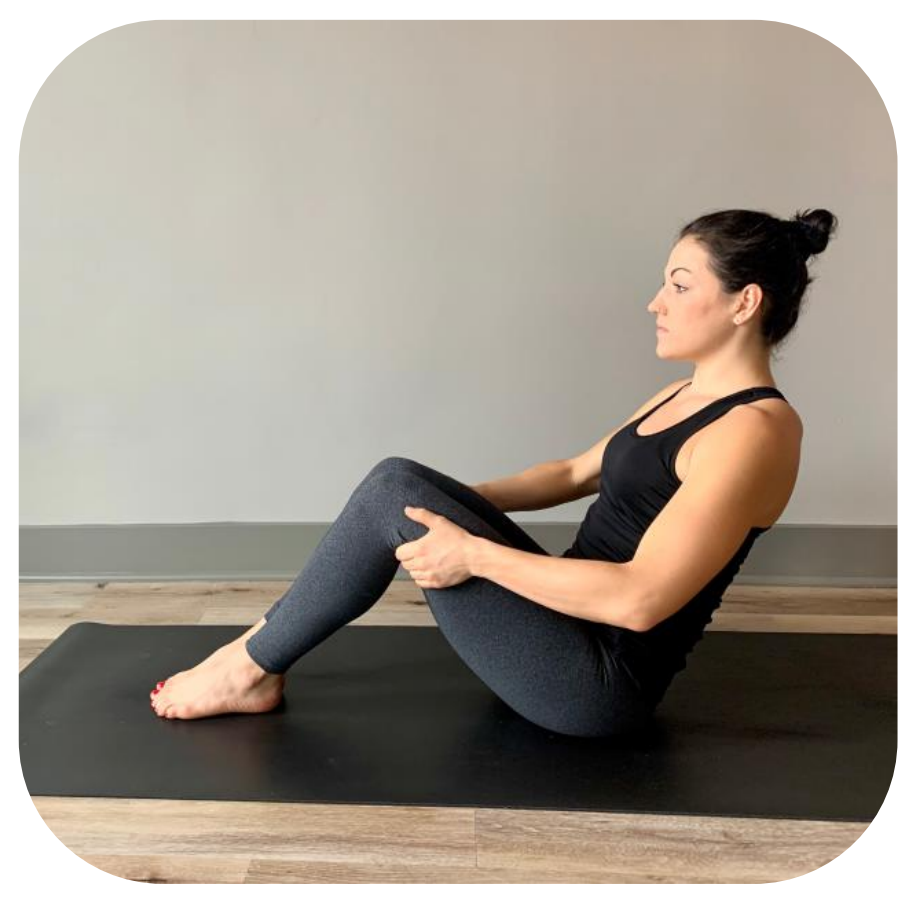

1. Starting seated, bend knees

2. Bring arms to support back of knees

3. Draw belly into spine, keep back neutral

4. Gaze forward

5. Breathe in... breathe out...

Notes/adaptations:

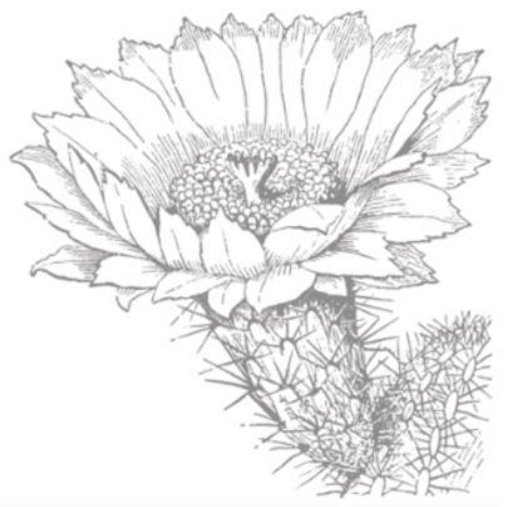

\section{Supported} Boat 


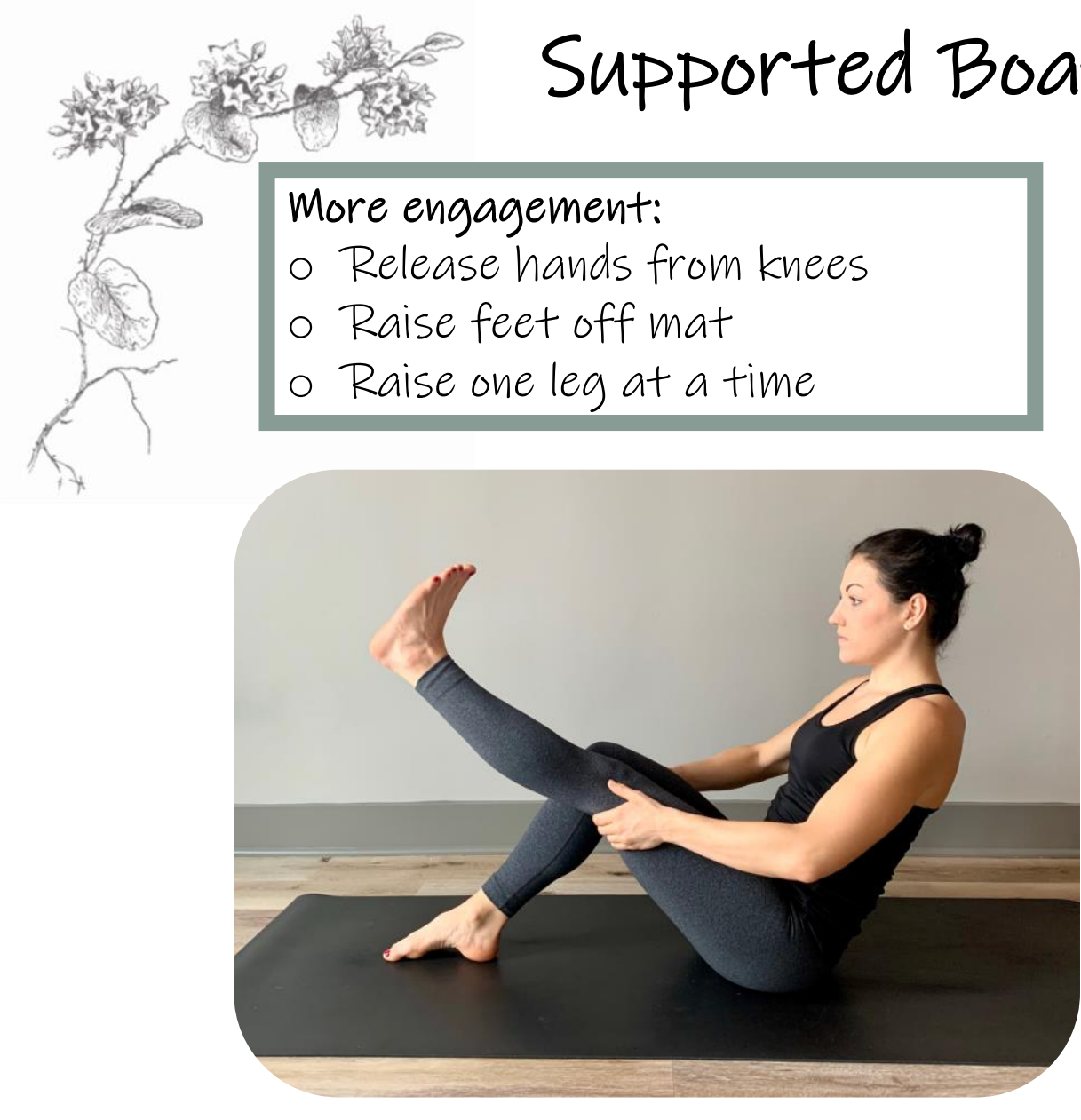

\section{More ease:}

- Use a cushion under bottom for extra support

\section{Special considerations:}

- Make sure to focus on your core muscles in this position 
EXPLORING OCCUPATIONAL DISRUPTION IN PARENTS WITH CANCER

27

Supported waterfall

1. Place a block under your sacrum 2. Flex and lift your feet into the air 3. Relax arms by your side, palms up 4. Breathe in... breathe out...

Notes/adaptations:

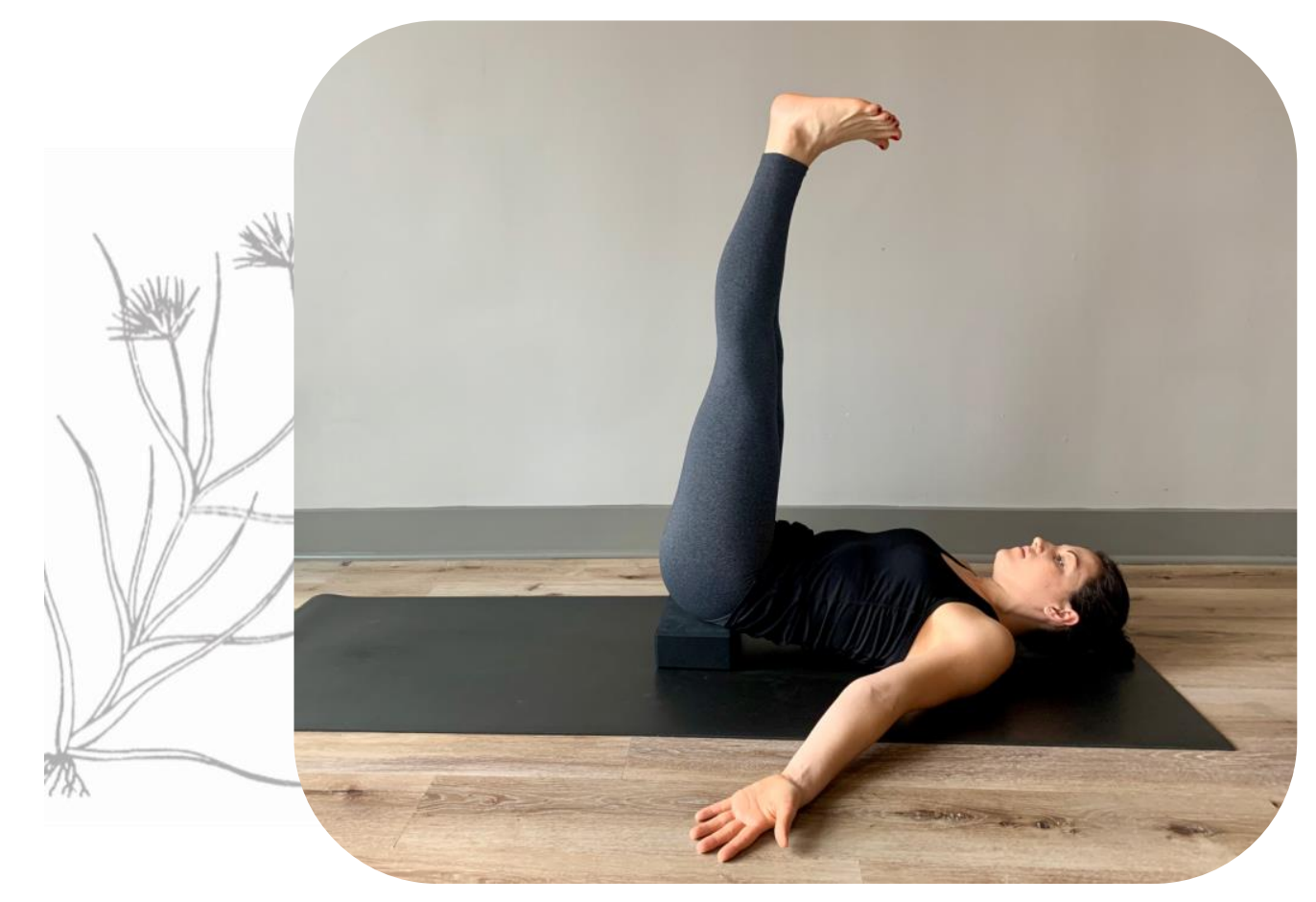




\section{Supported waterfall}

More engagement:

- Slowly bring legs closer to face for an increased hamstring stretch

o Remove the block

\section{More ease:}

- Use a wall to support legs lifted

- Replace block with a cushion

- Remove block and rest bent legs on chair

\section{Special considerations:}

- This pose is an inversion, meaning your feet are higher than your heart - this can be helpful for blood flow 


\section{Final Rest (savasana)}

1. Extend legs long

2. Bring palms up and close your eyes

3. Relax your breathing

4. Rest for 3-5 minutes
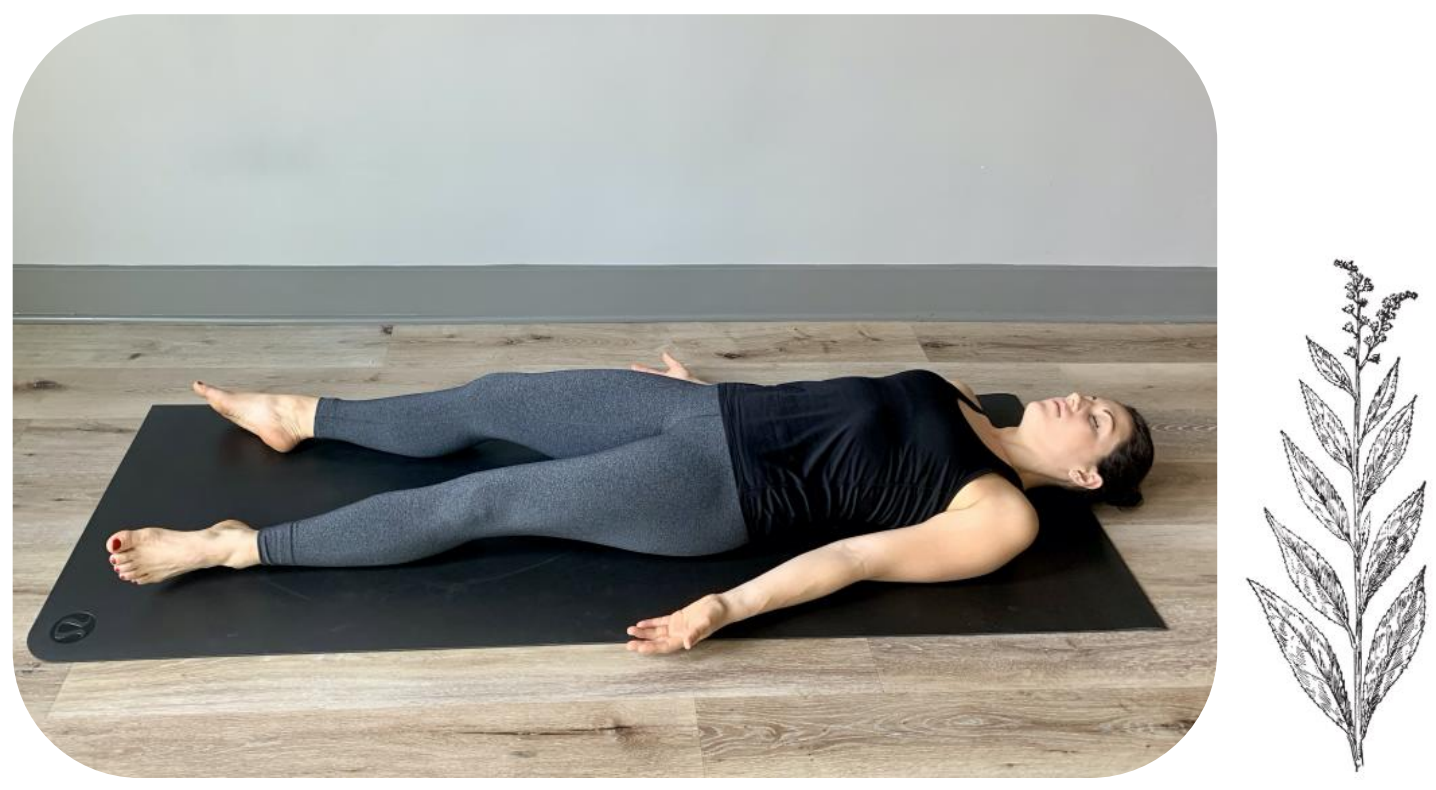

Notes/adaptations: 


\section{Meditation Practice}

A mantra is a short phrase or word that is repeated. For this practice, select a favorite word, phrase, prayer, or short quotation. Ideally, it is simple enough to repeat throughout practice.

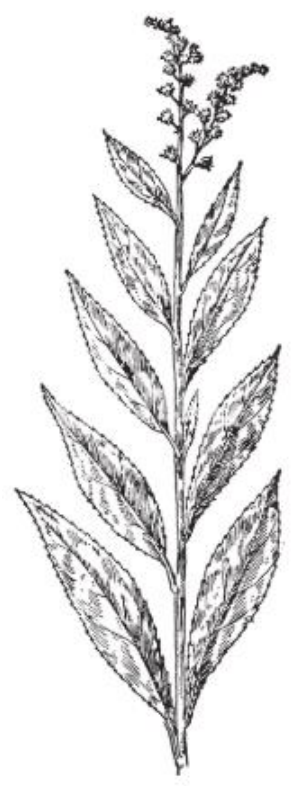

\section{common mantras:}

- I am that I am

- Love is everything

- I belong, I have faith

- I have resilience, I am resilient

- I change my thoughts, I change the world

My Mantra: 


\section{Write and Release}

What routines are essential in your family?

Where is there adequate support?

Where is there a need for support?

What are three things are essential to your healing? 


\section{Session Three:}

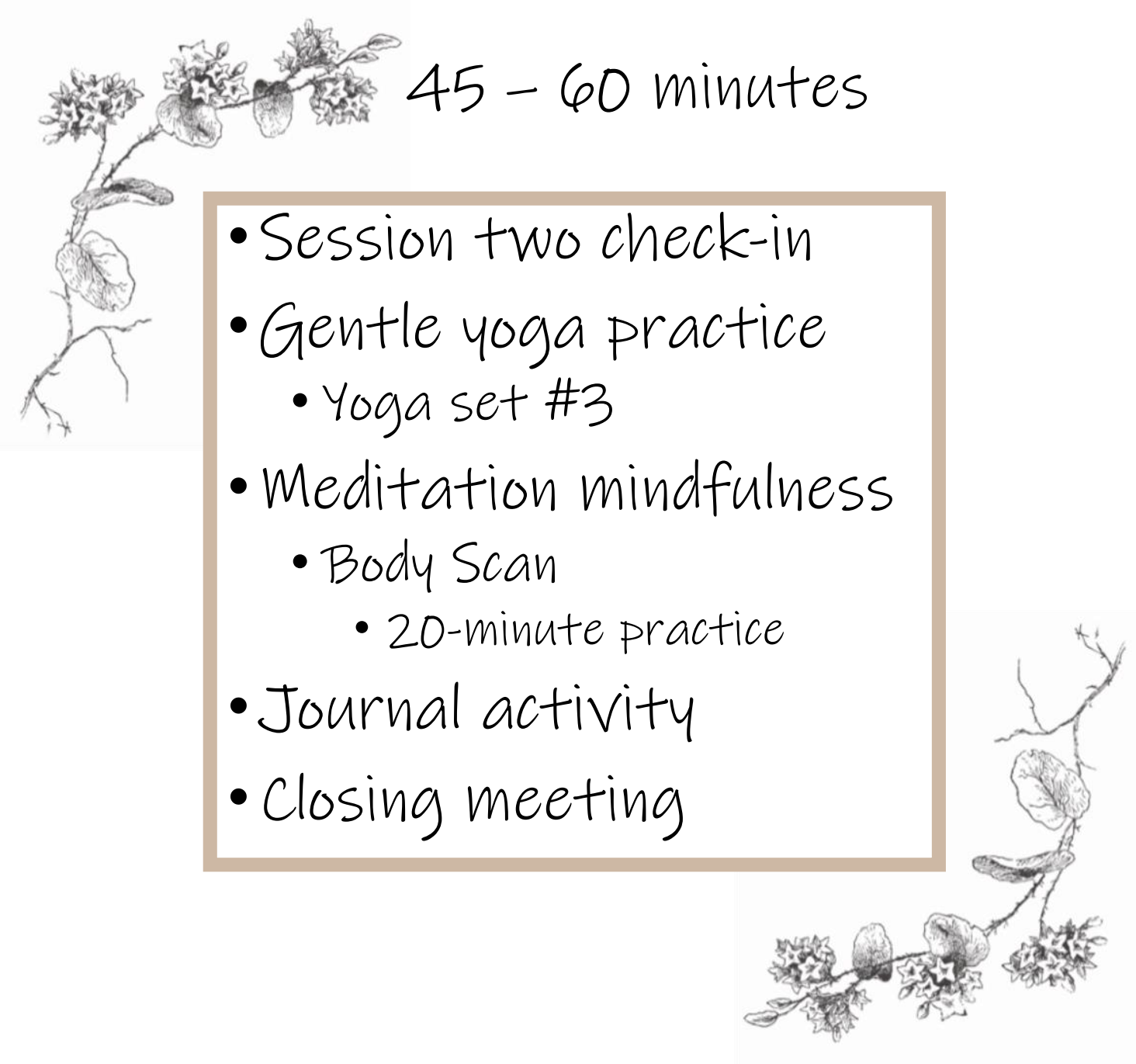


Yoga Se+ 3:

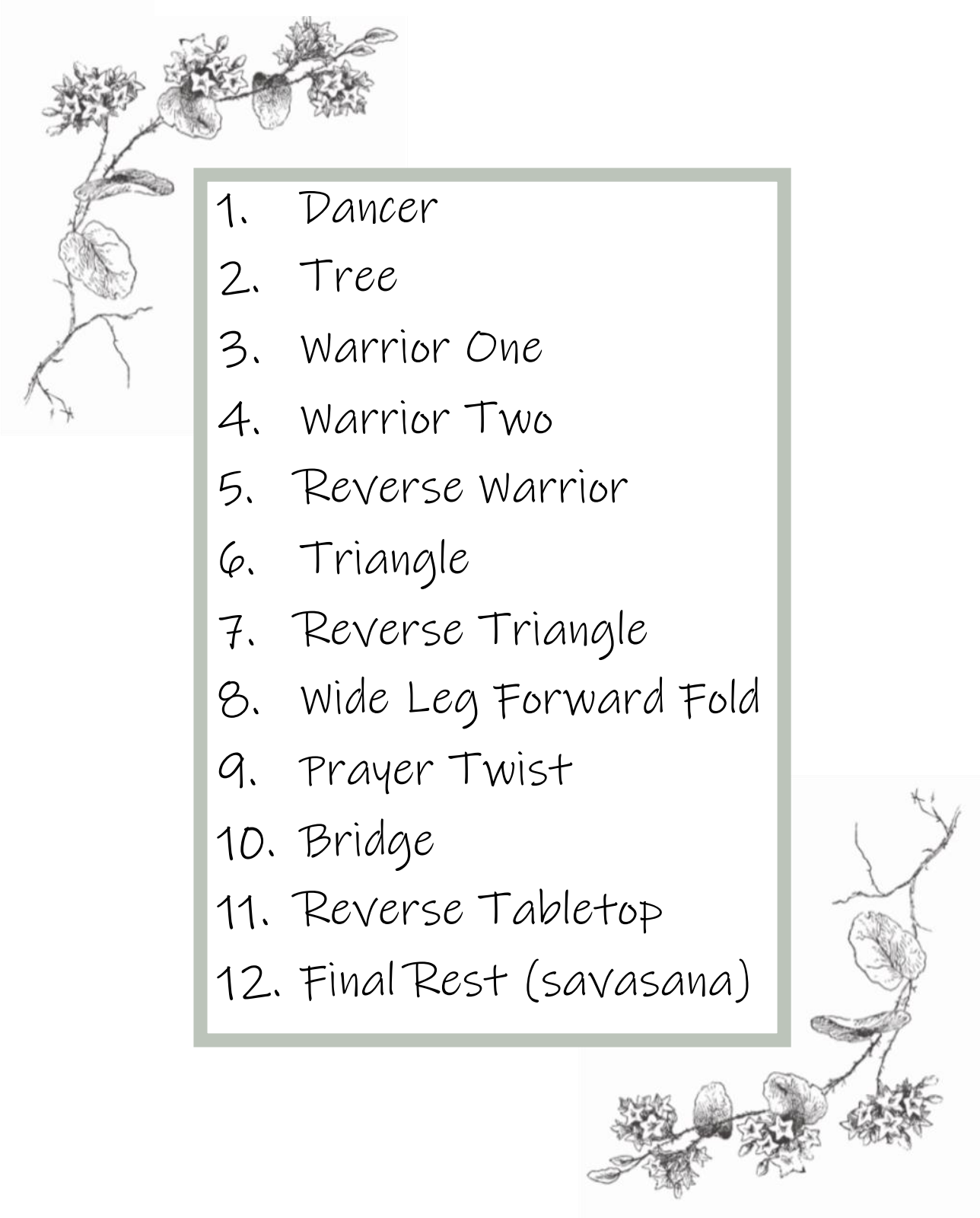




\section{Dancer}

1. Reach back and grab foot or ankle with your thumb facing up

2. Reach the opposite arm high, palm facing your face

3. Gaze forward, neutralize pelvis

4. Breathe in... breathe out...

5. *Repeat on other side*

Notes/adaptations:
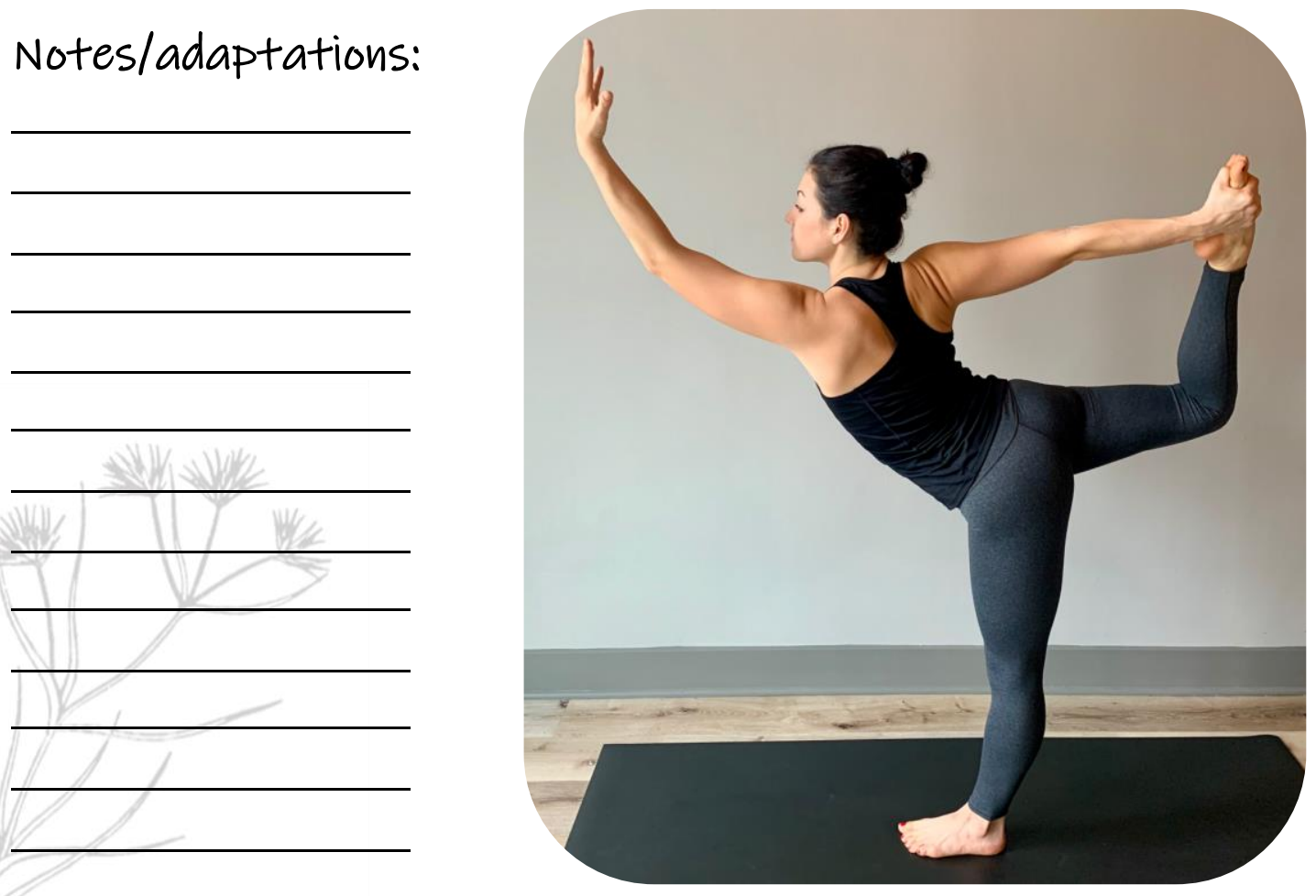


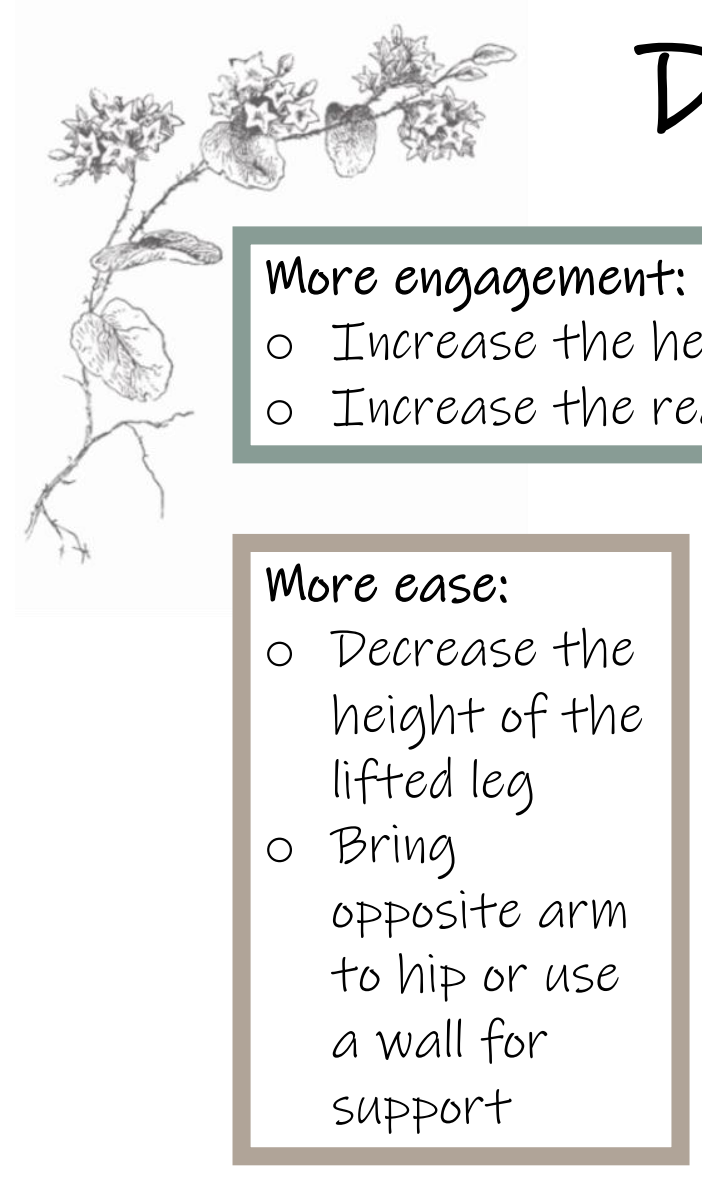

\section{Special}

considerations:

o Bring

softness to

standing knee joints
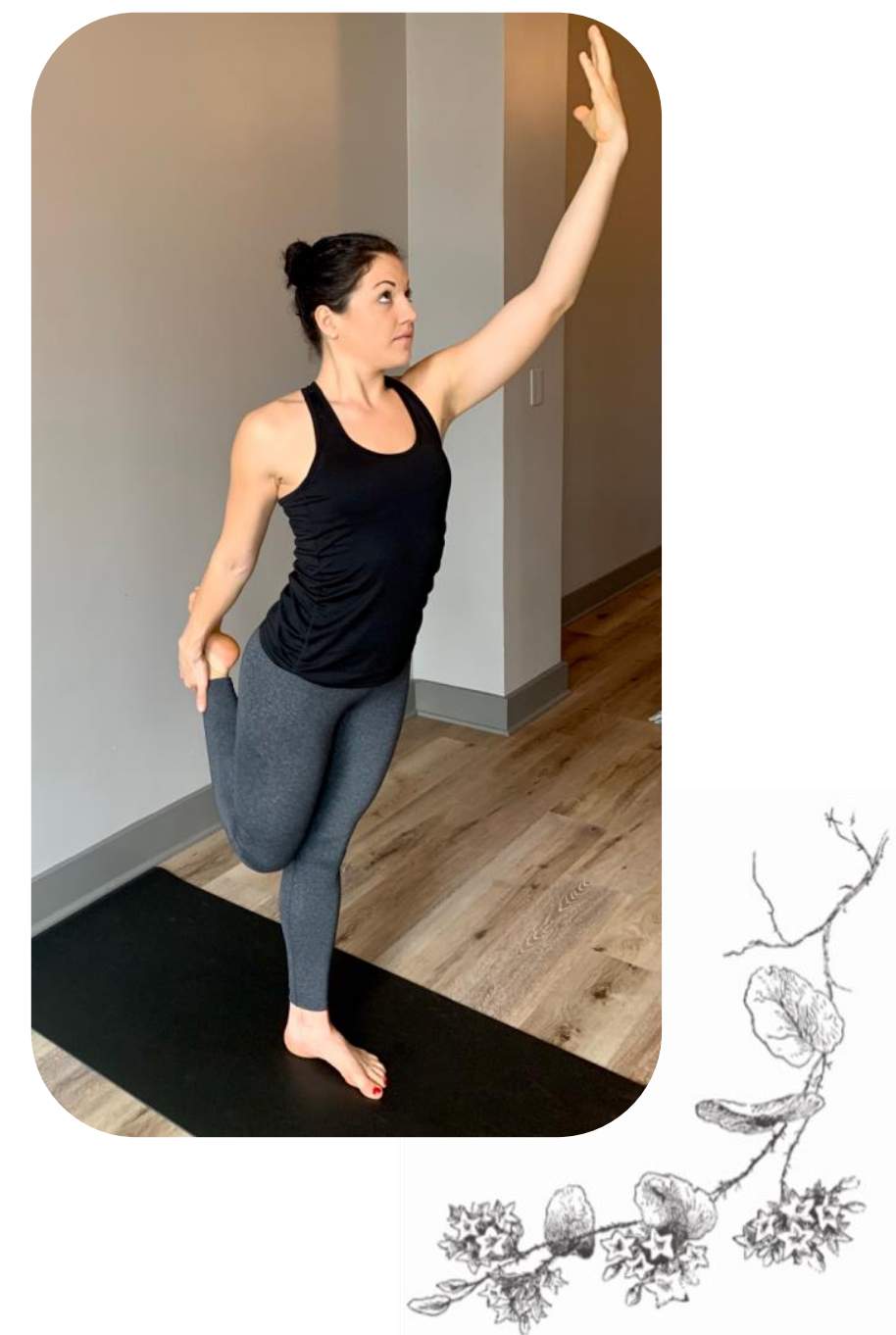

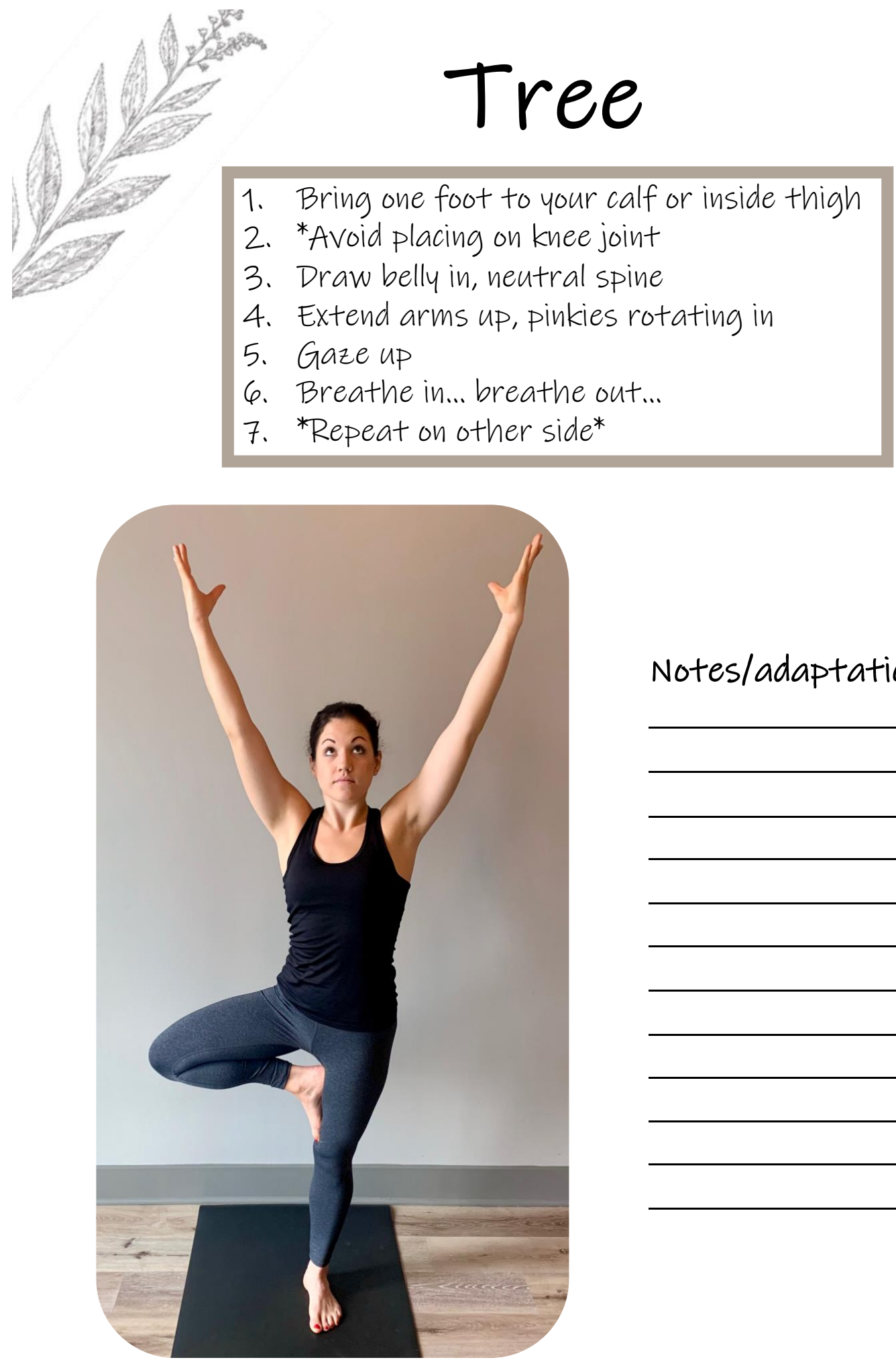

Notes/adaptations: 


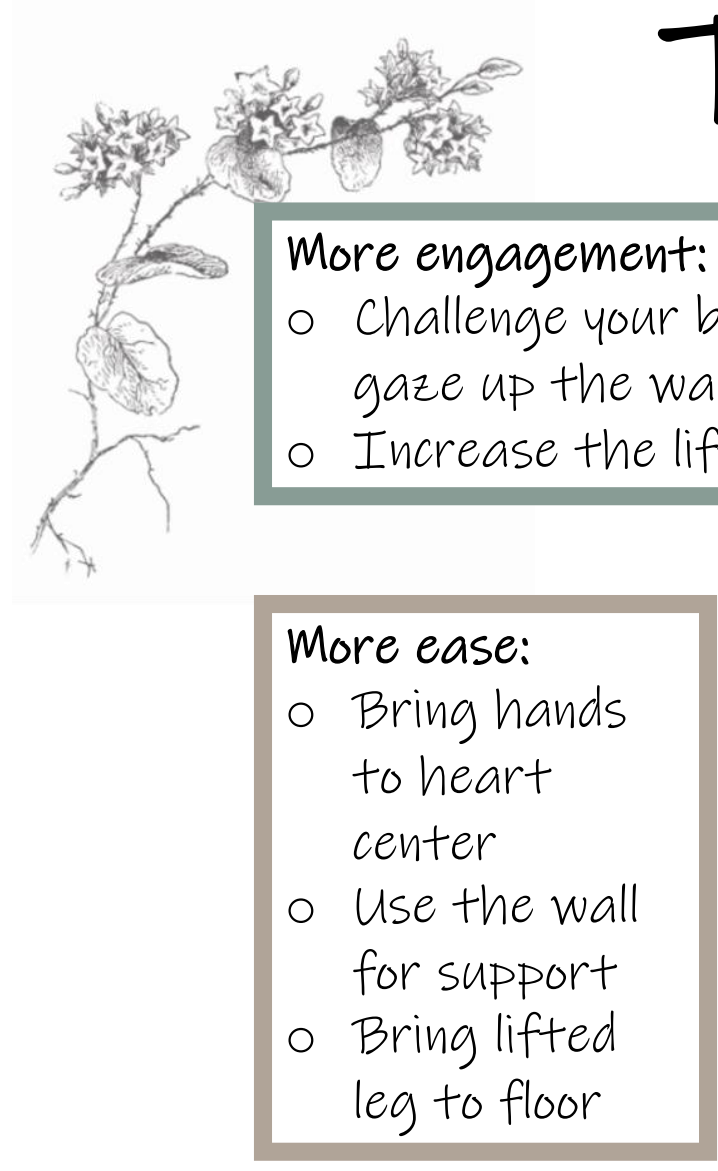

\section{Special}

considerations:

o Bring

softness to

your standing

knee joint

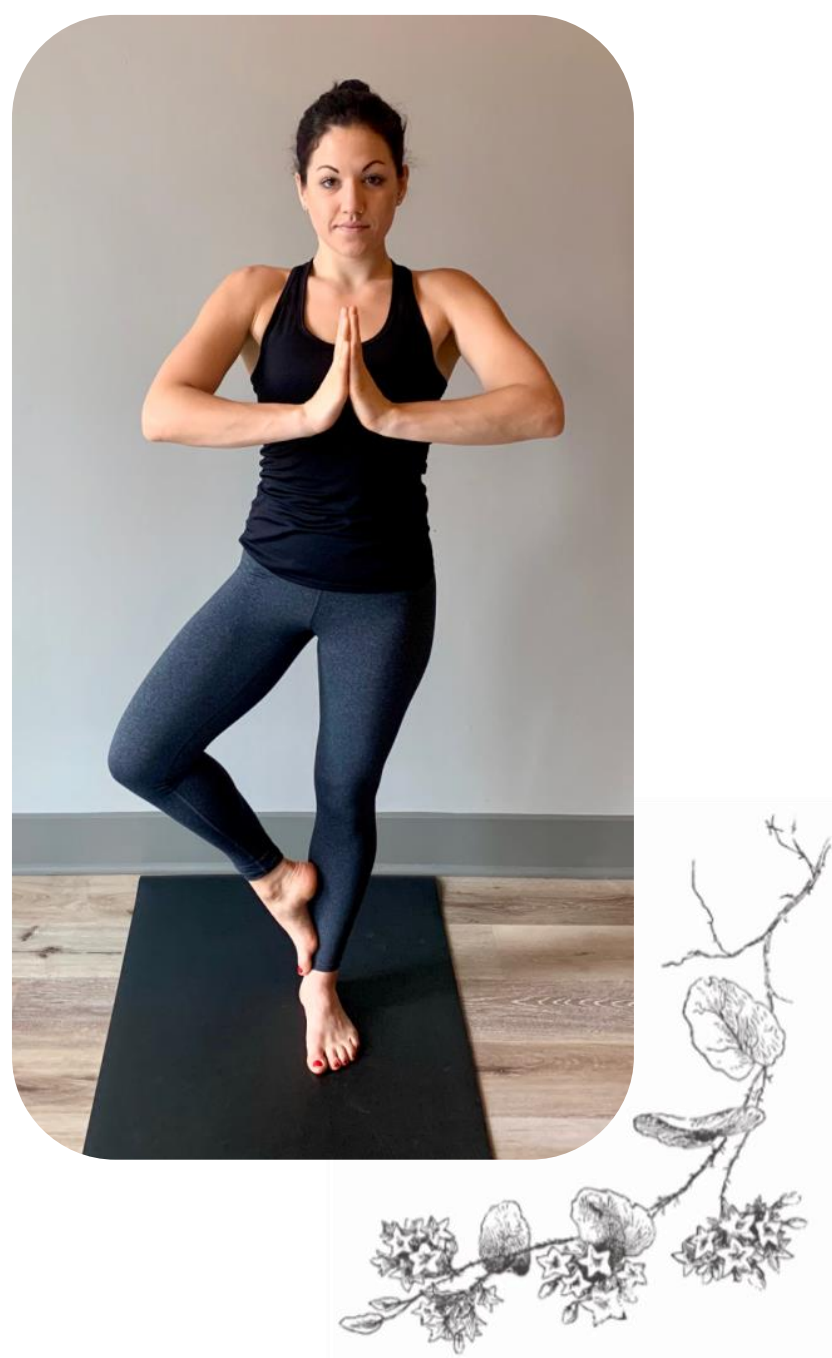




\section{Warrior One}

1. Extend one leg in front, extend the other back with toes facing about 45 degrees forward

2. Bend into front leg, neutralize hips

3. Extend arms up, pinkies rotated in

4. Breathe in... breathe out...

5. *Repeat on other

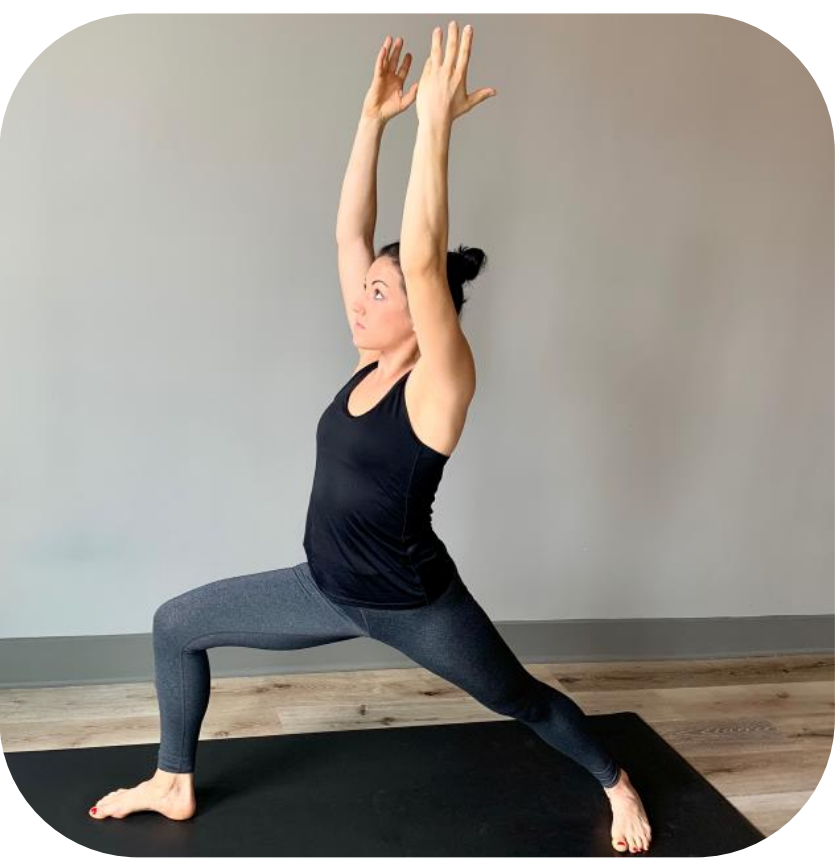
side*

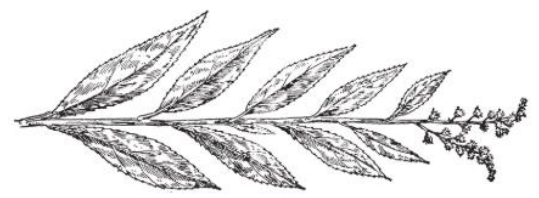

Notes/adaptations: 


\section{Warrior One}

More engagement:

- Increase the bend in front leg, do not bend beyond 90 degrees

- Increase reach in extended arms

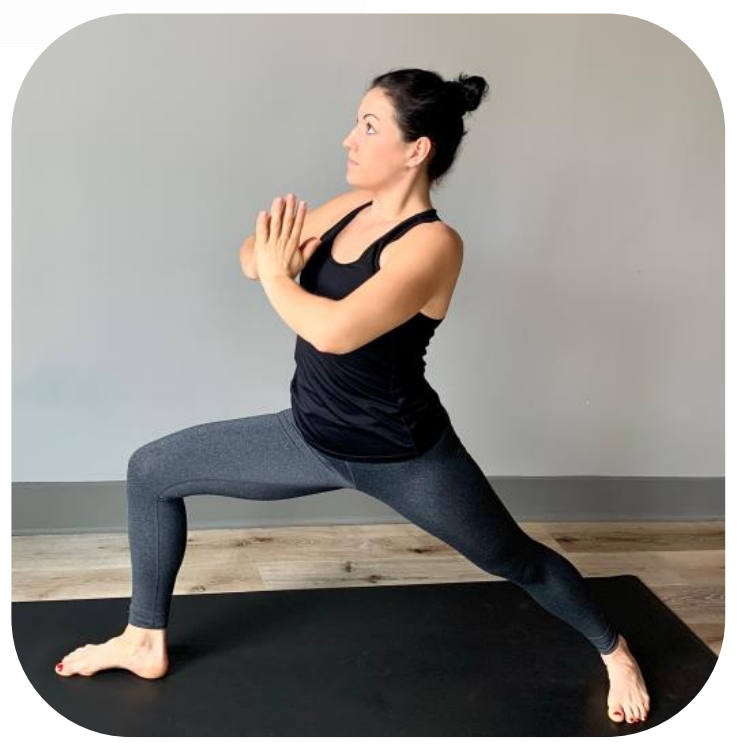

More ease:

- Try a different arm variation Bring hands to heart center or on hips.

- Decrease the bend in front leg

\section{Special considerations:}

- This is a challenging pose that requires core strength and balance

- Focus on the details in this pose to maintain alignment

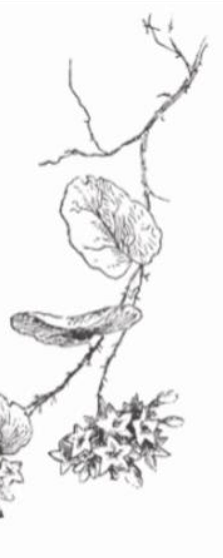




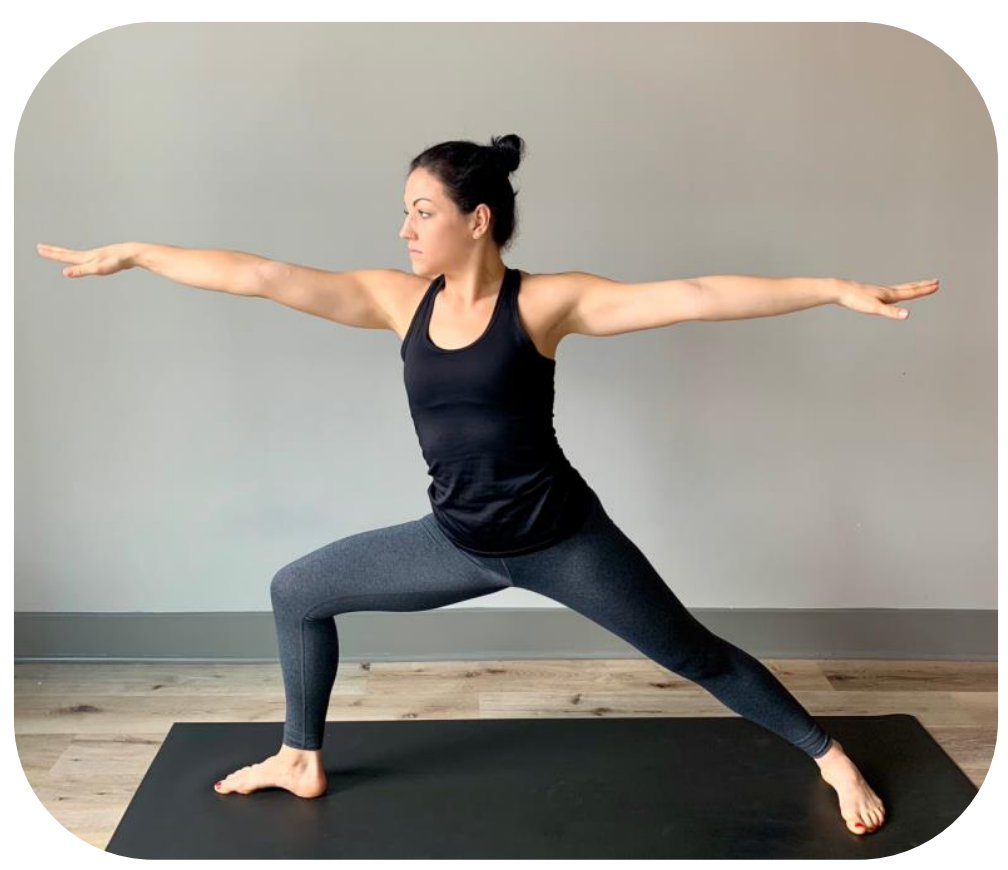

\section{Notes/adaptations:}

1. Open and extend arms out long

2. Rotate hips open

3. Bend into front leg, gaze over fingertips

4. Draw belly in

5. Breathe in... breathe out...

6. *Repeat on other side*

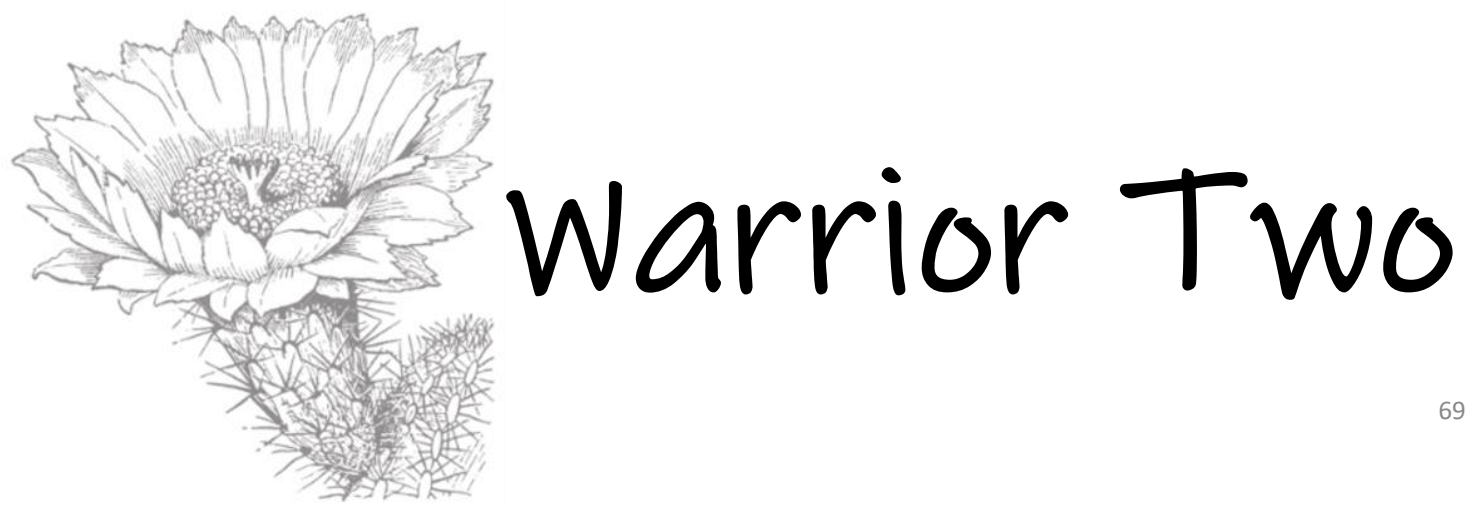




\section{Warrior Two}

More engagement:

- Increase the bend in front leg, do not bend beyond 90 degrees

- Increase reach in extended arms

\section{More ease:}

- Try a different arm variation. Bring hands to heart center or on hips

- Decrease the bend in front leg

\section{Special considerations:}

- This is a challenging pose that requires core strength and balance

- Focus on the details in this pose to maintain alignment 


\section{Reverse Warrior}

1. From Warrior Two on right side (see pg. 69), reach forward with your right arm

2. Then extend right arm up and back

3. Rest left hand on lower back

4. Maintain bend in front leg

5. Breathe in... breathe out...

6. *Repeat on other side*

Notes/adaptations:

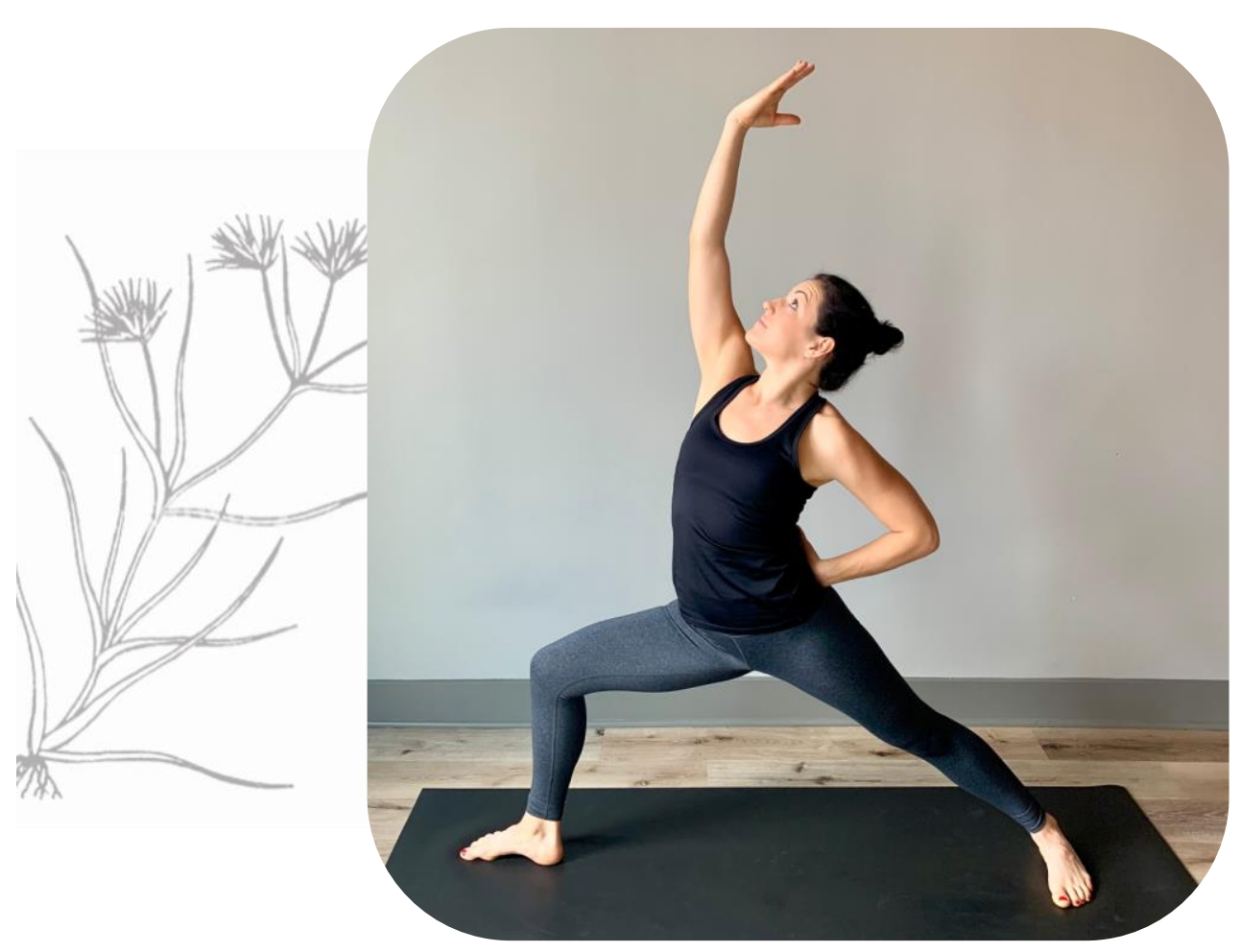




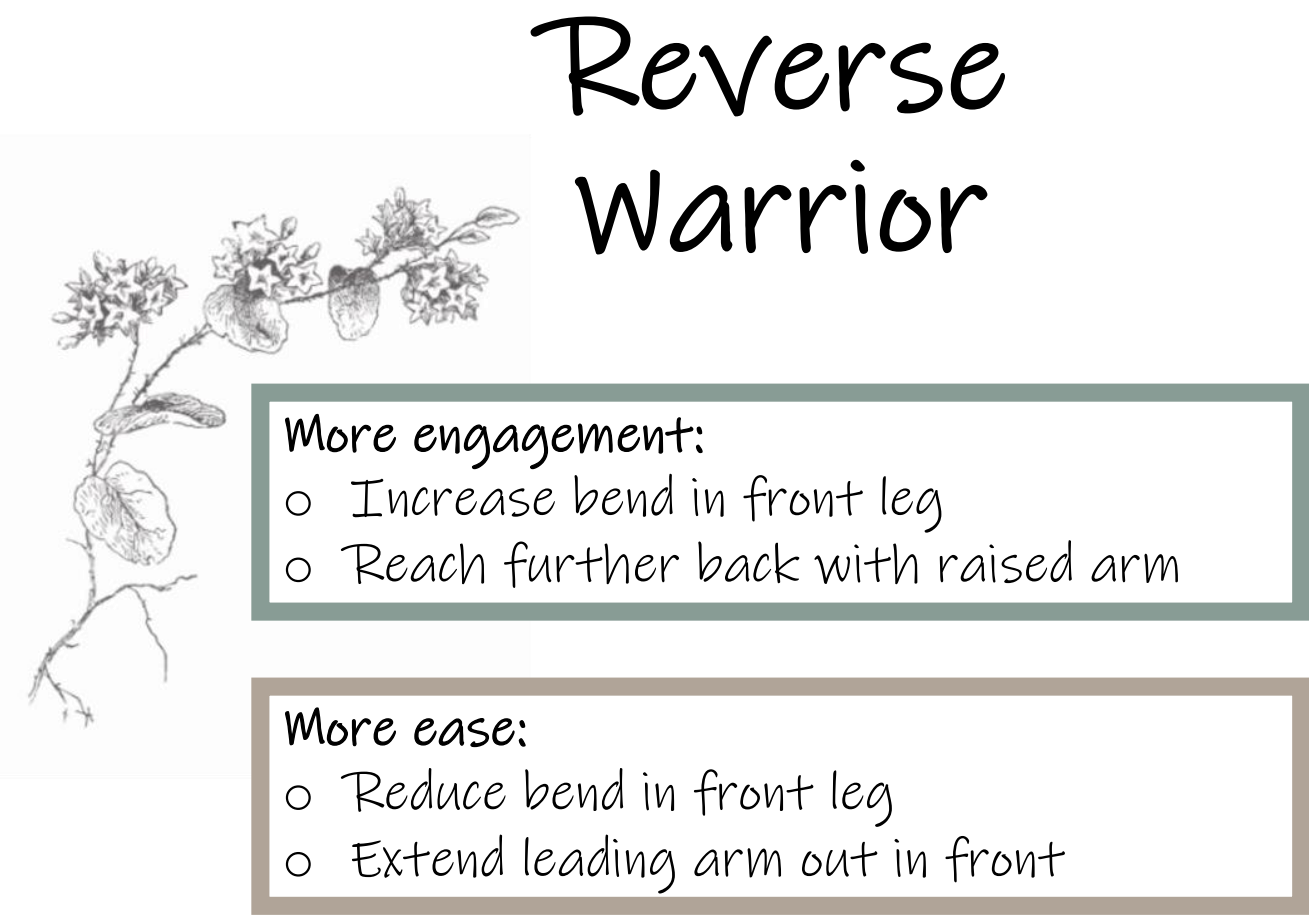

\section{Special considerations:}

- Injuries to shoulder or knee joints might impact this position

- This is a challenging pose that requires core strength and balance

- Focus on the details in this pose to maintain alignment

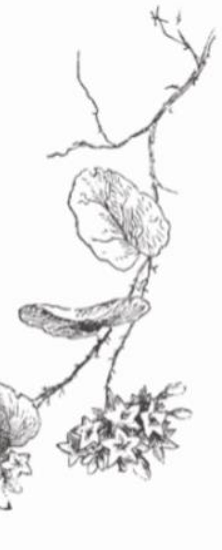




\section{Triangle}

1. Starting in right sided Warrior Two (see pg. 69), extend right leg, reach forward with right arm, and bend at the hips

2. Using blocks as needed, release the right arm toward the mat

3. Gaze upward

4. Breathe in... breathe out...

5. *Repeat on other side*

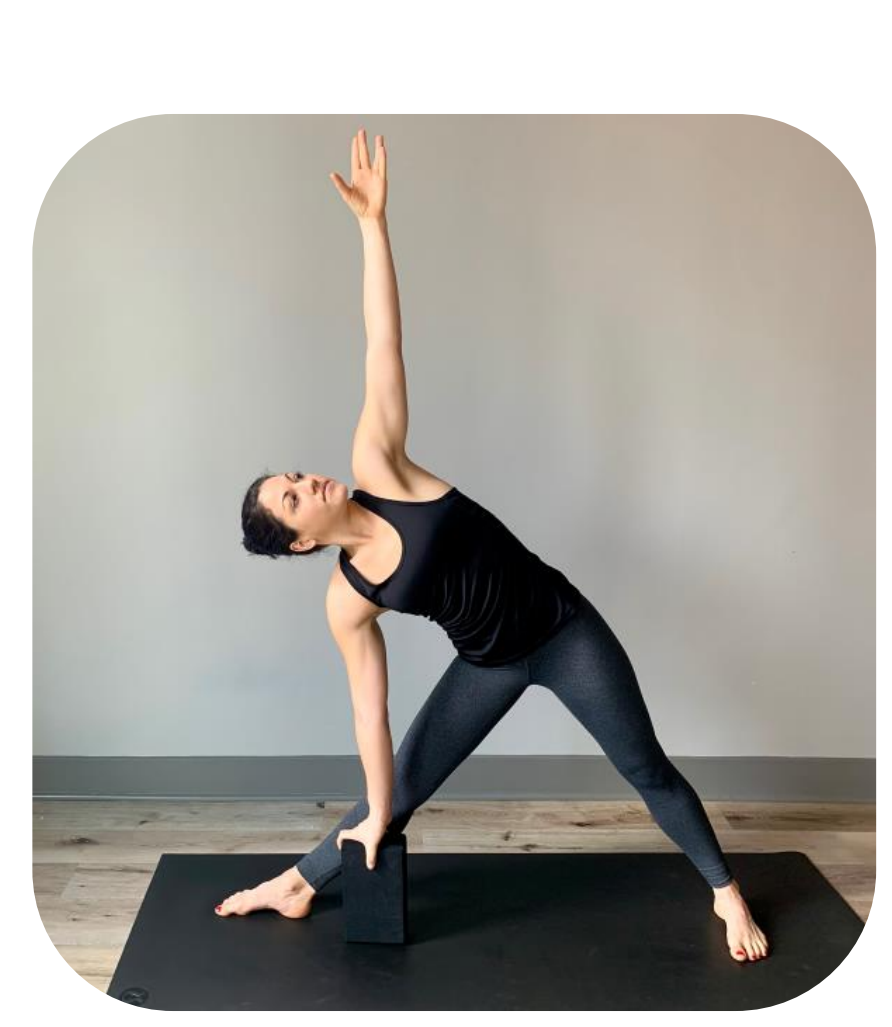

Notes/adaptations: 


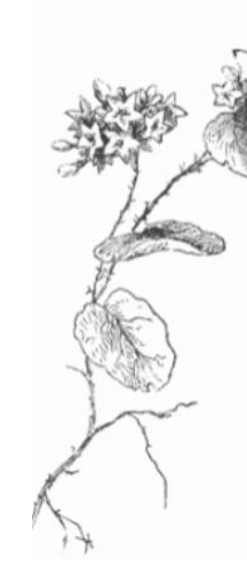

\section{Triangle}

\section{More engagement:}

- Remove the blocks

- Hover arm above the ground for core exercise

- Reach and extend both arms out in opposite directions

\section{More ease:}

- place right arm on thigh for more support

- Use two blocks

- Bring lifted arm to hip

\section{Special considerations:}

- If gazing upward challenges your balance too much, try gazing out in front, keeping your neck neutral

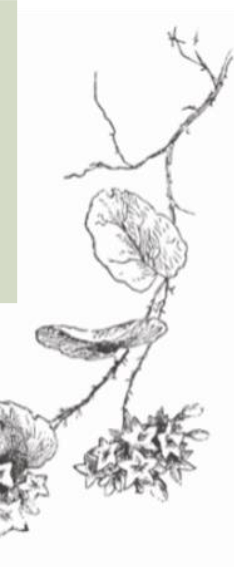




\section{Reverse Triangle}

1. Starting in right sided Triangle (see pg. 73), extend right arm up and back

2. Rest left arm on back of thigh

3. Gaze upward

4. Breathe in... breathe out...

5. *Repeat on other side*
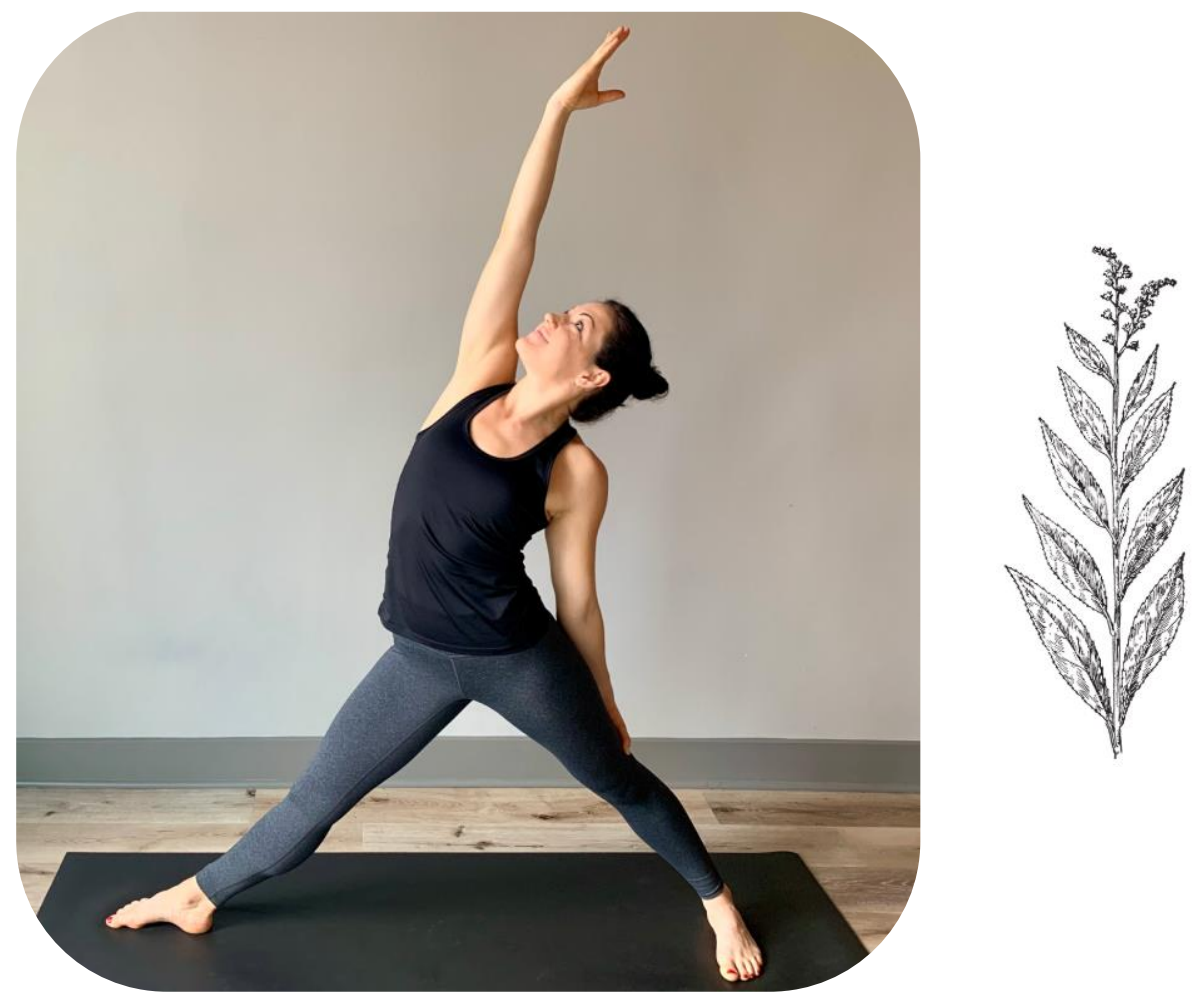

Notes/adaptations: 


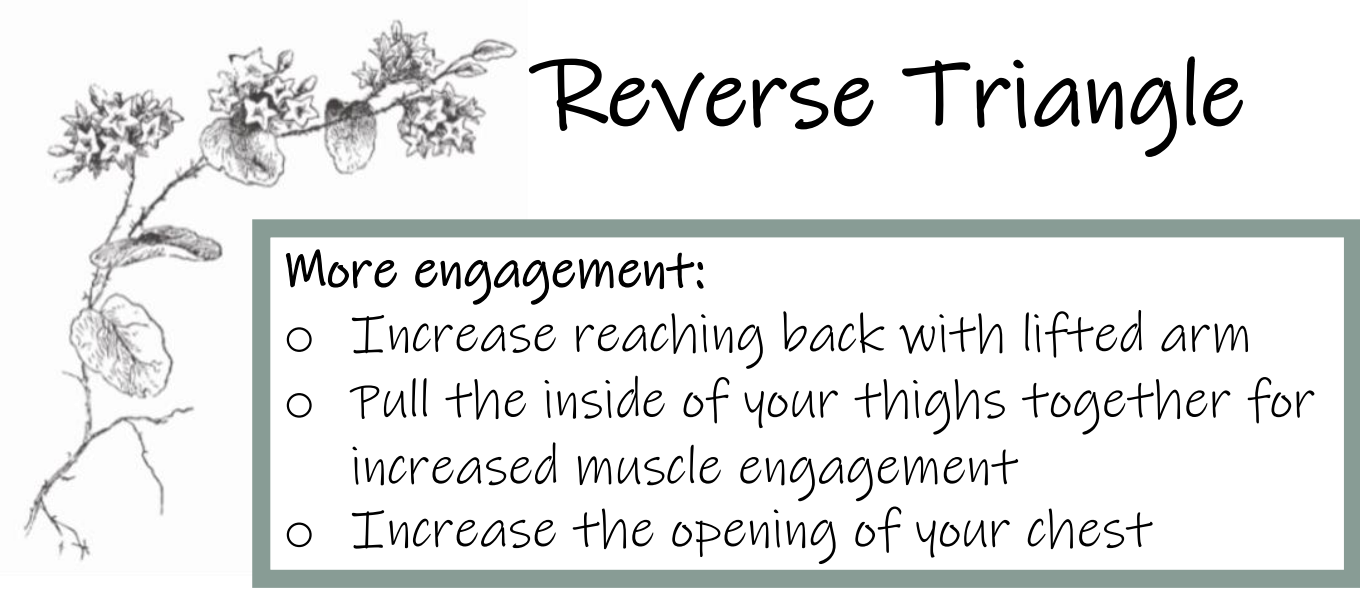

\section{More ease:}

- Decrease the amount of reach in lifted arm

- Bring rested arm to hip

\section{Special considerations:}

- While still engaging muscles, bring softness to your knee joints 


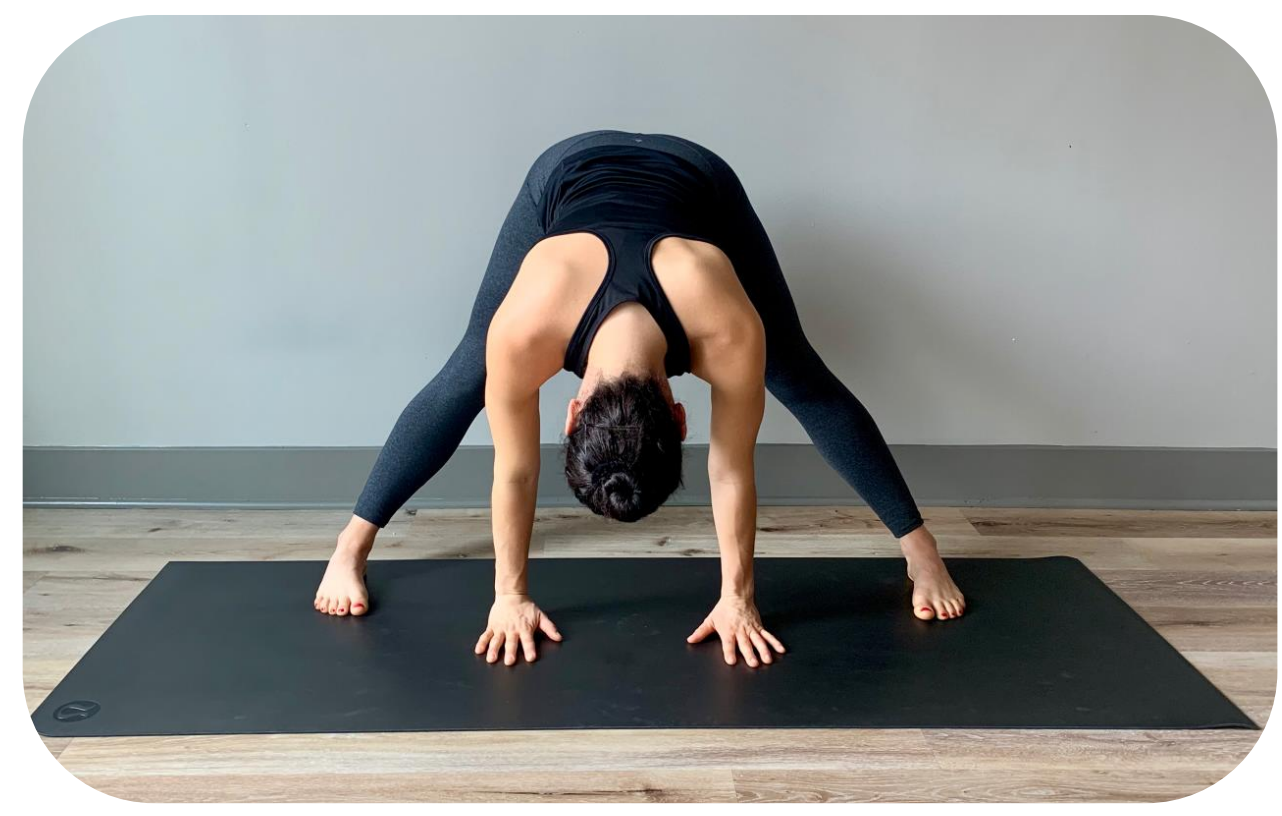

1. Widen your stance, toes pointing straight forward

2. Place your hands on your hips, slowly bend down with neutral spine

Bring hands to the mat and softness to your knees

3. Breathe in... breathe out...

Notes/adaptations:

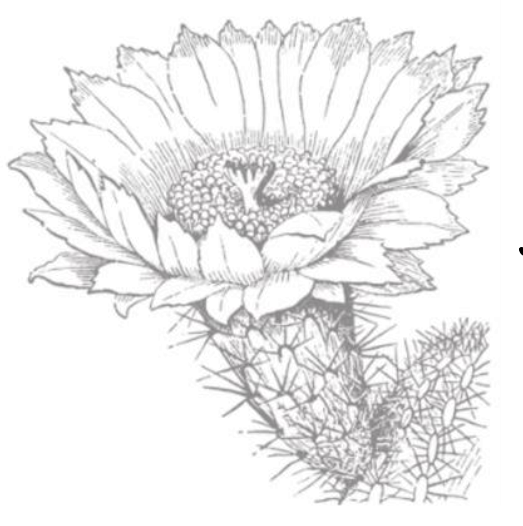

\section{Wide Leg Forward Fold}




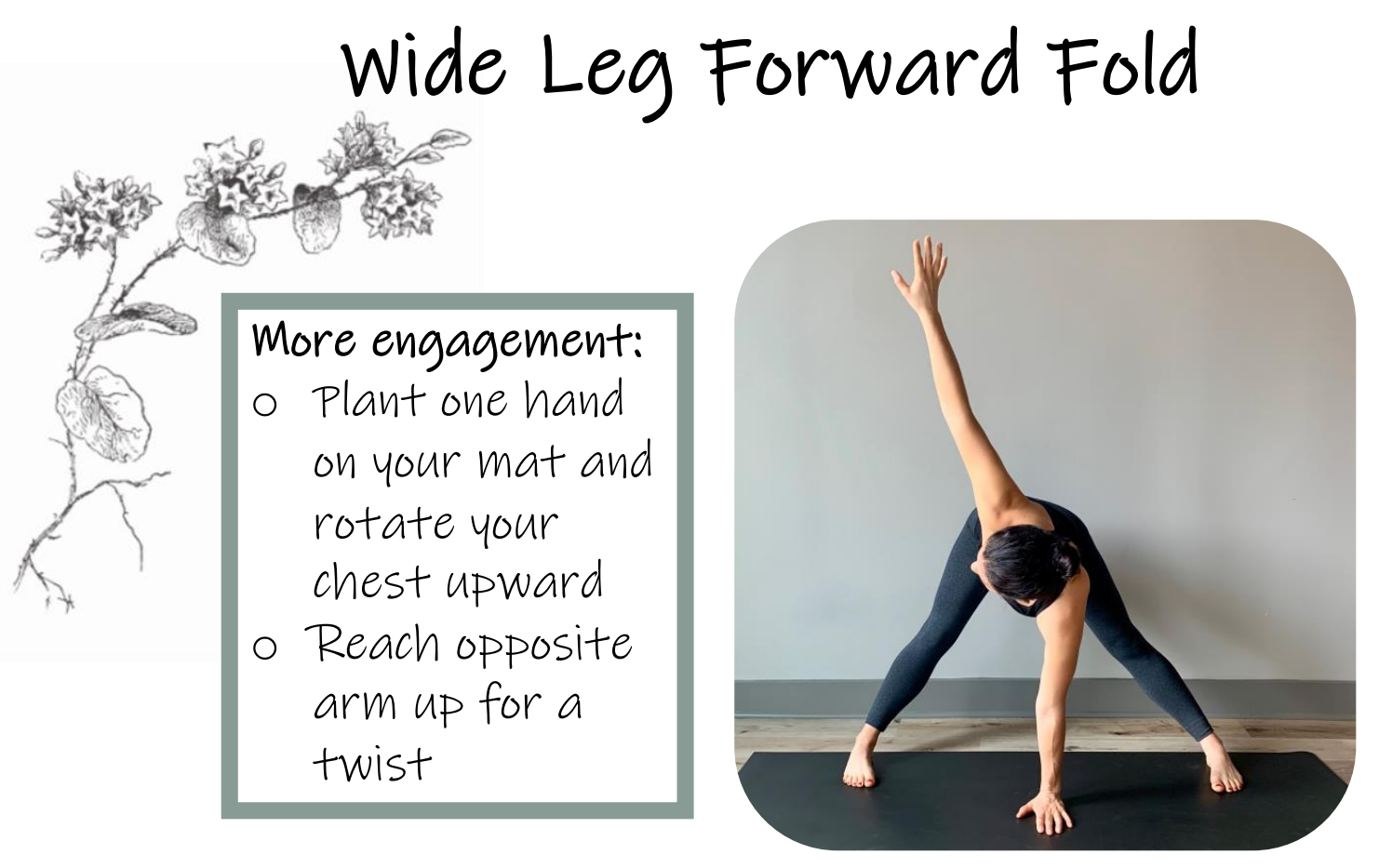

More ease:

- Use a block under hands for more support

- Reduce the amount of bend in hips

\section{Special Considerations:}

- Remember to bring softness to your knee joints

- Move slow when rotating chest

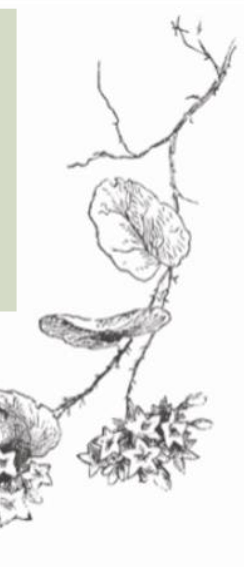




\section{Bridge}

1. Lie on your back with your knees bent and your feet planted on the floor, hips-width distance apart

2. Reach down and make sure your fingertips can touch your heels

3. Raise your hips by pushing into your heels

4. Push into your mat with your palms or clasp under

5. Breathe in... breathe out...

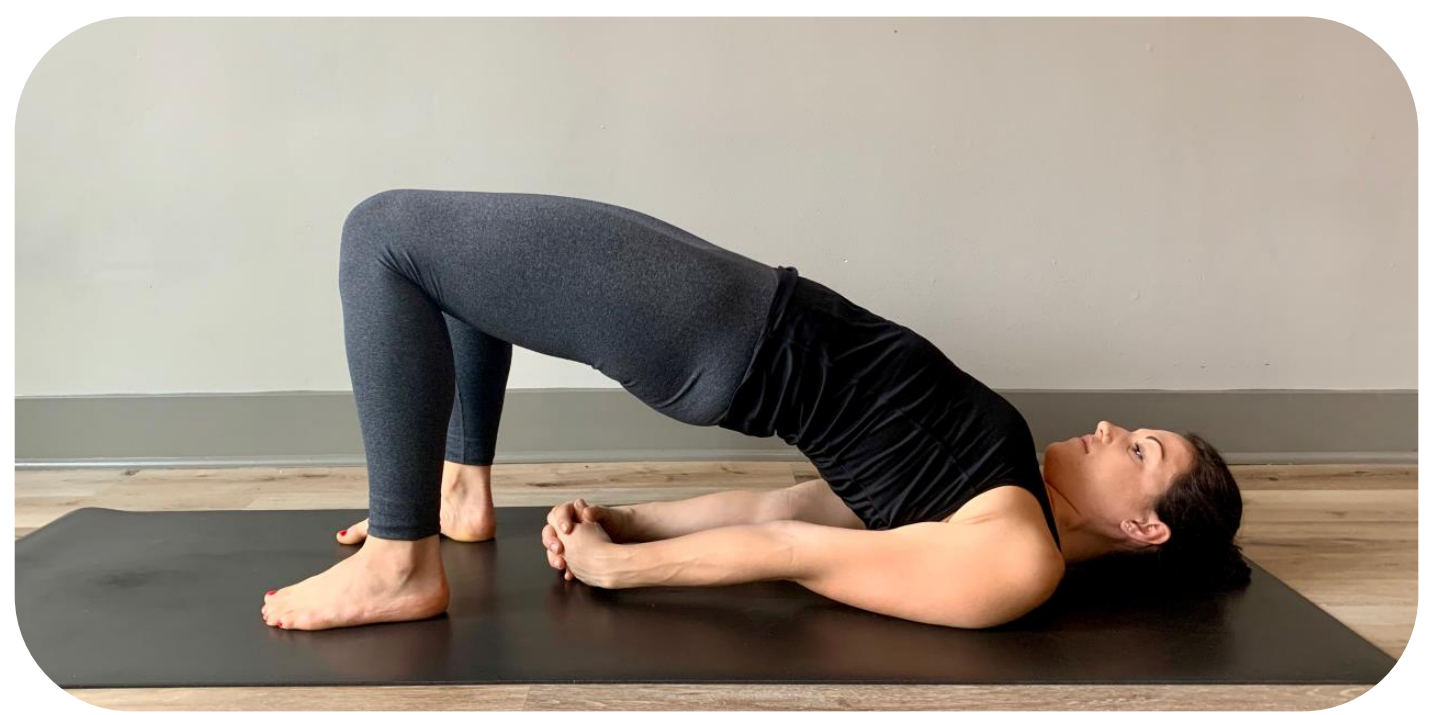

Notes/adaptations: 

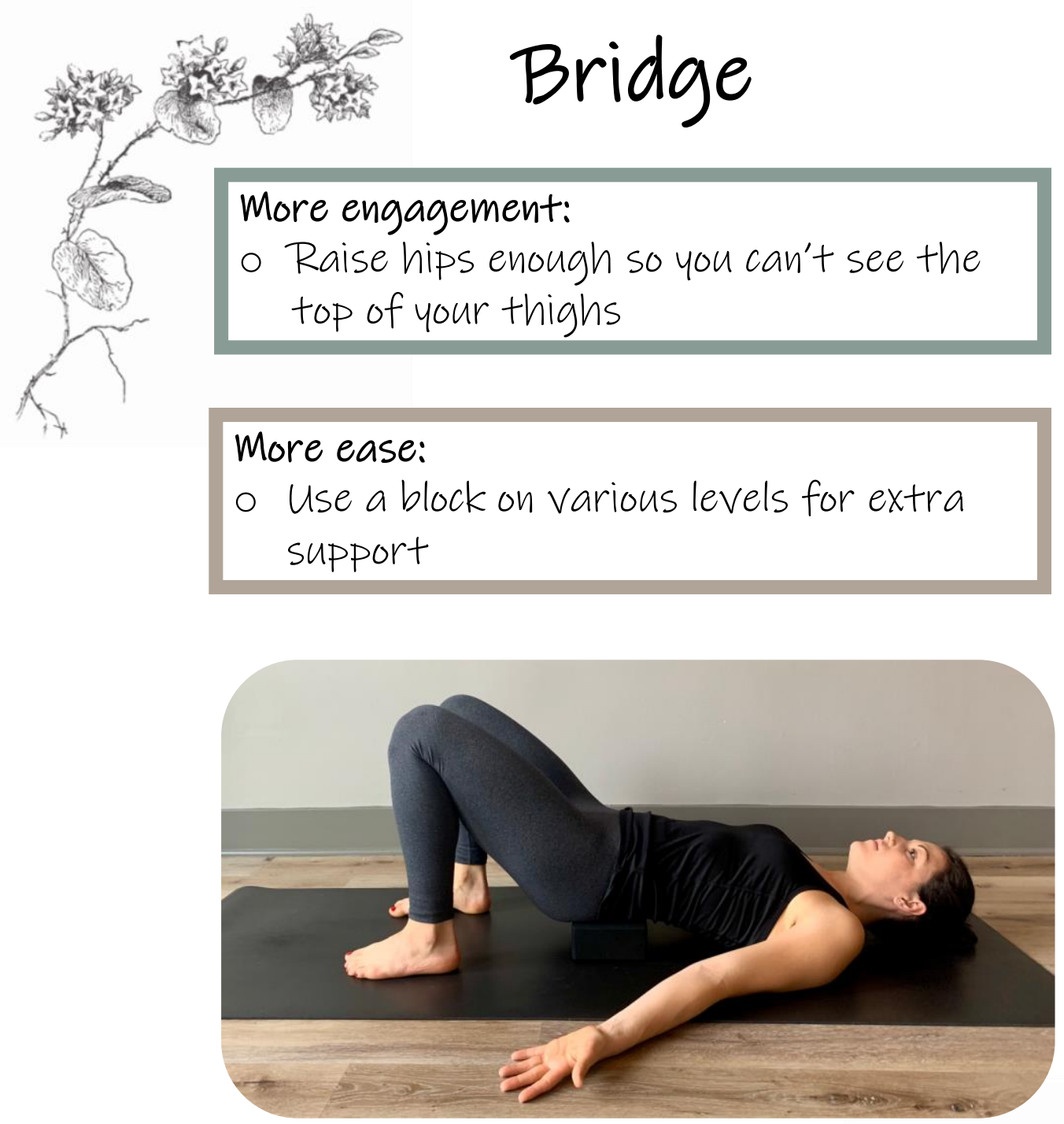

\section{Special considerations:}

- This is a great pose to increase hip flexibility

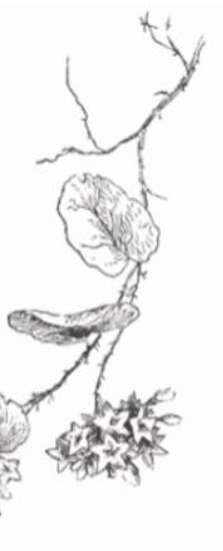




\section{Reverse Tabletop}

1. Starting seated, place palms next to your hips

2. With neutral knees, left hips up

3. Keeping spine neutral, gaze up

4. Breathe in... breathe out...
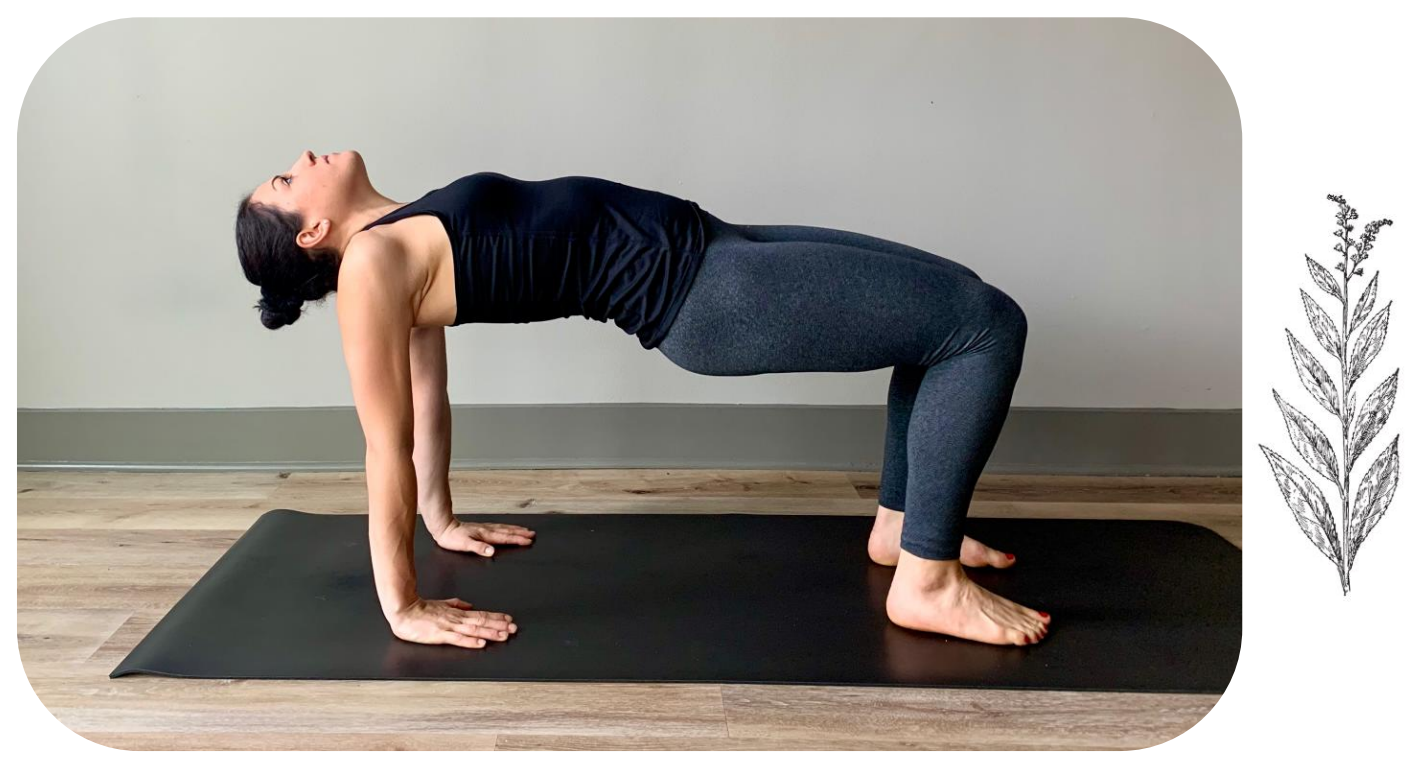

Notes/adaptations: 


\section{Reverse Tabletop}

\section{More engagement:}

- Increase lift in hips

- Try raising one leg at a time for increased difficulty

More ease:

- Use a block or two under hips for extra support

- Reduce the lift in hips

\section{Special considerations:}

- Injuries to shoulder joints, wrists, knees, or hips might impact this position

- Post-mastectomy individuals should consider their range of motion restrictions

- Remember to slowly and gently extend neck back

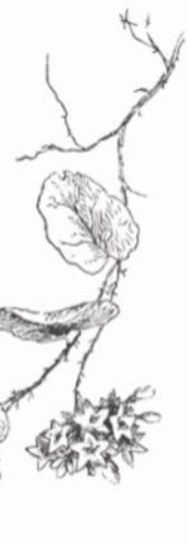




\section{Final Rest (savasana)}

1. Extend legs long

2. Bring palms up and close your eyes

3. Relax breathing

4. Rest for 3-5 minutes
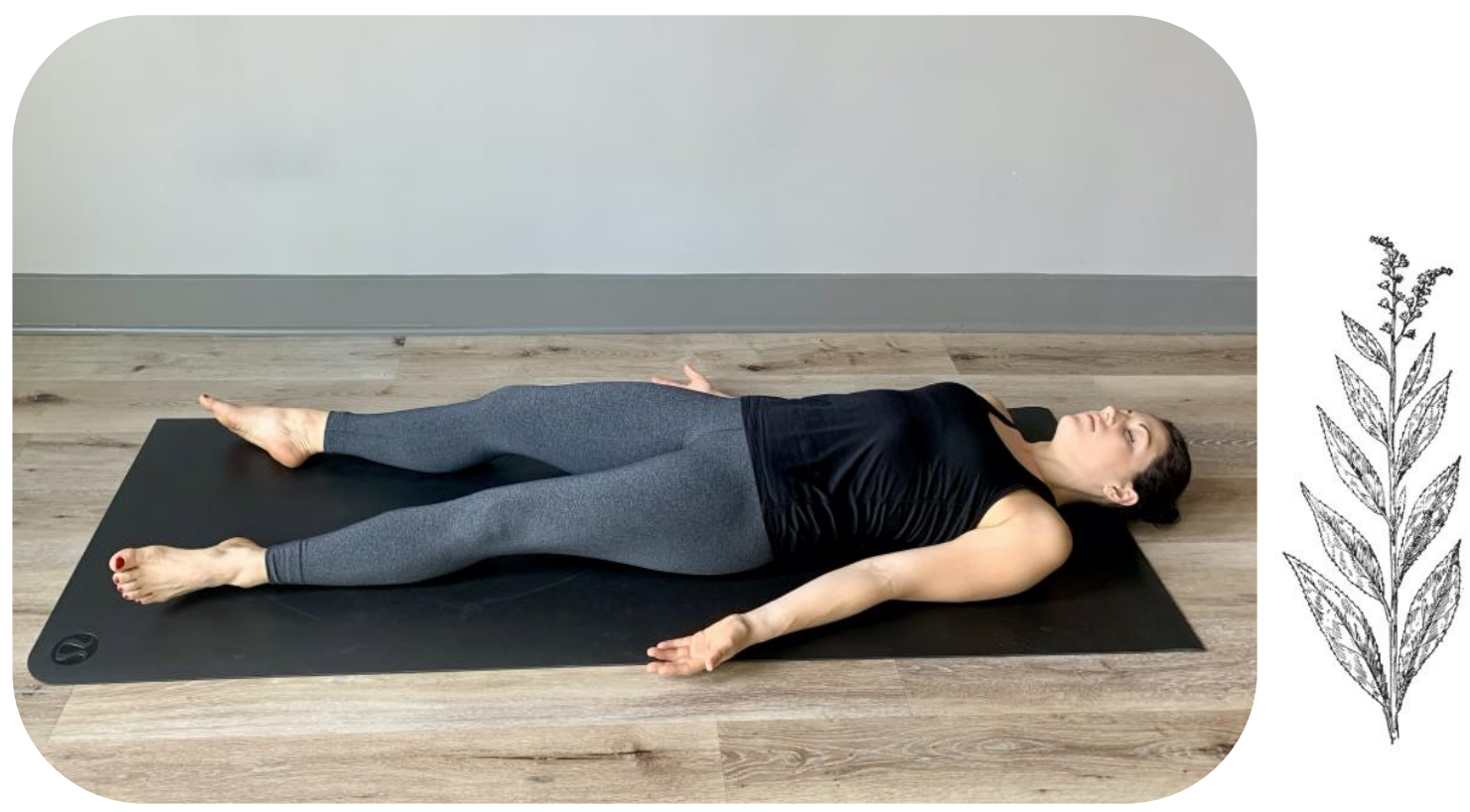

Notes/adaptations: 


\section{Body Scan Script}

\section{Read by the occupational therapist:}

Begin by making yourself comfortable. Sit in a chair and allow your back to be straight, but not stiff, with your feet on the ground. You could also do this practice standing. Or if you prefer, you can lie down and have your head supported. Your hands could be resting gently in your lap or at your side. Allow your eyes to close or to remain open with a soft gaze.

Take several long, slow, deep breaths. Breathing in fully and exhaling slowly. Breathe in through your nose and out through your nose or mouth. Feel your stomach expand on an inhale and relax and let go as you exhale.

Begin to let go of noises around you. Begin to shift your attention from outside to inside yourself. If you are distracted by sounds in the room, simply notice this and bring your focus back to your breathing.

Now slowly bring your attention down to your feet. Begin observing sensations in your feet. You might want to wiggle your toes a little, feeling your toes against your socks or shoes. Just notice, without judgment. You might imagine sending your breath down to your feet, as if the breath is traveling through the nose to the lungs and through the abdomen all the way down to your feet. And then back up again out through your nose and lungs. Perhaps you don't feel anything at all.

That is fine, too. Just allow yourself to feel the sensation of not feeling anything.

When you are ready, allow your feet to dissolve in your mind's eye and move your attention up to your ankles, calves, knees, and thighs. Observe the sensations you are experiencing throughout your legs. Breathe into and breathe out of the legs. If your mind begins to wander during this exercise, gently notice this without judgment and bring your mind back to noticing the sensations in your legs. If you notice any discomfort, pain or stiffness, don't judge this. Just simply notice it. observe how all sensations rise and fall, shift and change moment to moment. Notice how no sensation is permanent. Just observe and allow the sensations to be in the moment, just as they are. Breathe into and out from the legs.

Then on the next out breath, allow the legs to dissolve in your mind and move to the sensations in your lower back and pelvis. Softening and releasing as you breathe in and out. Slowly move your attention up to your mid back and upper back. Become curious about the sensations here. You may become aware of sensations in the muscle, temperature, or points of contact with furniture or the bed. With each outbreath, you may let go of tension you are carrying. 
And then very gently shift your focus to your stomach and all the internal organs here. Perhaps you notice the feeling of clothing, the process of digestion or the belly rising or falling with each breath. If you notice opinions arising about these areas, gently let these go and return to noticing sensations. As you continue to breathe, bring your awareness to the chest and heart region and just notice your heartbeat. Observe how the chest rises during the inhale and how the chest falls during the exhale. Let go of any judgments that may arise. On the next outbreath, shift the focus to your hands and fingertips. See if you can channel your breathing into and out of this area as if you are breathing into and out from your hands. If your mind wanders, gently bring it back to the sensations in your hands.

And then, on the next outbreath, shift the focus and bring your awareness up into your arms. Observe the sensations or lack of sensations that may be occurring there. You might notice some difference between the left arm and the right arm - no need to judge this. As you exhale, you may experience the arm soften and release tensions. Continue to breathe and shift focus to the neck, shoulder and throat region. This is an area where we often have tension. Be with the sensations here. It could be tightness, rigidity or holding. You may notice the shoulders moving along with the breath. Let go of any thoughts or stories you are telling yourself about this area. As you breathe, you may feel tension rolling off your shoulders.

On the next outbreath, shift your focus and direct your attention to the scalp, head and face. Observe all the sensations occurring there. Notice the movement of the air as you breathe into or out of the nostrils or mouth. As you exhale, you might notice the softening of any tension you may be holding.

And now, let your attention to expand out to include the entire body as a whole. Bring into your awareness the top of your head down to the bottom of your toes. Feel the gentle rhythm of the breath as it moves through the body. As you come to the end of this practice, take a full, deep breath, taking in all the energy of this practice. Exhale fully. And when you are ready, open your eyes and return your attention to the present moment. As you become fully alert and awake, consider setting the intention that this practice of building awareness will benefit everyone you come in contact with today.

Script written by Shilagh Mirgain, PhD, for Uw

Cultivating Well-Being: A Neuroscientific

Approach 


\section{Write and Release}

Where am I most present?

Where am I least present?

How is my quality and amount of sleep?

Who or what in my life is grounding? 


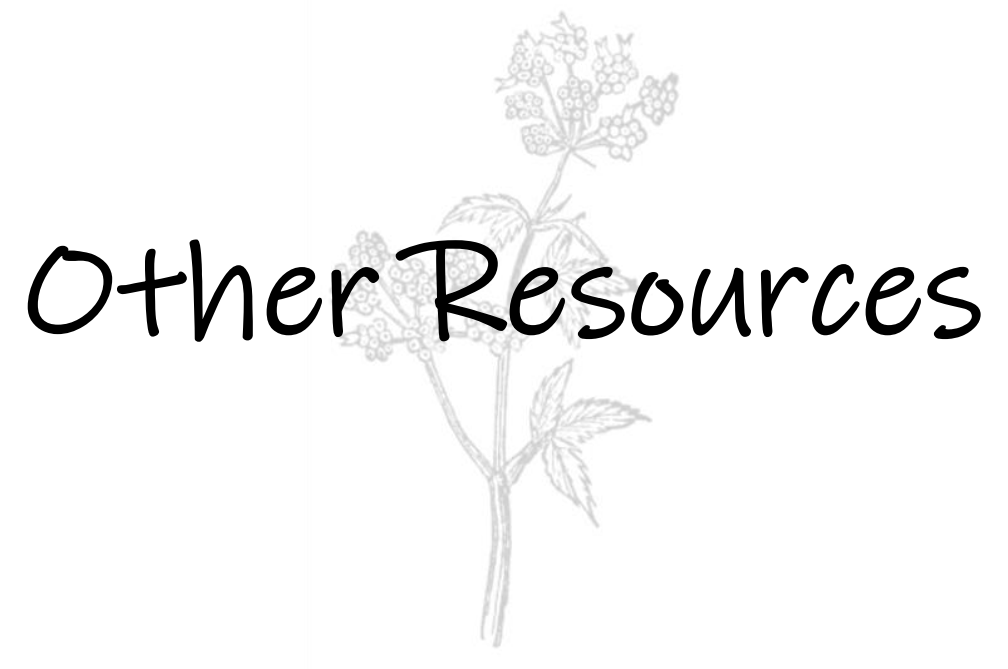




\section{Butterfly Breathing for Kiddos}

children can learn how to slow and deepen their breath by following tracing the butterfly with their finger. Starting in the center, follow the arrows to the left while taking a slow and deep breath in through your nose. Try to inhale for the length of the circle. Then follow the pattern to the right while slowly releasing your breath through your mouth. Repeat for five cycles.

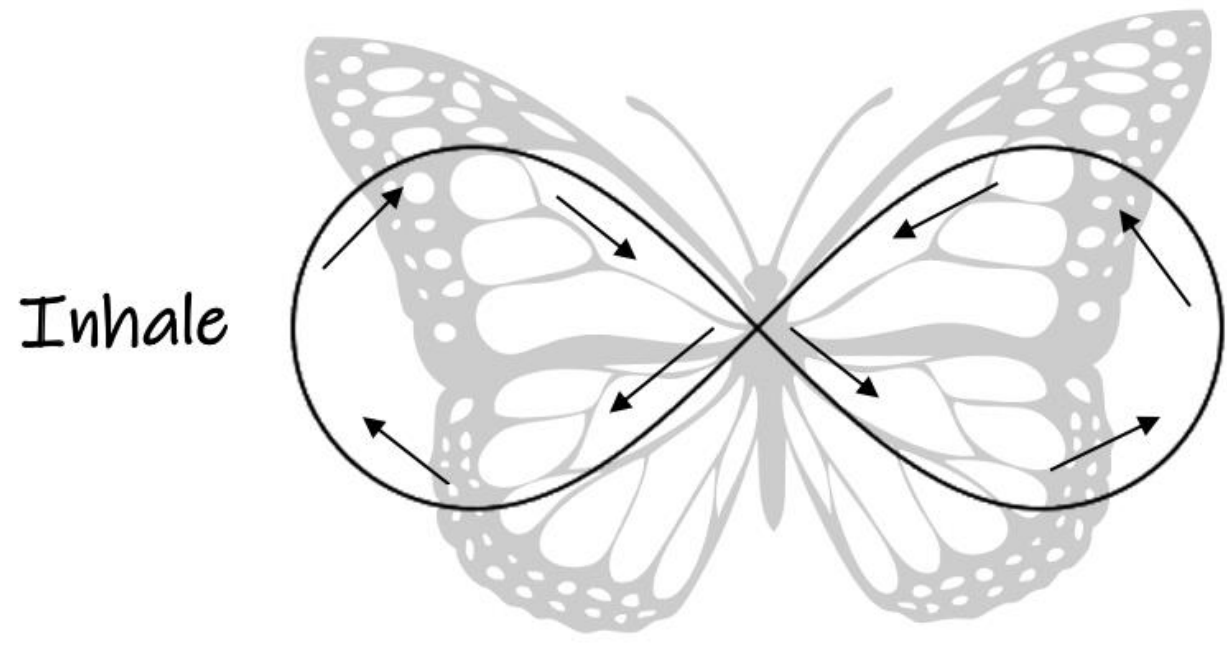

Exhale 


\section{Rest}

Rest is essential to your well-being. It comes in many forms, and it's often hard for us as a parent to take time to rest.

Here are a few alternative suggestions:

1. Time away

2. Permission to not be helpful

3. Something "unproductive"

4. connecting to art + nature

5. Solitude to recharge

6. Break from responsibilities

7. Stillness to decompress

8. Quiet space to write

9. Alone time at home 


\section{Additional seated poses:}

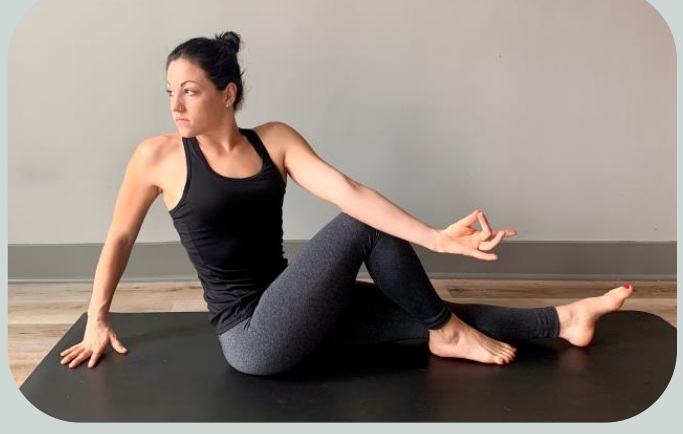

Seated Twist

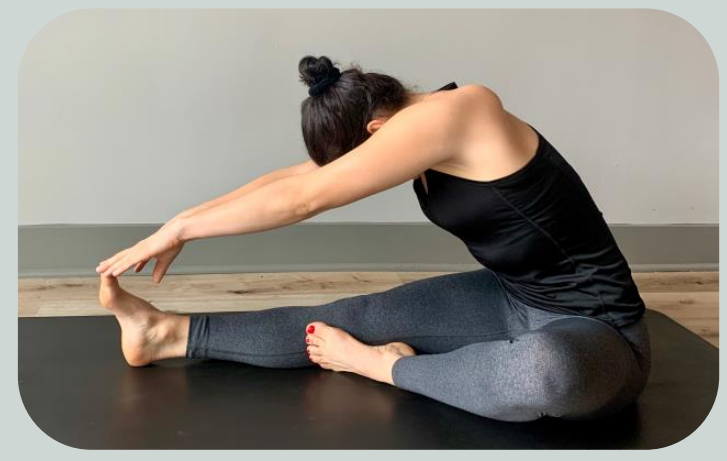

Single-Leg Forward Fold
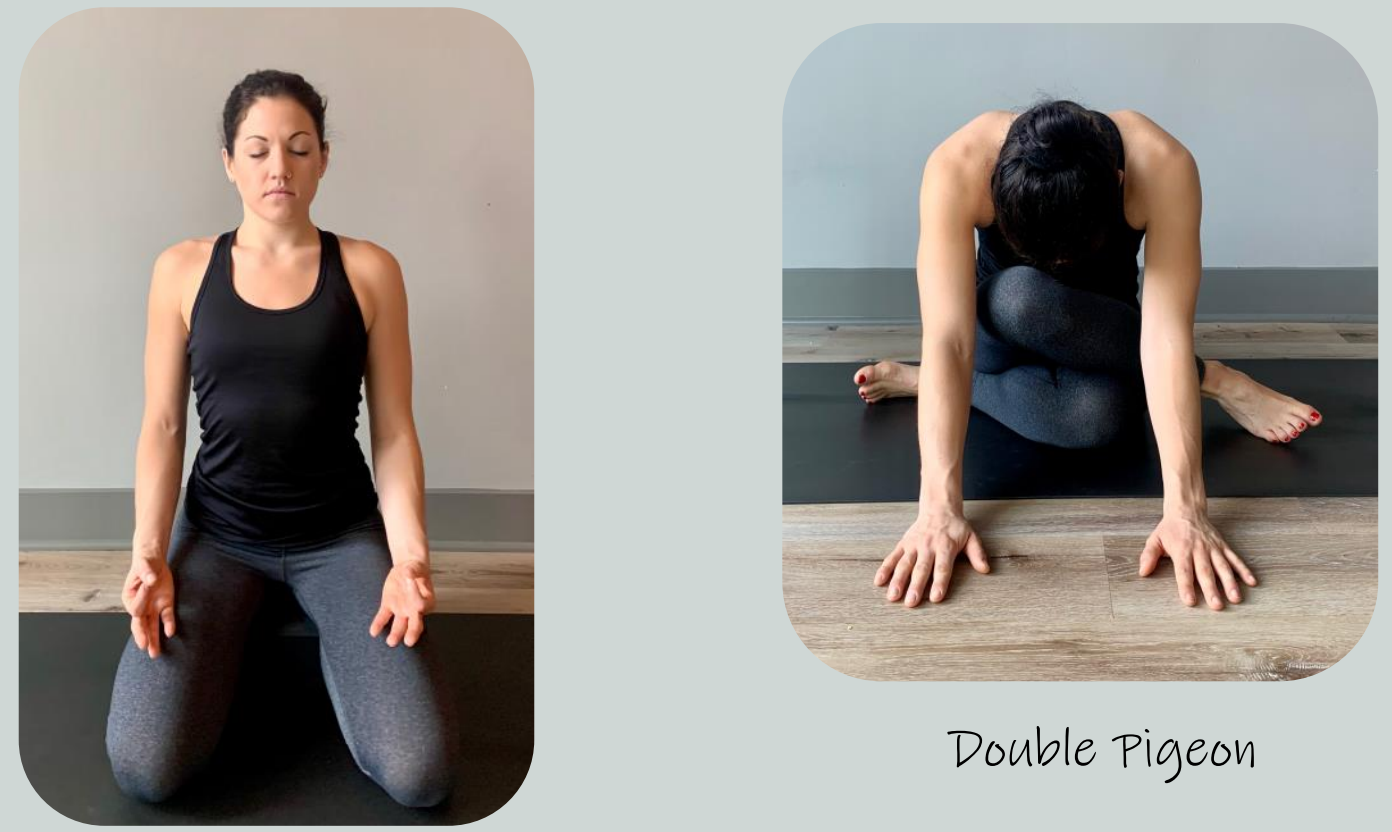

Double Pigeon

Hero 


\section{Additional standing poses:}

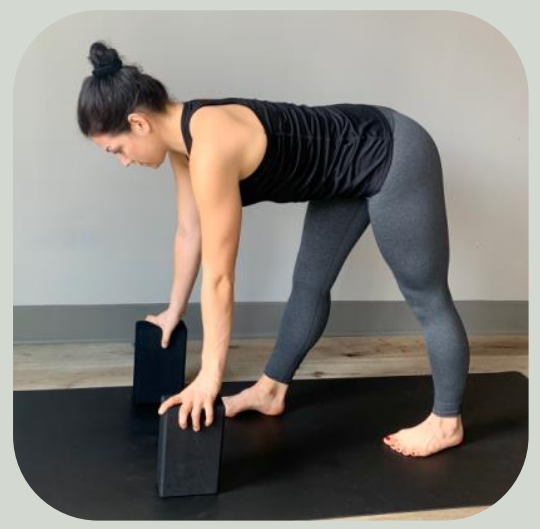

Supported Pyramid
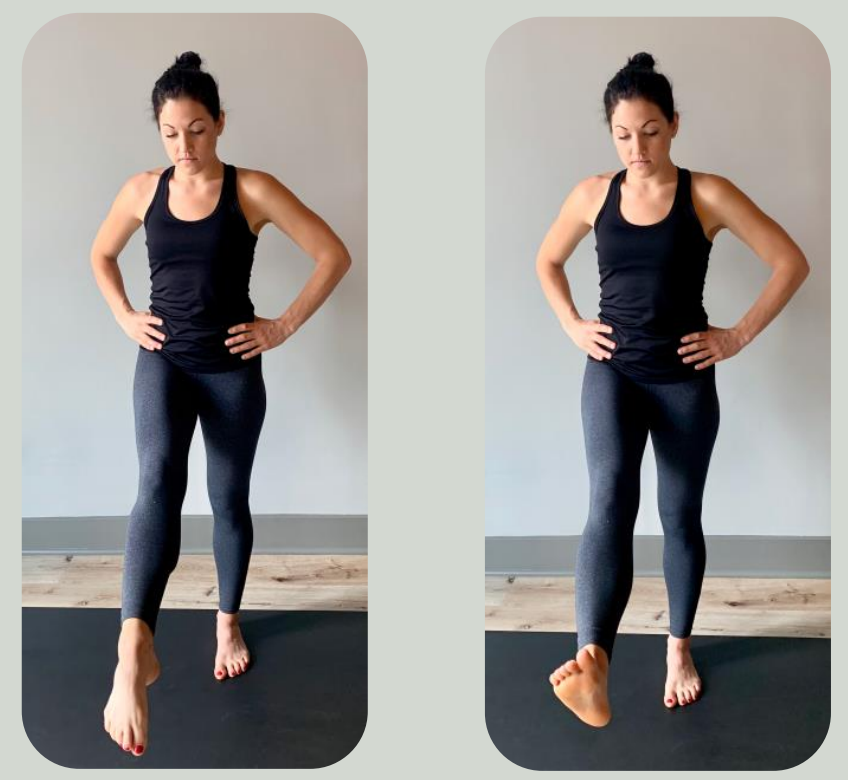

Single Leg Raise (point + flex)

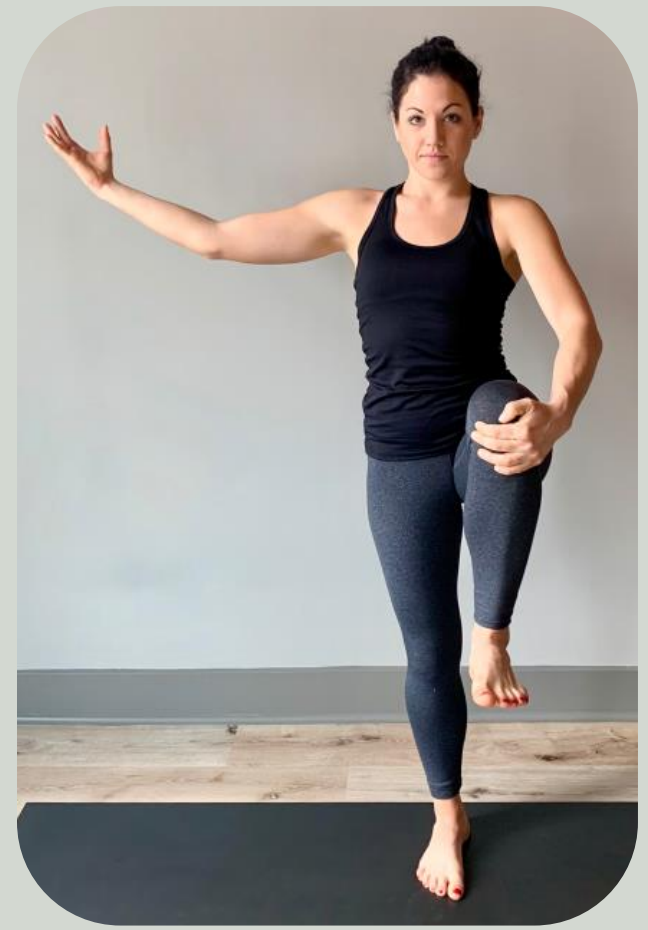

Single Leg Raise with Bent Knee

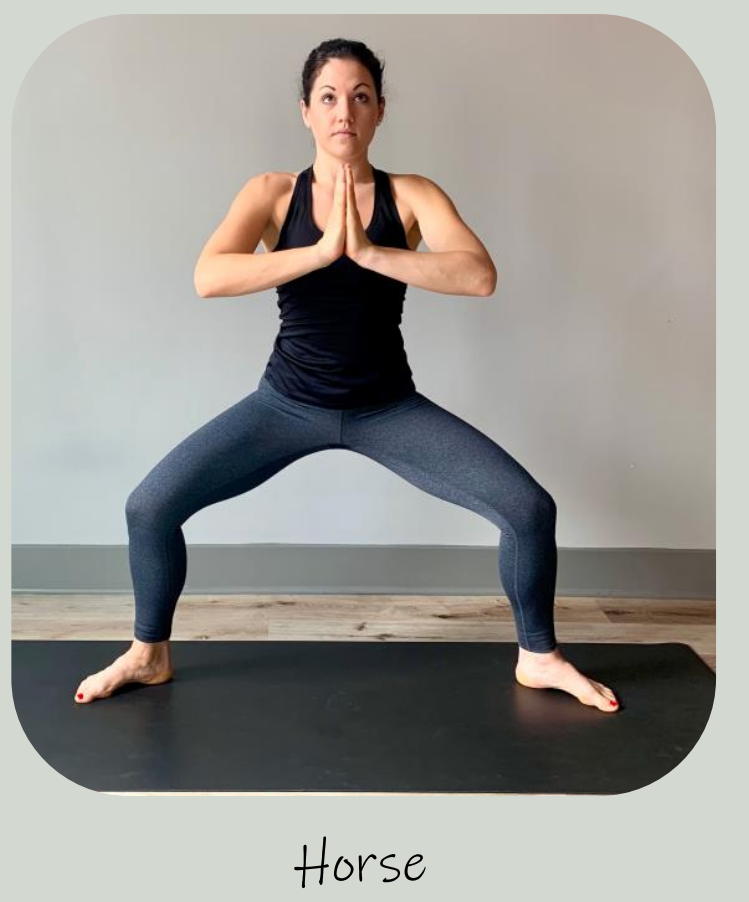


Additional supine poses:

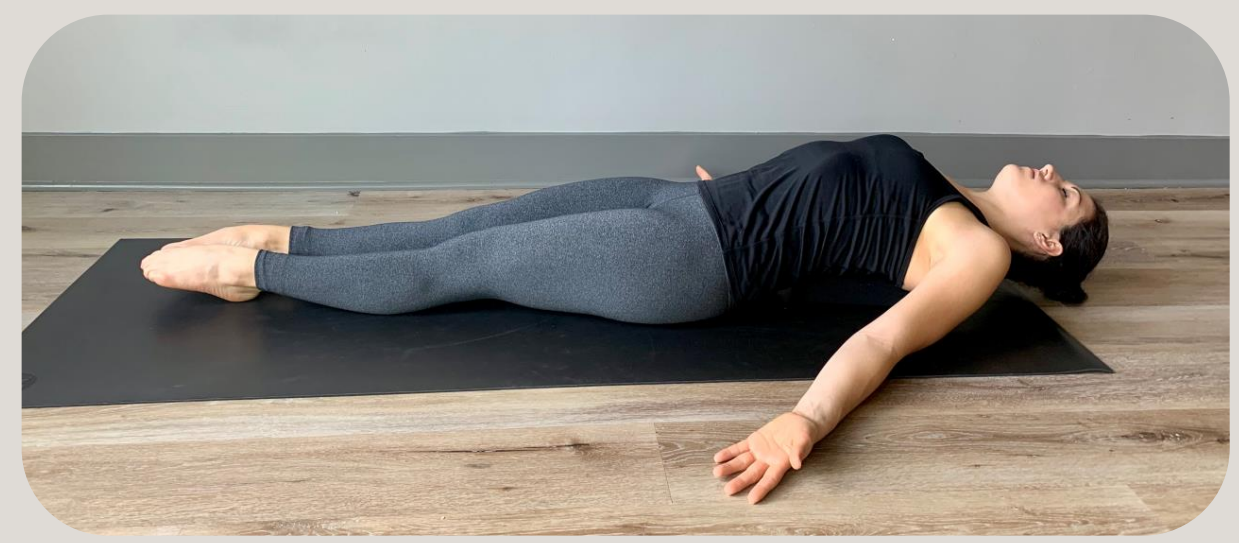

Fish (block between scapula)

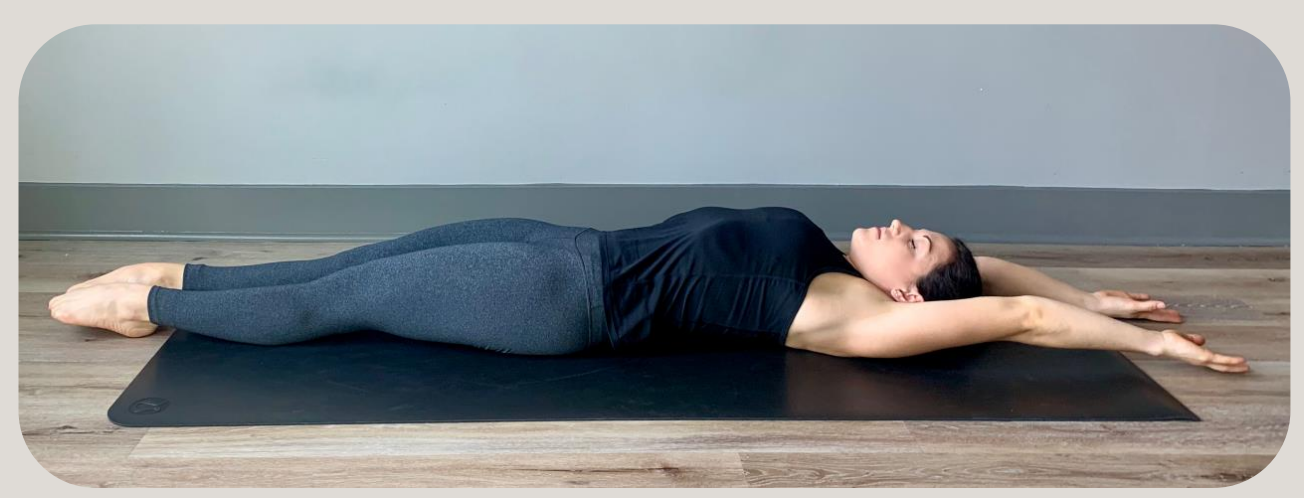

Supine Stretch

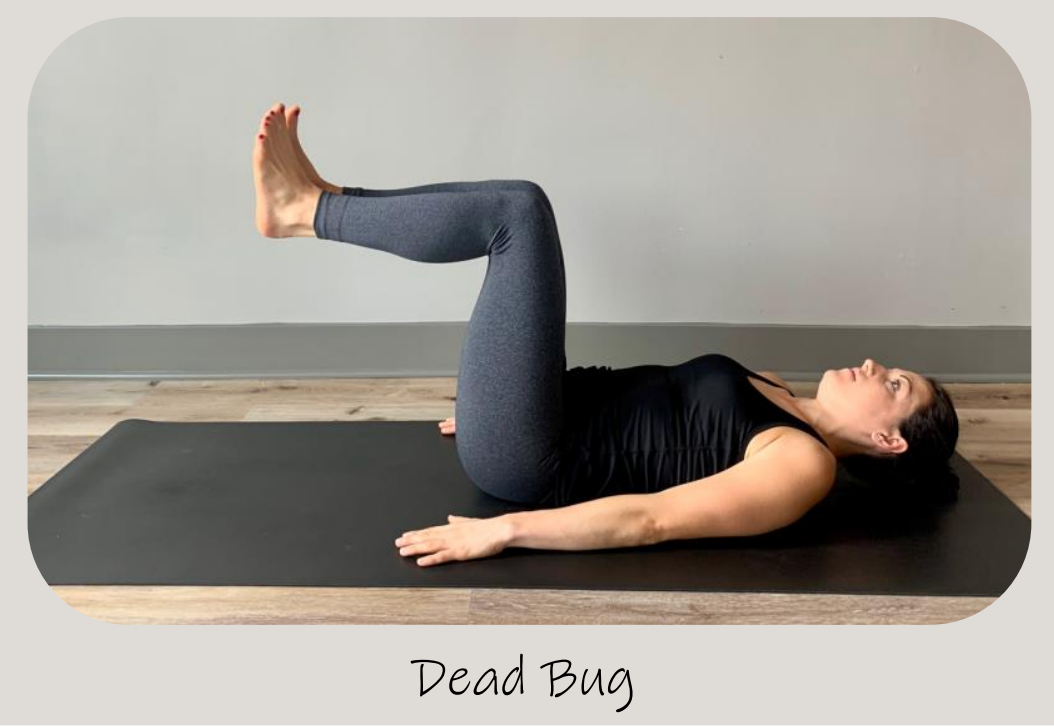




\section{Flow Sets}

\section{Set One:}

1. Child's Pose

2. Tabletop

3. cow

4. Cat

5. Downward Dog

6. Forward Fold

7. Halfway Lift

8. Extended Mountain

9. Rainbow (standing side stretch-both sides)

10. Standing Hands at Heart Center

11. Eagle (modified) both sides

12. Extended Mountain

13. Airplane (R)

14. Extended Mountain

15. Airplane (L)

16. Forward Fold

17. Halfway Lift

18. Plank (modified)

19. Upward Dog (modified)

20. Downward Dog

21. Supported Lunge (R)

22. Warrior One (R)

23. Warrior Two (R)

24. Plank (modified)

25. Upward Dog (modified)

26. Downward Dog

27. Supported Lunge (L)

28. Warrior One (L)

29. Warrior Two (L)

30. Plank (modified)

31. Forward Fold

32. Halfway Lift

33. Seated Sitting

34. Seated Butterfly (supported)

35. Supine Butterfly

36. Hip Flexor Stretch

37. Supine Twist (both sides)

38. Supine Knee-to-chest

39. Supine Stretch

40. Final Rest (savasana)
When you 'flow' in yoga, you move through a set of poses guided by breath. Typically, you move one breath per pose. The intention is to build heat within the body, while increasing range of motion.

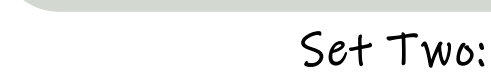

1. Child's Pose

2. PUPPY

3. Puppy Twist (both sides)

4. Sphinx

5. Downward Dog

6. Three-legged Dog (both sides)

7. Crescent Lunge (R)

8. Warrior One (R)

9. Warrior Two (R)

10. Half-moon (modified) ( $R$ )

11. Forward Fold

12. Halfway Lift

13. Extended Mountain

14. Forward Fold

15. Plank (modified)

16. Upward Dog (modified)

17. Crescent Lunge (L)

18. Warrior One (L)

19. Warrior Two (L)

20. Half-moon (modified) (L)

21. Forward Fold

22. Halfway Lift

23. Forward Fold

24. Extended Mountain

25. Single Leg Raise-point (R)

26. Single Leg Raise-Flex (R)

27. Single Leg Raise-point (L)

28. Single Leg Raise-Flex (L)

29. Garland

30. Seated Sitting

31. Seated Side Stretch (rainbow)

32. Seated Straight Leg

33. Single-leg Seated Forward Fold (both sides)

34. Supported Boat

35. Supported Boat Leg Raise (both sides)

36. Seated Twist (both sides)

37. Fish

38. Supported waterfall

39. Final Rest (savasana) 


\section{Special Acknowledgments}

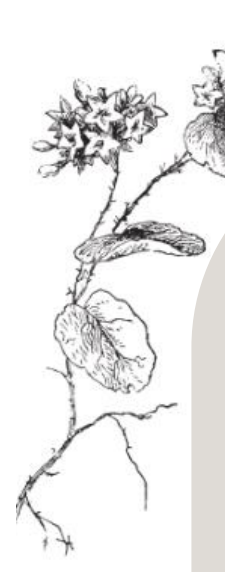

Kimberly Carson, M.P.H., C-I.A.Y.T., E-R.Y.T.

meditation mindfulness mentor and yoga specialist

Elaine Cohn, gentle yoga instructor for individuals healing from cancer

yoga mentor and Oncology yoga specialist

G. Rosanna Sanger, yoga instructor at PDX Power Yoga Portland, OR

program photographer and yoga mentor

Melinda Luksch, owner of PDX Power Yoga

Portland, OR

Yoga mentor + all photos were taken at PDX Power Yoga studio 